\title{
BUILDING THE BEST: A QUANTITATIVE EVALUATION OF A STATE-LEVEL TEACHER RETENTION STRATEGY DESIGNED TO INCREASE SELF-EFFICACY, REFLECTIVE CAPACITY, AND JOB SATISFACTION THROUGH EFFECTIVE PROFESSIONAL DEVELOPMENT
}

A Dissertation
presented to
the Faculty of the Graduate School
at the University of Missouri-Columbia
In Partial Fulfilment
of the Requirements for the Degree
Doctor of Education
TRACY L. GROSS
br. Cynthia MacGregor, Dissertation Supervisor
DECEMBER 2020


The undersigned, appointed by the Dean of the Graduate School, having examined the dissertation entitled

BUILDING THE BEST: A QUANTITATIVE EVALUATION OF A STATE-LEVEL TEACHER RETENTION STRATEGY DESIGNED TO INCREASE SELF-EFFICACY REFLECTIVE PRACTICE AND JOB SATISFACTION THROUGH EFFECTIVE PROFESSIONAL DEVELOPMENT

Presented by Tracy Gross, a candidate for the degree of Doctor of Education, and hereby certify that, in their opinion it is worthy of acceptance.

Dr. Cynthia MacGregor

Dr. William Agnew

Dr. Ximena Uribe-Zarain

Dr. T.C. Wall 


\section{DEDICATION}

This work is dedicated to the following people:

My husband, Jim Gross, who has sacrificed his own life for the lives of his wife and children. Without him and his support, the pathway to this accomplishment would never have existed. There are no words enough to convey my love and appreciation for his commitment to embrace my pursuits as ours, many times at the expense of his own.

My children, Stephaney Hutchings and Thomas Gross. It is for you I have done this, and all the generations to come. The door to more is cracked, something our family has never achieved before. I hope you will find ways to follow and to encourage your children to find their way earlier than I.

My grandchildren, Major Dominguez, Rylee and Shae Hutchings, and Jaxon and Madison Gross who lost precious time with me during this process, but whom I hope will be inspired by my endeavor to pursue this journey for themselves one day.

My mother, who listened endlessly when no one else would and was excited to learn with me. Thank you.

My sister, Gigi. We did it! 


\section{ACKNOWLEDGEMENTS}

This journey could never have been completed without the help of many. However, I must begin by acknowledging my most cherished mentor and professor, William Agnew, $\mathrm{PhD}$, without whom there would have never been a beginning to this journey. Dr. Agnew challenged me while making me feel like I had something unique and special to share with the world - for many years! His investment of confidence in me has gotten me through times when I thought about giving up. For this I am forever grateful.

I acknowledge the leadership, guidance, and patience of Dr. Russ Brock who gave me the freedom to grow beyond any level(s) I imagined or set for myself. Without his support, I would not have been able to fully engage in the capacity needed to walk into this moment.

I acknowledge Linda Dooling and Dr. Paul Katnik for providing the opportunity to complete this project. Without their support, this project would not exist.

I acknowledge Drs. Merica Clinkenbeard and Sandy Humbyrd for being my cheerleaders and accountability partners! Thank you for always being there!

I acknowledge soon-to-be doctor Trisha Bradley for the unexpected partnership we found in supporting each other through this process with ongoing zoom check-ins, goal-setting, progress monitoring, and shared experiences. You will be next!

I acknowledge my committee. I have been blessed to have the support of: Dr. Ximene Uribe-Zarain to encourage and guide me through the scariest part of this dissertation... the quantitative analysis! Dr. T.C. Wall who provided excellent guidance during coursework, always modeling exceptionality. She contributed to my learning and 
growth in more ways than she knows. Dr. MacGregor, who provided steady direction, timely assurances of being able to reach the goal, and kindness in sharing wisdom along the way. Dr. Agnew, who believed I could. I am forever grateful for the support I have received as I took this dissertation journey.

For all I have not named, who have cheered for me and helped me, I acknowledge you too. Your friendship sustained me along the way. 


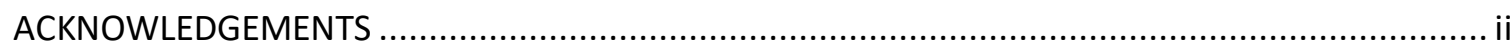

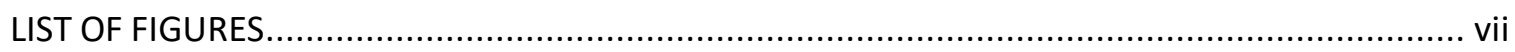

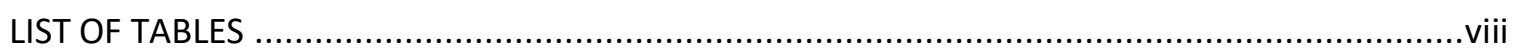

SECTION ONE: INTRODUCTION TO THE DISSERTATION ...................................................... 1

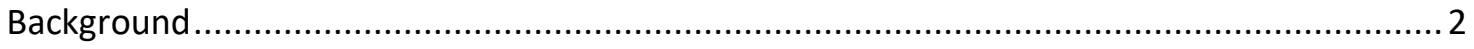

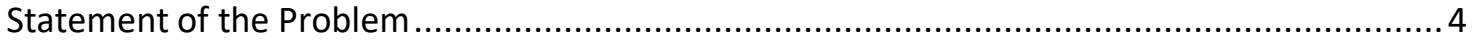

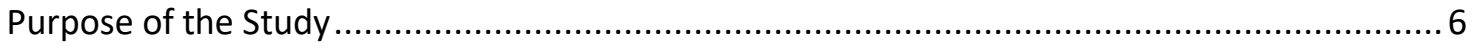

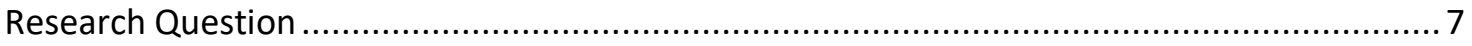

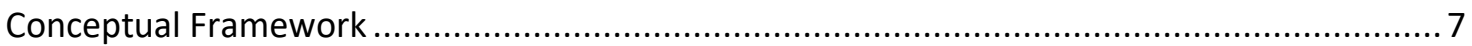

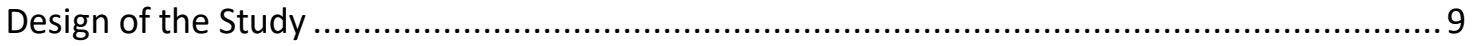

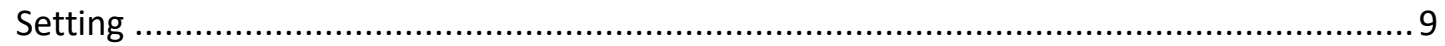

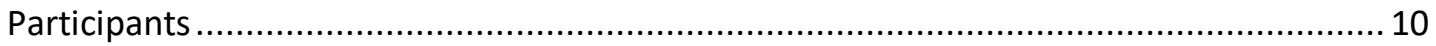

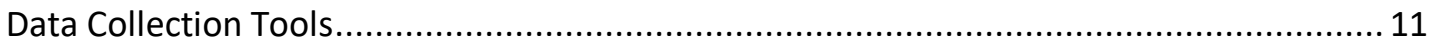

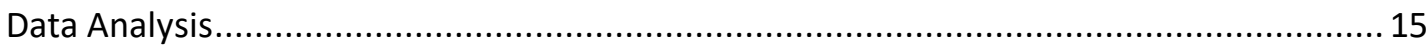

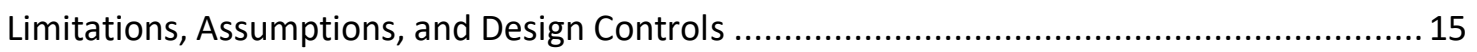

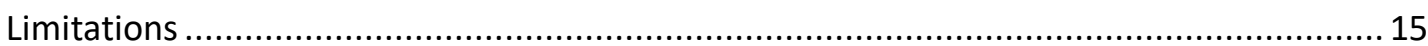

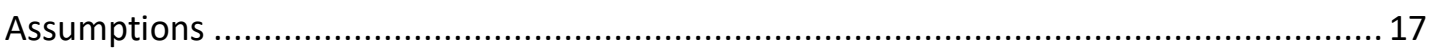

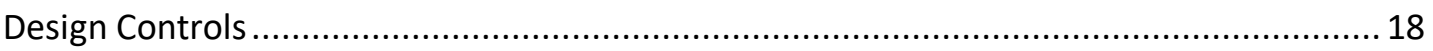

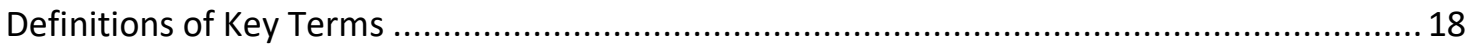

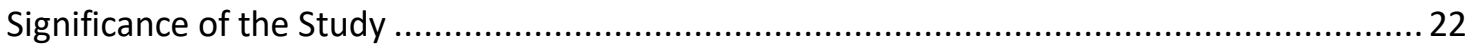

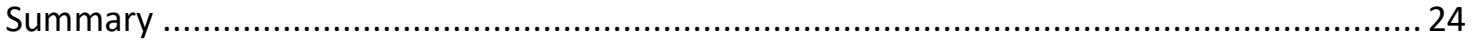

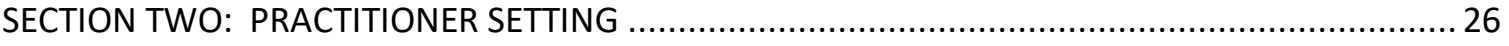

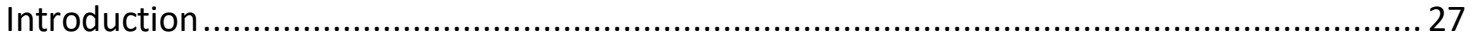

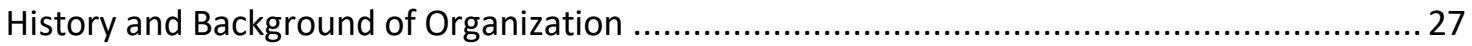

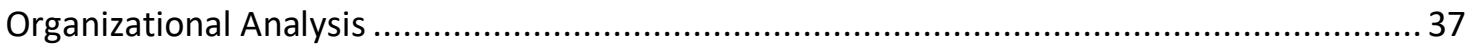

Missouri Department of Elementary and Secondary Education ...................................... 38

Regional Professional Development Centers ................................................................. 42

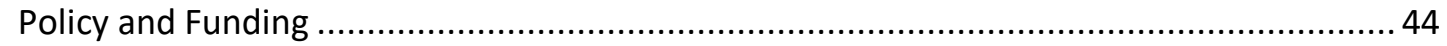

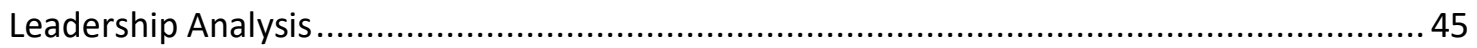

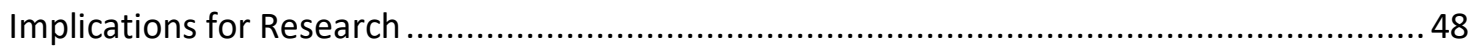

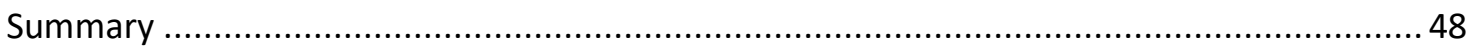

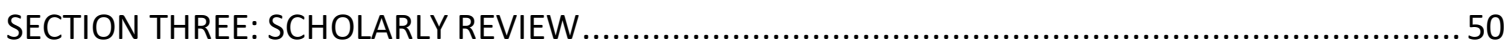




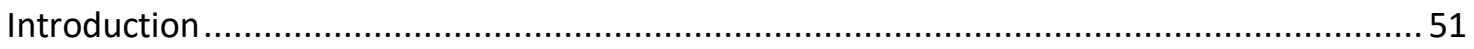

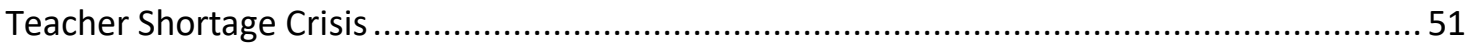

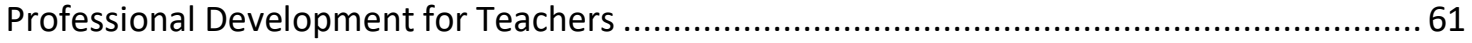

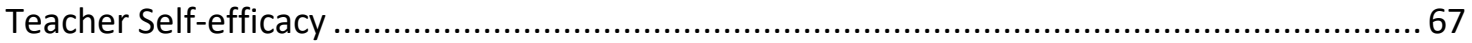

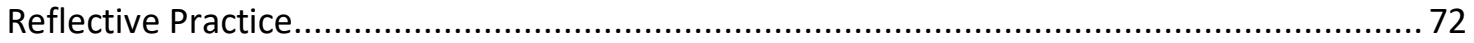

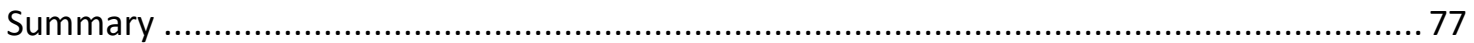

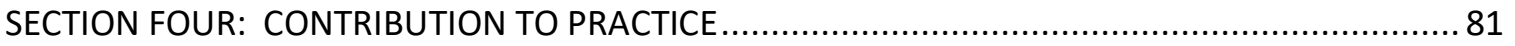

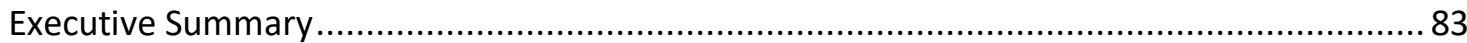

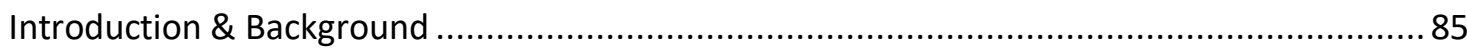

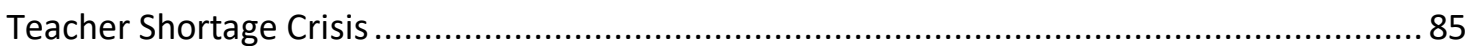

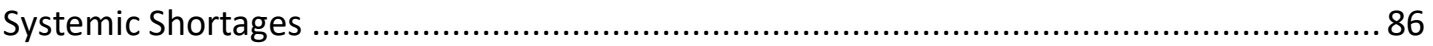

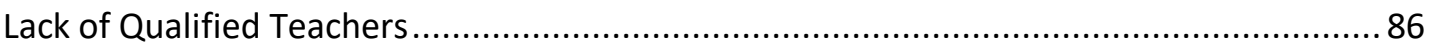

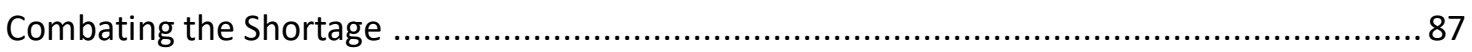

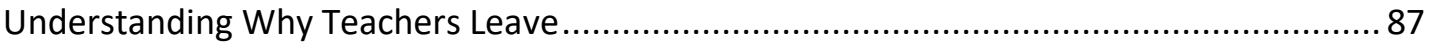

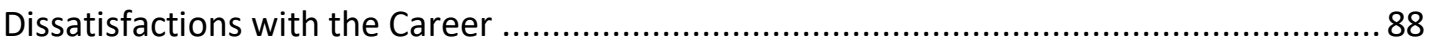

Retention through Professional Development .............................................................. 89

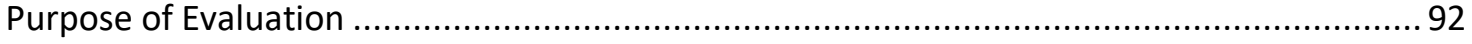

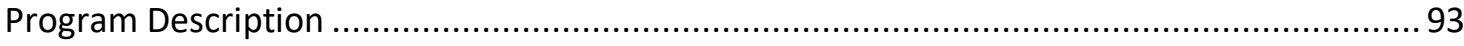

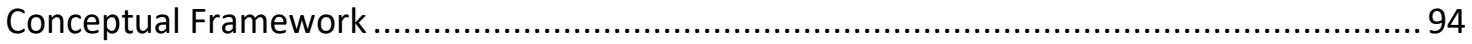

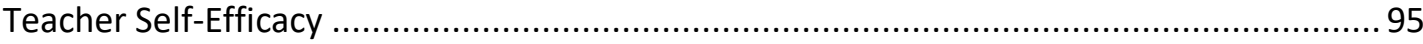

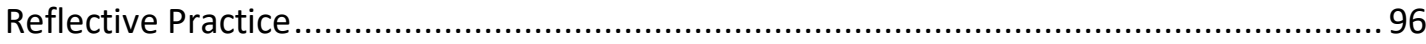

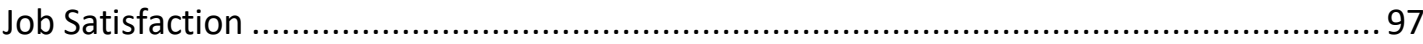

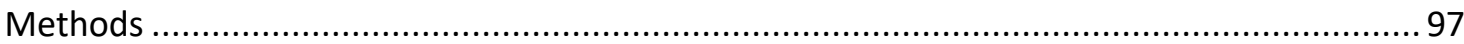

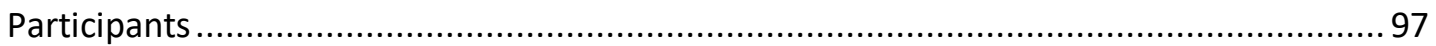

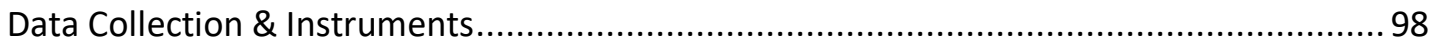

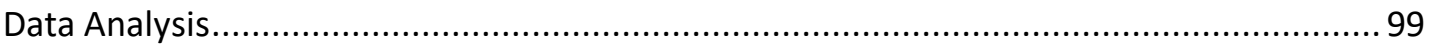

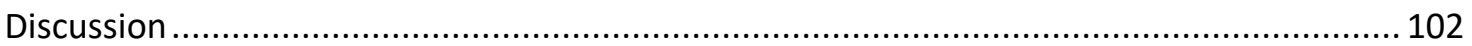

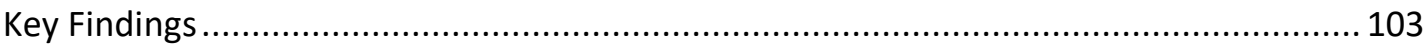

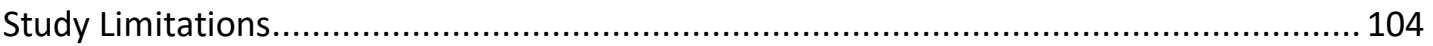

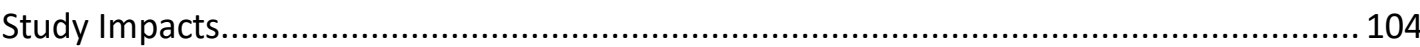

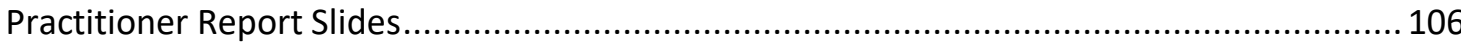

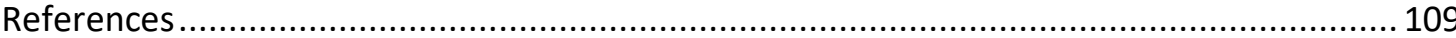

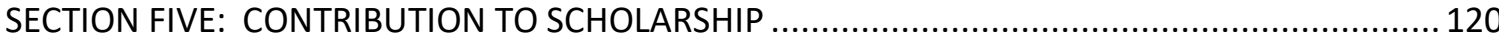

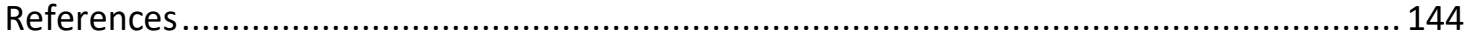




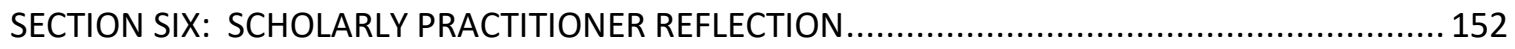

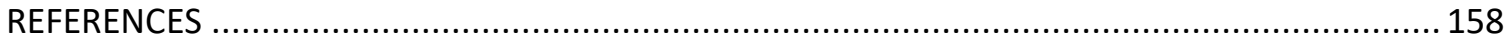

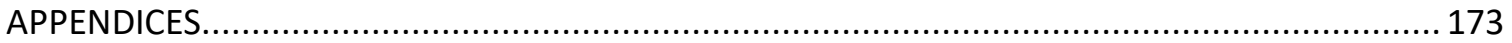

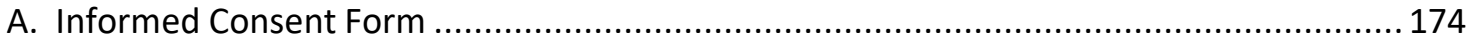

B. Independent Samples (Whole Group) Demographic Charts ....................................... 175

C. Paired Samples (Subgroup) Demographic Charts ........................................................ 178

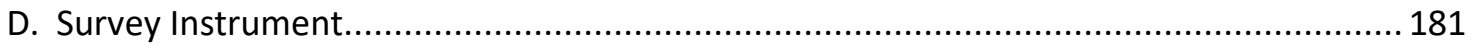

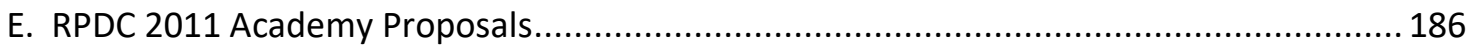

F. Teacher Academy Common Language Artifact from 9.16.15 ......................................... 194

G. "What is our Why?" Artifact from Facilitator Meeting 9.16.15_................................... 197

H. Missouri Teacher Development System Competencies by Domain ................................ 198

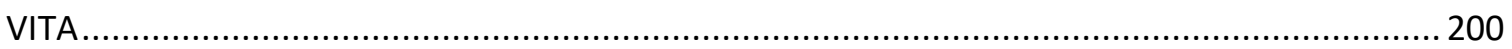




\section{LIST OF FIGURES}

1. Conceptual Frame................................................. 13

2. ESSE Tiers of Evidence.............................................24

3. July 2015 Facilitator Meeting Artifact................................... 38

4. Missouri DESE Organizational Chart ..................................44 


\section{LIST OF TABLES}

1. Missouri Teacher Academy Attendance 1996-2019............................37

2. Independent Samples T-test Self-Efficacy Subscale Results.................108

3. Independent Samples $T$-test Reflective Capacity Subscale Results............109

4. Paired Samples $T$-test Self-Efficacy Subscale Results.....................110

5. Paired Samples $T$-test Self-Efficacy Subscale Results....................111 
SECTION ONE: INTRODUCTION TO THE DISSERTATION 


\section{Background}

There is a teacher shortage crisis due to unprecedented drops in pre-service enrollment (Sutcher, Darling-Hammond \& Carver-Thomas, 2016) and non-retirement teacher attrition (Carver-Thomas \& Darling-Hammond, 2017; Garcia \& Weiss, 2019a; Gray, Taie, \& O’Rear, 2015; Ingersoll \& Smith, 2003; Reeves, 2018; Strunk \& Robinson, 2006; Sutcher, Darling-Hammond, \& Carver-Thomas, 2016;). The shortage is a complex crisis, and while increasing the number of teachers entering the profession is an important mitigation strategy, "it is equally important to keep strong teachers, since attrition is a much greater problem in the overall teacher supply picture than is producing enough teachers to fill the nation's needs" (Darling-Hammond, 2003, p. 7). In thinking about the impact of teachers leaving the profession, understanding who is at the greatest risk of attrition is an important part of developing solutions to meet the crisis. One might prefer to think it is those who are not a fit for teaching who leave the career behind, however, it is the nation's best teachers, those "who are so successful that they are nearly impossible to replace" (Jacob, Vidyarthi, \& Carroll, 2012, p.2) who are more likely to leave their classrooms behind when compared to all teachers. Greater than $50 \%$ of these “irreplaceables" (Jacob et al., 2015) will be gone from the career within their first five years (Jacob et al., 2012), far exceeding the $17 \%$ attrition rate for all teachers within five years of beginning the career(Gray, et al., 2015). The loss of one of these irreplaceable teachers impacts the entire system as "when an Irreplaceable leaves a low-performing school, it can take 11 hires to find one teacher of comparable quality" (Jacob et al., 2012, p.4). Keeping the best teachers in the career is central to solving the current teacher shortage crisis (Darling-Hammond, 2003). Dissatisfaction with teaching as a career is 
one of the main factors of attrition (Carver-Thomas \& Darling-Hammond, 2017;

Ingersoll, 2001; Ingersoll \& Smith, 2003; Sutcher et al., 2016).

Teachers dissatisfied with teaching as a career leave (Carver-Thomas \& DarlingHammond, 2017; Ingersoll, 2001; Ingersoll \& Smith, 2003; Sutcher et al., 2016). Twothirds of all beginning teacher attrition is related to teachers leaving for better jobs or different careers (Ingersoll \& Smith, 2003) with the majority of teachers "voluntarily leav[ing] the classroom list[ing] some area of job dissatisfaction as very important or extremely important in their decision to leave the profession” (Sutcher et al., 2016, p. 49). When deciding to continue in the career, teachers, like other professionals, evaluate if the career "remains the most attractive in terms of compensation, working conditions, and intrinsic rewards” (Guarino, Santibáñez,\& Daley, 2006, p. 186). When challenges involved in teaching outweigh the rewards of the profession, teachers leave for other jobs that offer better compensation, working conditions, and personal rewards (Borman \& Dowling, 2008, p. 371). As work loses importance and meaning for a teacher, burnout occurs (Maslach \& Leiter, 2008; Skaalvik \& Skaalvik, 2010) and teacher self-efficacy erodes.(Chang, 2009).

While teacher burn-out is "one of the critical components influencing teacher attrition" (Aloe, Amo, \& Shanahan, 2014, p. 101). Teacher self-efficacy and reflective practice are associated with job-satisfaction, and high levels of self-efficacy have been found to protect teachers against burn-out, which often leads to attrition (Aloe et al., 2014; Brown, 2012; Brouwers et al., 2001; Cherniss, 1993; Schwerdtfeger, et al., 2008; Skaalvik \& Skaalvik, 2007; Skaalvik and Skaalvik, 2010; Tschannen-Moran, et al., 1998). Given the known relationships between level of self-efficacy and teacher 
retention (Glickman \& Tamashiro, 1982; Pfitzner-Eden, 2016; Sass, et al., 2010; \& Yost, 2006), as well as the relationship between self-efficacy and reflective capacity (Kelley, 2004; Yost, 2006), high quality professional development programs leading to increases in these constructs may help support retention efforts.

While ineffective professional development contributes to teacher attrition (Garcia \& Weiss, 2019; Ingersoll, 2003; and Podolsky, Kini, Bishop, \& DarlingHammond, 2016), programs focused on increasing teacher levels of self-efficacy and reflective capacity may provide some protections against burn-out and support teachers as they continue in a career of constantly changing challenges. Providing "proper professional development not only validates teachers' professional standing and strengthens the teaching workforce, but it also correlates with teacher retention and thus could contribute to ameliorating the national teacher shortage" (Garcia \& Weiss, 2019e, p.28).

\section{Statement of the Problem}

Missouri Teacher Academy is a program within the scope of the Missouri Department of Elementary and Secondary Education's (DESE) Teacher Workforce Outreach Plan (2020), which promotes "high quality professional learning opportunities" (Missouri DESE, 2020) as a strategy for increasing teacher retention. Missouri Teacher Academy adheres to research-based teacher development structures aligned with the Every Student Succeeds Act (ESSA) suggestions for building systems of professional learning, and utilizes learning modalities designed to empower educators, such as lesson study, action research, appraisal, and feedback, (Darling-Hammond, Burns et al., 2017). Program outcomes include: (a) supporting teacher retention through development of self- 
efficacy, reflective capacity, and job satisfaction; (b) promoting teacher empowerment; and (c) creating regional and state-level teacher networks. Program learning is competency-based with priority areas including: (a) using data to make decisions, (b) engaging in on-ongoing reflective practice, (c) working in a community of practice, and (d) engaging students in content. Increasing teacher self-efficacy in instructional strategies and engaging students in content are central to teacher learning, as is fostering reflective practice with emphasis on building teacher ability to reflect in- and forpractice. Teachers are guided through a year-long reflective action-research project which continually engages teachers in reflection on the efficacy of their own practice while simultaneously supporting risk-taking by encouraging the use of emerging research and innovative practices.

Missouri Teacher Academy has been in operation in some regions of the state since 1996 and reached full state-wide implementation in 2015. The program is currently offered by nine Regional Professional Development Centers (RPDCs) and one additional approved program provider. Program impact has been measured in the past through surveys of participants and building principals and data consistently revealed evidence of perceived changes in teacher practice. Respondents self-evaluated changes in their use of: (a) instructional strategies, (b) engagement strategies, and (c) reflective practice. Qualitative data, including open-ended survey questions and participant projects demonstrated improvement to teacher practice. These data supported the rationale that Missouri Teacher Academy meets the definition of a "promising program" under the ESSA, which "requires states to reference a positive evaluation of some kind in 
relationship to a chosen intervention and to track its effects in the field" (Chiefs for Change, 2016, p. 4).

Most recently, Missouri Teacher Academy was included in the National Council on Teacher Quality (2019) state analyses of teacher leadership development where the program was noted to "provide a strong model for leadership development" (p. 6). Other than a presentation paper (Belcher \& Vinson, 1996) discussing the first year of Missouri Teacher Academy, no peer-reviewed published research studies specifically evaluating statistical relationships between participation in Missouri Teacher Academy and level of teacher self-efficacy, reflective capacity, and/or job satisfaction were found.

\section{Purpose of the Study}

Given the role of this program as a state-level teacher retention strategy and the potential of the program to serve as a model of effective professional development for teachers, research into program impacts was desired by program stakeholders; this study was conducted in response. Additionally, findings from this study may contribute to current understanding within the research regarding the implementation of state level professional development programs implemented as a teacher retention strategy. This study evaluated the impact of Missouri Teacher Academy on factors related to teacher retention: (a) teacher self-efficacy (Sass et al., 2010; Yost, 2006), (b) reflective practice (Kelley, 2004; Yost, 2006), and (c) job satisfaction (Ingersoll \& Smith, 2003; Sutcher, et al., 2016; Strunk \& Robinson, 2006; Zee \& Koomen, 2016). A quantitative survey research design with predetermined "closed-ended questions" (Creswell, 2014, p. 18) from instruments with known reliability and validity was utilized. Post-attendance data gathered Spring 2020 were compared to pre-attendance survey results from Fall 2019 
with statistical analyses conducted to identify differences in levels of: (a) teacher selfefficacy; (b) reflective capacity; and (c) job satisfaction (variables with known correlations to teacher retention).

\section{Research Question}

This study utilized a "pretest-posttest survey design"(Creswell, 2014, p. 172) to answer the question: Does participation in Missouri Teacher Academy impact teacher selfefficacy, reflective capacity, and job satisfaction?

\section{Conceptual Framework}

The conceptual framework for this study (see Figure 1) combined constructs directly related to teacher retention. These included: (a) self-efficacy, (b) reflective practice, (c) job satisfaction, and (d) effective professional development. Each construct has a known direct relationship to teacher retention. In addition to direct correlations of each of these constructs to teacher retention, mediating relationships within the framework were also included to provide additional support, such as the relationship between teacher selfefficacy and teacher burn-out. The relationship between self-efficacy and teacher burnout, as well as teacher retention, is well known (Brown, 2012; Evers, Brouwers, \& Tomic, 2002; Glickman \& Tamashiro, 1982; Pfitzner-Eden, 2016; Sass, Seal, \& Martin, 2010; Yost, 2006; Skaalvik \& Skaalvik, 2010).

Teachers who perceive "their work is making a difference in the lives of their students are able to tolerate a great deal of stresses inherent in teaching and to avoid burnout" (Friedman \& Farber, 1992, p. 33). Level of teacher self-efficacy has also been shown to have a direct relationship to job satisfaction (Klassen \& Chiu, 2010; Skaalvik \& Skaalvik, 2010; Viel-Ruma, Houchins, Jolivetee, \& Benson, 2010) with level of self- 
efficacy serving as a protection against burnout (Aloe et al., 2014; Schwerdtfeger, Konermann, \& Schönhofen, 2008). Job dissatisfaction is mentioned by the majority of those leaving the field (Sutcher et al., 2016) and is a key predictor of retention (Bobbitt, Faupel, \& Burns, 1991). Studies have found job satisfaction to be related to teacher selfefficacy (Johnson, Berg, \& Donaldson, 2005). Additionally, self-efficacy and reflective capacity have significant relationships to each other (Babaie, \& Abednia, 2016).

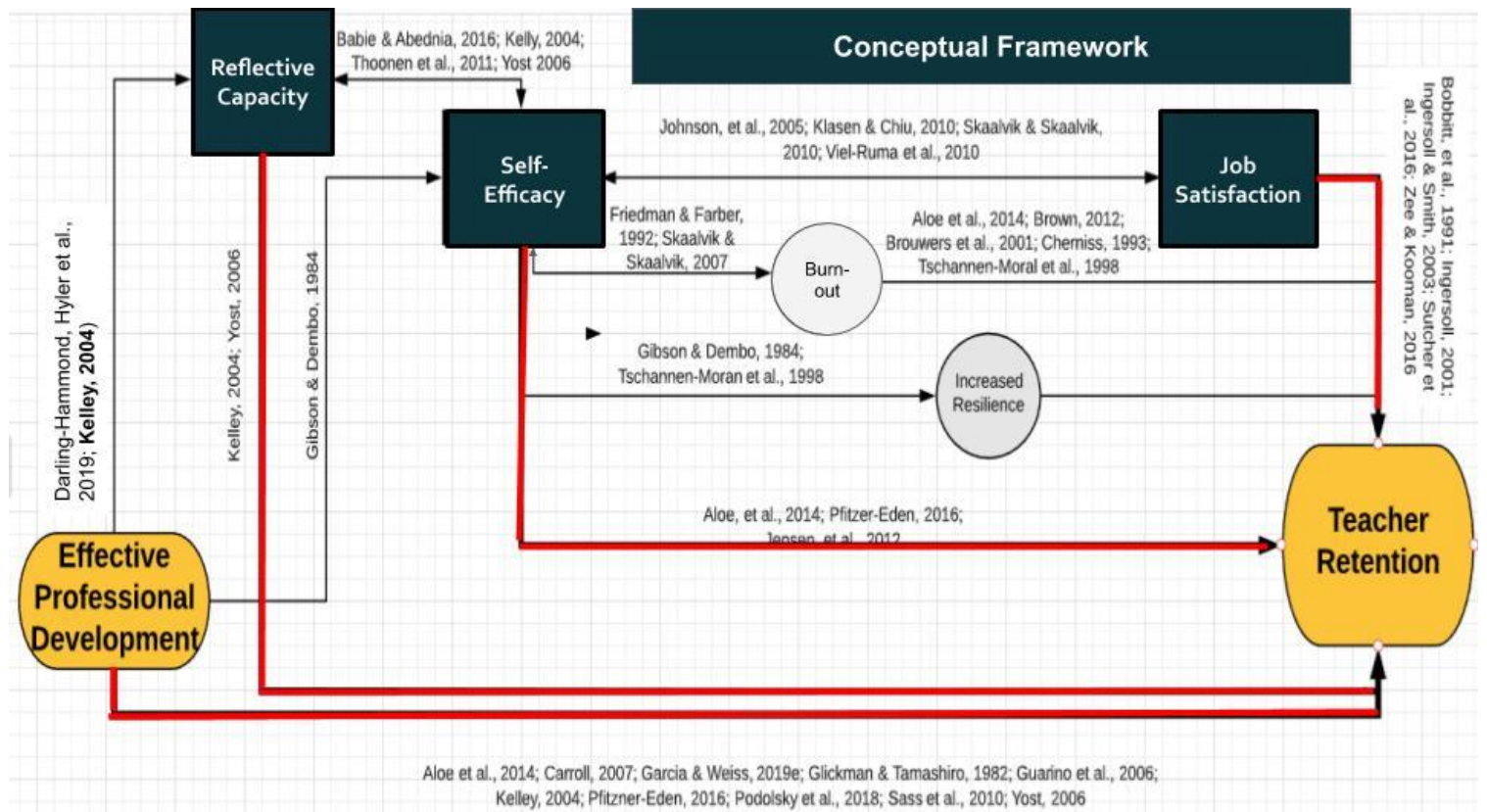

Figure 1. Conceptual framework for study showing connections between constructs. Effective professional development, reflective capacity, self-efficacy, and job satisfaction have direct relationships to teacher retention. Reflective capacity and self-efficacy correlate to each other, and self-efficacy has direct relationships to teacher burn-out and increased resilience, and job satisfaction, which all relate directly to teacher retention.

Programs leading to increases in teacher self-efficacy may contribute to efforts aimed at combating the current teacher shortage by indirectly supporting teacher retention through professional development supports for teachers throughout their career. Given these connections, this study evaluated the impact of Missouri Teacher Academy on teacher self-efficacy, reflective capacity, and job satisfaction from a lens of supporting teacher retention through effective professional development. 


\section{Design of the Study}

From an impact evaluation approach, this quantitative study was conducted utilizing a one-group pretest-posttest survey design (Creswell, 2014). Comprehensive purposive sampling (Ilker, Sulaiman, \& Rukayya et al., 2016) was employed with all 2019-2020 Missouri Teacher Academy candidates asked to complete a survey at the completion of the Missouri Teacher Academy. Informed consent (Appendix A) was completed by participants, which explained participation as voluntary with no effect on participant's position in Missouri Teacher Academy, relationship with their facilitator, or their employment in any way. Greater than $60 \%$ of candidates responded resulting in $n=97$. Survey data were compared to archival data collected from an identical survey taken by participants $(n=148)$ in Fall 2019 prior to attending Missouri Teacher Academy.

\section{Setting}

Missouri Teacher Academy is a program within The Missouri Teacher Development System (MTDS), which consists of a complement of state-supported, career-spanning teacher development programs. All MTDS programs provide participants with long-term, cohort-style learning experiences, which promote: (a) state and regional teacher collaboration and networking, (b) job-embedded learning with application of knowledge and skills within classrooms during experiences, and (c) the development of teacher reflective capacity through reflective supervision supports. Missouri Teacher Academy, emphasizes developing teacher competency in instructional strategies, student engagement, and reflective practice. Reflective journaling, questioning, and a classroom-based action research project conducted from a lesson study cycle framework are used by teachers to evaluate the effectiveness of their use of 
instructional and engagement strategies. Teachers implement their learning within their classrooms, use multiple sources of data to evaluate the effectiveness of instruction, reflect upon their impact on student learning, and adapt practices based on their new learning.

Missouri Teacher Academy is administered through the state's nine Regional Professional Development Centers (RPDCs), as well as one additional approved provider of the program. While the RPDCs are networked with each other, as well as with the Missouri Department of Elementary and Secondary Education (DESE), each program location is a separate entity contracting with the Missouri DESE to facilitate the Missouri Teacher Academy program, which is partially funded by the Missouri DESE through participant scholarships and program funds. Program providers select their own facilitators, session dates, and locations in alignment to the contractual requirements of the Missouri DESE, which require participants to attend two days of state meetings and six regional sessions for a total of eight full days of learning for participants. All program facilitators are highly skilled and experienced educational consultants.

\section{Participants}

Comprehensive purposive sampling (Ilker, Sulaiman, \& Rukayya, 2016) was used for this study with all teachers registered for the 2019-2020 Missouri Teacher Academy asked to participate. Ninety-six teachers were included in the post attendance sample, which was compared to an archival pre-attendance group of one-hundred forty-eight teachers. All participants attended Missouri Teacher Academy at one of ten program sites across the state. All participants had greater than three years of teaching experience and were identified, either by themselves or their administrators, as effective teachers 
with a desire for continued growth. The sample included teachers from all grade levels and content areas. Additionally, the sample included teachers from rural, suburban, and urban school districts with varying demographic backgrounds. While both men and women were included in the sample, the majority of participants were women. This is not surprising given that nationally the majority of teachers are white women (Taie \& Goldring, 2018). See Appendix B for whole group demographic charts.

Paired subgroup. The archival survey data included identifying information from a subgroup of teachers of tested content areas (ELA, Math, and Science). This allowed for the addition of a small paired subgroup sample $(n=22)$ in this study. Subgroup participants included teachers identified as teaching ELA (50\%), Math (22.7\%), and/or Science (27.3\%). While the paired sample demographics, such as experience level and age, were similar to the whole group in most respects, given the content-specific distinction, the sample included a larger concentration of grade 6-8 $(45.5 \%)$ and $9-12(31.8 \%)$ than the whole group representation of 6-8 (21.9\%) and grade 9-12 (25\%) teachers (see Appendix C for subgroup demographic charts).

\section{Data Collection Tools}

Communication with participants was conducted through regional program site facilitators who were trained on administration of the survey and were provided with online access through Qualtrics. Paper versions of the survey were available to accommodate for variations in technological access. Facilitators provided participants with a brief explanation of the purpose of the survey and instructions on how to access the Qualtrics survey link. Informed consent was embedded within the on-line survey tool 
and provided participants with researcher contact information. Survey data collection began March 14, 2020 and was completed by June 1, 2020.

Data was collected using an instrument (Appendix D) comprised of two subscales from the Teacher Self-Efficacy Scale (TSES): (a) efficacy in instructional strategies, and (b) efficacy in student engagement (Tschannen-Moran \& Woolfolk Hoy, 2001) and the reflective capacity and job satisfaction subscales from the Reflective Practice Questionnaire (RPQ) (Priddis \& Rogers, 2018; Rogers et al., 2019). Demographic data were also collected.

Teacher Self-Efficacy Scale. The TSES (Tschannen-Moran \& Woolfolk Hoy, 2001) was designed to expand upon prior scales used to measure teacher efficacy, measuring a "wider range of teaching tasks" (Tschannen-Moran \& Woolfolk Hoy, 2001, p. 801). While only the above-referenced subscales were used for this study, the full form of the TSES does include three dimensions of teacher efficacy, including "efficacy for instructional strategies, student engagement, and classroom management" (Tschannen-Moran \& Woolfolk Hoy, 2001, p. 801). It is noted that "both the subscale scores and the total score for both forms can be used to assess efficacy" (TschannenMoran \& Woolfolk Hoy, 2001, p. 801).

The original TSES included 52 items. Through sequential testing using principalaxis factoring with varimax rotation and the use of scree test, the number of items was able to be reduced into three factors in the second study, which were labeled as subscales: "efficacy for student engagement (8 items), efficacy for instructional strategies ( 7 items), and efficacy for classroom management (3 items)" (Tschannen-Moran \& Woolfolk Hoy, 2001, p. 797). Subscale reliabilities in the third study were found to be high at " 0.82 for 
engagement, 0.81 for instruction, and 0.72 for management" (Tschannen-Moran \& Woolfolk Hoy, 2001, p. 797). The instrument was field-tested and factor reliability was seen with scree test replication of "the three factors identified in Study 2" (TschannenMoran \& Woolfolk Hoy, 2001, p. 799). Additionally, high subscale reliabilities were again seen and "the factor structure remained intact" (Tschannen-Moran \& Woolfolk Hoy, 2001, p. 799).

Heneman, Kimball, and Milanowski (2006) tested the validity and reliability of the TSES (Tschannen-Moran \& Woolfolk Hoy, 2001) and concluded "the TSES should be the preferred measure of teachers' sense of efficacy in future research" (Heneman et al., 2006, p. 13). They conducted "several confirmatory factor analyses with the TSES" (Heneman, et al., 2006) and found "the three-correlated factor model was substantially a better fit...suggesting that the scales successfully represent the intention to reflect three separate subscales" (Heneman, et al., 2006, p. 10). To directly compare their findings to those of Tschannen-Moran and Wolfolk Hoy (2001), they performed exploratory factor analysis, and "results provide strong replication of the Tschannen-Moran and Hoy results" (Heneman, Kimball, \& Milanowski (2006).

Reflective practice questionnaire. The RPQ (Priddis \& Rogers, 2018; Rogers, et al., 2019) was selected for this study due to its close alignment to the conceptual framework of the study, as well as its ability to gather data at multiple intervals. It "can be utilized for education where students and practitioners complete the questionnaire as part of their own self-reflection and professional development" (Rogers, et al., 2019, p 8). The tool "was designed for flexible use across different professions" (Rogers, et al., 
2019, p. 4). In this study the word clients was changed to student to represent the educational context of the study.

The RPQ consists of 10 sub-scales of four items each for a total of 40 items. The tool measures reflective capacity using the subscales: (a) reflecting in action; (b) reflecting on action; (c) reflecting with others; and (d) self-appraisal. An additional subscale connected to reflective capacity is included to evaluate "desire for continual improvement" as are four subscales connected to the concept of reflective supervision. These include: (a) confidence; (b) job satisfaction; (c) uncertainty; and (d) stress (uncertainty and stress subscales will not be included in this study). Instrument subscales directly align with the body of research and factor analysis has been conducted (Rogers et al., 2019). Of these four reflective supervision subscales, only the job satisfaction subscale was used in this study.

While the RPQ is a new instrument, it has been found to be reliable in initial studies across different career contexts (Priddis \& Rogers, 2018; Rogers et al., 2019), as well as within the general population (Priddis \& Rogers, 2018), with the tool revealing acceptable internal consistency with each administration. The RPQ was piloted within a general population sample with a Cronbach's alpha $>0.82$ for all sub-scales. A followup study conducted with mental health practitioners revealed Cronbach's alpha $>0.70$ for all subscales except for job satisfaction, which was 0.68 ; "results provide evidence that the RPQ contains internally consistent items for assessing domains of reflection that are relevant to reflective supervision practices in work settings" (Priddis, 2018). An additional study (Rogers, Priddis, Michels, Tieman, \& Van Winkel, 2019) was conducted using the scale to measure reflective capacity of medical students and was found to be 
reliable in medical students with Cronbach's alpha 0.84; factor analysis was also conducted. Results of this study state the "RPQ can be utilized for education where students and practitioners complete the questionnaire as part of their own self-reflection and professional development” (para 44).

\section{Data Analysis}

Archival and study data sets were analyzed. Descriptive statistics were used to evaluate the distribution of the data. Independent samples $t$-tests were conducted to compare pre- and post- attendance means of self-efficacy, reflective capacity, and job satisfaction with level of significance established as $p<0.05$ (Fields, 2018). Given the differences in sample sizes between the pre $(n=148)$ and post $(n=95)$ data, Hedges' $g$ was conducted to evaluate effect size. However, when compared to Cohen's $d$, differences were negligible, so only Cohen's $d$ was reported.

Paired samples $t$-tests were conducted to compare pre- and post- attendance means for self-efficacy, reflective capacity, and job satisfaction for the subgroup. To control for Type I error within this small sample, as well as given that a total of nine analyses were performed on the same data set, a Bonferroni-corrected level of significance for all analyses was established as $p<0.006$.

\section{Limitations, Assumptions, and Design Controls}

\section{Limitations}

Non-random sampling. The study utilized purposive sampling with all teacher academy participants being asked to complete the program evaluation survey. Although statistically significant differences between pre- and post- program groups were identified, random sampling was not utilized and individual participant growth was only 
able to be evaluated for a small subgroup. Further analysis of individual participant growth within a larger sample would benefit the program and strengthen understanding of impact. Participants represented typical teacher academy participants, who were thought to have a strong desire for improvement; one may even question the mitigating effects of teacher academy participant characteristics on any study results obtained. Additionally, with $70 \%$ of participants representing rural schools, the findings of this study may be specific to teachers within rural settings. Future studies comparing impacts across district settings may increase the generalizability of these findings to include suburban and/or urban settings.

Sample bias. Missouri Teacher Academy invited teachers who were highly motivated with a great desire for improvement. Due to the specific characteristics of the study population, findings from this study are not generalizable to all teachers. Differences in teacher self-efficacy, reflective capacity, and job satisfaction correlated to teacher academy participation, may only be considered within the context of a typical teacher academy participant; one may even question the mitigating effects of teacher academy participant characteristics on any study results obtained. Although results are not generalizability, as this is the first correlational study to be conducted on the Statewide Teacher Academy, identification of impacts on teacher practice, even when comparing whole group change, has great implications for the program. This study serves as an important first step in understanding potential impacts of Missouri Teacher Academy.

Access. Of note, the data collection window for this study occurred during the beginning of the Covid-19 crisis. It is unclear as to what effect the disruptions due to the 
crisis may have had on participant responses. It is thought there was some effect on the number of whole group responses received given the fall archival survey data represented $n=148$ as compared $n=96$ seen during the data collection for this study, which occurred in Spring 2020. Due to the unprecedented situation caused by Covid-19 in Spring 2020, the study was somewhat limited by decreases in access to participants given widespread cancelations of programming resulting in participants being asked to complete the survey on their own outside of the scheduled sessions.

Researcher positionality. In addition to potential limitations from methods of sampling, researcher positionality should be considered. The researcher is a Missouri Teacher Academy facilitator and leads the development of the Missouri Teacher Development System. This study was conducted within the scope of the researcher's employment with the main intents and purposes of the study being the informing of stakeholders, designers, and facilitators regarding the impact of teacher academy on level of teacher self-efficacy, reflective capacity, and/or job satisfaction. The quantitative nature of the study diminished researcher bias, and study interpretations, conclusions, and reporting decisions were vetted by the dissertation committee.

\section{Assumptions}

Given the characteristics of Missouri Teacher Academy participants, this study assumed participants were thoughtful in their completion of the survey, and due to the provision of confidentiality, answered honestly. Data were ordinal in nature. For the whole group sample, $n \geq 30$, so normality was assumed. For the paired subgroup, given the small sample size of $n=22$, the assumption of normally distributed difference was confirmed with Shapiro Wilk and further satisfied with skew and kurtosis levels for each 
analysis conducted. Furthermore, acceptable correlations were noted suggesting paired samples $t$-test was appropriate. Homogeneity of variance was noted for all analyses except for independent samples $t$-test of the subscale: reflecting-on-action.

\section{Design Controls}

Data for the study was through an on-line survey using Qualtrics. This allowed participants to complete the survey independently and transmit their data confidentially. This protocol supported a consistent method for collecting data across all ten program sites. Having participants access the survey digitally, including completion directions, minimized the participation of the program facilitators and decreased facilitator influence on participant responses.

\section{Definitions of Key Terms}

\section{Every Student Succeeds Act (ESSA)}

In 2015, President Barack Obama signed the Every Student Succeeds Act (ESSA), which re-authored the 1965 Elementary and Secondary Education Act. The act is the Federal Law for public schools in the United States. The ESSA replaced the former version of the act, No Child Left Behind (NCLB), which was known for its heavy emphasis on accountability through student achievement scores. The ESSA provided states with more authority in creating their own accountability plans. It is a departure from the NCLB era accountability requirements. Under ESSA, states are no longer required to use student achievement as a part of evaluating teacher performance.

\section{Evidence-Based Intervention}

Under the recently re-authored Elementary and Secondary Schools Act, ESSA, there is an emphasis to identify and support students with the greatest need and to 
increase equitable access for students. The act limits the use of Title I, Section 1003

funds, which are reserved for schools targeted for comprehensive school improvement, to

fund interventions with Tier I - Tier III evidence (see Figure 2).

\author{
WHAT IS AN “EVIDENCE-BASED” INTERVENTION? \\ (from section 8101(21)(A) of the ESEA)
}

“...the term 'evidence-based,' when used with respect to a State, local educational agency, or school activity, means an activity, strategy, or intervention that -

(i) demonstrates a statistically significant effect on improving student outcomes or other relevant outcomes based on -

(I) strong evidence from at least one well-designed and well-implemented experimental study;

(II) moderate evidence from at least one well-designed and well-implemented quasiexperimental study; or

(III) promising evidence from at least one well-designed and well-implemented correlational study with statistical controls for selection bias; or

(ii) (I) demonstrates a rationale based on high-quality research findings or positive evaluation that such activity, strategy, or intervention is likely to improve student outcomes or other relevant outcomes; and

(II) includes ongoing efforts to examine the effects of such activity, strategy, or intervention.

Figure 2. ESSA Tiers of Evidence. The ESSA describes the meaning of evidence-based by providing four tiers of evidence that increase from promising to strong. Federal monies to support schools determined to be in need of school improvement and have been given Title I (section 1003) funding may only use those funds for programs and interventions that meet Tiers I, II, and III levels of evidence. Level IV, rationale-based, evidence does not qualify for the use of section 1003 Title I funding. United States Department of Education. (2016). Non-Regulatory guidance: Using evidence to strengthen education investments.

\title{
Job Satisfaction
}

In this study, level of job satisfaction was measured using the job satisfaction subscale of the RPQ (Priddis \& Rogers, 2018; Rogers et al., 2019). This subscale asked respondents to evaluate: (a) level of fulfilment gained through participation in their job, (b) the extent to which they value their work beyond the extrinsic motivation of monetary gain, (c) how much enjoyment they receive from engaging in their work, and (d) level of motivation for attending their job (Priddis \& Rogers, 2018; Rogers et al., 2019). For this study job satisfaction was defined as the sense of fulfilment and level of enjoyment 
teachers reported from their work as a teacher. It also considered the level with which they valued their work over their monetary compensation.

\section{Reflective Capacity}

Rogers et al. (2019) stated "reflective capacity refers to the ability, desire, and tendency of [teachers] to engage in reflective thought during their academic studies and clinical practices" (Rogers et al, p. 1). Priddis and Rogers (2018) designed the RPQ to measure reflective capacity. Within their explanation of what the tool measures, further clarification of reflective capacity can be found by looking at the reflective capacity subscales.

Both Priddis and Rogers (2018) and Rogers et al. (2019) described the use of four subscales in measuring reflective capacity. Each is based on Schön's concepts of reflective practice, including "reflection-in-action, reflection-on-action, reflection with others, and self-appraisal" (Rogers, et al., 2019, p. 2).

\section{Reflective Practice}

Donald Schön wrote of reflection as the recognition of what you are doing while you are in the middle of doing it, a conscious awareness and evaluation of actions in real time (Schön, 1983). Kinsella (2010) referred to Schön's thoughts on the practice of reflection as the practitioner learning "through transaction with the situation" (p. 568). Although there is a vast amount of research on reflection and reflective practice, including discussions of levels of reflection (Laviree, 2008; Thompson \& Pascal, 2012) and the temporal dimensionality of the practice (Conway, 2001; Farrell, 2012; \& VanManen, 1995), "there is evidence of considerable confusion among a large number of practitioners about what reflective practice entails" (Thompson \& Pascal, 2012, p. 311). 
This study utilizes the Reflective Practice Questionnaire (Priddis \& Rogers, 2017; Rogers et al., 2019), which was created based on Schön's conceptualizations of reflecting - on and -in action, therefore reflective practice will be considered in alignment to his thinking. From Schön's perspective, a practitioner can, "surface and criticize the tacit understandings that have grown up around the repetitive experiences of a specialized practice, and can make new sense of the situations of uncertainty or uniqueness which he may allow himself to explore" (Schön, 1983, p. 61).

\section{Regional Professional Development Center}

In 1995, "DESE established nine Regional Professional Development Centers...to provide regional professional development services to districts to ensure equity of opportunity” (Learning Forward-Missouri, n.d.). The Regional Professional Development Centers (RPDCs) are intermediary organizations that connect school districts to the Missouri Department of Elementary and Secondary Education (DESE). Most of the RPDCs are housed within universities, which serve as fiscal agents. This strategic placement allows the RPDCs to serve in connecting roles for schools to universities and universities to the Missouri DESE. While each of the nine RPDCs is independent of the other, they are bound together through their work with the Missouri DESE and through long-standing relationships and commitments to each other as a network. Although RPDCs are not officially designated as state educational service agencies (ESAs), they function much the same as an ESA, and are authorized by the Missouri DESE through contractual agreements to work as agents of the Missouri DESE to promote state initiatives and provide supports to school districts throughout distinct regional locations across the state. 


\section{Teacher Self-Efficacy}

Tschannen-Moran, et al. (1998) described teacher self-efficacy as "the teacher's belief in his or her capability to organize and execute courses of action required to successfully accomplish a specific task in a particular context" (p. 22). They developed the Teacher Self-Efficacy Scale (Tschannen-Moran, et al., 1998) to measure teacher sense of capability in three key domains of teaching: (a) instructional strategies, (b) classroom management, and (c) student engagement. The Missouri Teacher Academy emphasizes the development of teacher capacity in the use of instructional strategies and student engagement. This study will utilize these subscales to evaluate differences in teacher sense of capability in these areas related to attending the Missouri Teacher Academy.

\section{Significance of the Study}

With teacher shortages plaguing the profession (Carver-Thomas \& DarlingHammond, 2017) and given the relationship between teacher retention and self-efficacy (Kelley, 2004; Yost, 2006), identifying programs that increase teacher self-efficacy may contribute to conversations focused on finding solutions to the problem. This study recognizes there are various levels of factors leading to attrition, including state-level contributions (Strunk \& Robinson, 2006) and may provide insights into a potential statelevel intervention. Missouri Teacher Academy has the potential to serve as a national model for states seeking ways to use career development to support teacher retention (Sutcher et al., 2016), which could "make a greater difference in balancing supply and demand than any other intervention" (Sutcher et al., 2016, p. 37). With the potential for wide-reaching impact, this study provided quantifiable program data analyses to evaluate 
relationships between Missouri Teacher Academy and levels of teacher self-efficacy, reflective capacity, and job satisfaction. The results of this study informed policy-makers within the Missouri Department of Elementary and Secondary Education, Office of Educator Quality, and the results may impact future funding, legislative actions, and/or expansion of the program to other states.

Additionally, the results of this study informed the Missouri Teacher Development System Design Team with findings used to guide the development of additional programs designed to support teacher retention through professional learning focused on the development of teacher self-efficacy and reflective practice. As the researcher is the leader of the design team, knowledge gained by conducting this study informed the entire teacher development system and may impact teachers who participate in MTDS programs in the future.

The ESSA requires states to submit a plan for the development of human capital, which "address[es] systems of educator development, retention, and advancement..." (Chiefs for Change, 2017, p. 19). Given the known relationship between level of teacher self-efficacy and teacher retention (Glickman \& Tamashiro, 1982; Pfitzner-Eden, 2016; Sass et al., 2010; \& Yost, 2006), this study may potentially support the inclusion of Missouri Teacher Academy in the state's human capital development plan if participation in Missouri Teacher Academy is found to positively influence teacher level of selfefficacy, reflective practice, and/or job satisfaction.

In addition to providing program data, this study utilizes the Reflective Practice Questionnaire (Priddis \& Rogers, 2018; Rogers,et al., 2019), which is a new instrument designed to measure reflective capacity across disciplines. It is believed this is the first 
study where this instrument has been used within an educational context, and the findings may contribute to the body of current research pertaining to this instrument. Prior studies using this instrument have been conducted with samples from the general population and mental health students (Priddis \& Rogers, 2018), as well as medical students (Rogers et al., 2019), and data from this study will contribute to the body of research with the inclusion of data from this sample of educators.

\section{Summary}

There are not enough teachers (Ingersoll, 2001; Ingersoll \& Smith, 2003; Sutcher, et al., 2016). Focusing on retention is crucial to combatting shortages (DarlingHammond, 2003); it is critical to specifically target retention of the very best teachers, who leave the profession at a greater rate and impact student learning the most (Jacob et al., 2012). Supporting teacher growth is a strategy to increase retention by providing career development, which improves working conditions, ultimately leading to increases in job satisfaction for teachers. Teacher self-efficacy and reflective practice are both related to teacher retention (Yost, 2006). Teacher self-efficacy is known to be a protective factor against burnout (Aloe et al., 2014; Brown, 2012; Brouwers et al., 2001; Cherniss, 1993; Schwerdtfeger, et al., 2008; Skaalvik \& Skaalvik, 2007; Skaalvik and Skaalvik, 2010; Tschannen-Moran, et al., 1998) and is positively related to teacher retention (Kelley, 2004; Yost, 2006). Engaging in reflection with reflective supervision is correlated with desire for improvement and job satisfaction (Priddis \& Rogers, 2018), both of which are connected to teacher retention.

Missouri Teacher Academy is a state-level initiative designed to support teacher retention. The program content focuses on instructional strategies and student 
engagement, which are aligned to two of the dimensions measured by the TSES (Tschannen-Moran \& Woolfolk Hoy, 2001). Additionally, the program emphasizes reflective practice, which has been found to be positively related to teacher self-efficacy (Babaei \& Abednia, 2016). Given the relationship between teacher retention and selfefficacy (Kelley, 2004; Yost, 2006), program impacts on these two important constructs should be evaluated.

The TSES (Tschannen-Moran \& Woolfolk Hoy, 2001) and the RPQ (Priddis \& Rogers, 2018; Rogers et al., 2019) were used to measure levels of participant selfefficacy and reflective capacity. The RPQ has not been used in an educational context, and this study may add to the body of research regarding the application of this tool across multiple disciplines. The results of this study may be used to inform future program and policy decisions regarding Missouri Teacher Academy. 
SECTION TWO: PRACTITIONER SETTING 


\section{Introduction}

This study was conducted within the setting of Missouri Teacher Academy, which is a state-sponsored teacher support initiative designed to strengthen teacher practice. The program was recently recognized by the National Council on Teacher Quality (2019) to "provide a strong model for leadership development" (p. 6). In order to facilitate potential generalization of study findings to similar contexts, a detailed description of the program setting (Merriam \& Tisdell, 2016), including its simultaneous positioning as both a regional and state-level professional development support for teachers, is provided. The description includes a background of Missouri Teacher Academy with program details related to the structures and content of the experience. However, to understand the scope and scale of this program, its systemic positioning within a complement of state-level teacher development supports, is defined. Additionally, consideration is given to the potential impacts of this study on the program as a statelevel intervention for teacher practice, as well as implications to other state-level programs currently in development. In addition to the history of the organization and organizational analysis of the program, a leadership analysis and implications for research is shared.

\section{History and Background of Organization}

Missouri Teacher Academy entered its twenty-third year with its kickoff in September, 2019. A version of teacher academy, the St. Louis Teacher Academy, is noted to have been in existence as early as 1988 (Belcher \& Vinson, 1997), however, the official beginning of what would become the current Missouri Teacher Academy did not occur until August of 1996. Through a university, state, and RPDC collaboration (Central 
Missouri State, the Central RPDC, the Missouri Department of Elementary and Secondary Education, and the St. Louis Teacher Academy) the first year of the statewide teacher academy piloted with "19 teachers from 12 school districts" (Belcher \& Vinson, 1997, p. 3) in two areas of the state. The original academy spanned a thirteen-month period of time (Belcher \& Vinson, 1997). At the end of the first year, the goal was to "revert to a practitioner driven model" (Belcher \& Vinson, 1997, p. 6), which appears to have occurred for at least the second year of the program with Belcher and Vinson (1997) reporting the expansion of Missouri Teacher Academy to include teacher-facilitated, operational academies, in four regions of the state.

While no attendance data is available for Missouri Teacher Academy between 1998 and 2006, Missouri Teacher Academy is reported by RPDC directors and facilitators of the time to have continued to operate across many regions of the state. Given decreases in state funding, official data collection and reporting were not required and regions maintained their own information. In 2004, Missouri Teacher Academy saw a resurgence when work began on the writing of a grant proposal to support the RPDCs work on developing the Statewide Teacher Academy. In 2006, a Missouri Department of Elementary and Secondary Education Professional Development Grant (Baldwin, 2006) was filed by the Northwest Regional Professional Development Center to fund "A Statewide Network of Teacher Academies through the Nine Regional Professional Development Centers" (Baldwin, 2006, p.1). This grant application outlined program objectives and goals and solidified a cooperative partnership among the nine RPDCs to offer the program statewide. As seen in Table 1, beginning with the 2006-2007 school 
year, Missouri Teacher Academy attendance tracking appears with greater than 150 teachers attending Missouri Teacher Academy in the 2006-2007 school year.

Table 1

Missouri Teacher Academy Attendance by Year

\begin{tabular}{ccc} 
Year & Participants & Regions \\
\hline $1997^{\mathrm{a}}$ & 19 & 2 \\
$1998^{\mathrm{a}}$ & - & 4 \\
$1999-2005$ & - & - \\
2006 & $193^{\mathrm{b}}$ & - \\
2008 & $168^{\mathrm{b}}$ & - \\
2009 & $28^{\mathrm{c}}$ & - \\
$2010-2014$ & - & - \\
2015 & $176^{\mathrm{b}}$ & 10 \\
2016 & $199^{\mathrm{b}}$ & 10 \\
2017 & $150^{\mathrm{b}}$ & 10 \\
2018 & $200^{\mathrm{b}}$ & 10 \\
2019 & 158 & 10
\end{tabular}

Note: Source: Missouri Department of Elementary and Secondary Education ${ }^{a}$ Belcher \& Vinson, (1997)

${ }^{\mathrm{b}}$ Includes $\approx 10-20$ facilitators

${ }^{\mathrm{c}}$ Might be inaccurate

The professional development grant in 2006 continued the original academy's emphasis on reflective practice, and the grant presented the work of Joellen Killion, What Works in the Middle, as a research-base to support the program. It is stated in the grant that this work, "has shown that teachers who reflect on their practice, study student work, do 
action research using their students' work, and reevaluate their teaching based on these findings, make a difference for kids" (Baldwin, Miller, \& Callison, 2006, p.2). The grant also asserts:

If the state of Missouri wants to make significant gains in student achievement, we will need to support the professional growth of teachers. Missouri needs to create a critical mass of teachers in schools that reflect on their practice, work in collaborative groups to study student work and test data and make changes in their practice as a result of their findings. In Missouri we want to ensure that all students have equal opportunities to meet the challenges of our changing world. This will only happen if there is an exceptional teacher in every classroom. (Baldwin, et al., 2006, p.2)

True to the original structure of Teacher Academy, the 2006 grant plan included the combination of regional and state-wide gatherings that provided teachers exposure to national speakers, time for reflection and conversation, and support for completing the action-research component of Missouri Teacher Academy, which was called an inquiry project in the grant application. The grant lists the "advantages of the academy" (Baldwin, et al., 2006) obtained through this facilitated learning opportunity as:

- A chance to be recognized as a master teacher that is involved in continuous professional learning.

- A chance to learn and collaborate with other master teachers from other districts, other grade levels and other content disciplines.

- A chance to hear the latest educational trends, strategies and philosophies from excellent national and local presenters. 
- A chance to collaboratively process, reflect, and implement (with support) ideas to increase student learning.

- A chance to demonstrate expertise in their content area.

- A chance to create a pool of regional resource teachers for priority schools.

- A chance to bond and build a career-long support system for continued professional growth.

- A chance to learn new skills and strategies to raise test scores and effect student achievement in their classrooms. (Baldwin et al., 2006, p. 2-3)

Of note, the writing of this grant connected Missouri Teacher Academy to teacher leadership development in its discussion of its role in the development of teacher leadership. It was specifically noted that "the academy curriculum would be structured so as to serve as a natural stepping-stone for those teachers aspiring for National Board Certification or the Select Teachers as Regional Resources (STARR) program" (Baldwin et al., 2006, p. 2). Additionally noted, Missouri Teacher Academy would work to identify and recognize "a pool of master teachers who can serve as resource teachers for priority schools across the state" (Baldwin et al., 2006, p. 4). The grant promoted teacher leadership and asserted the hope that, "schools will put these teachers in leadership roles and use them to mentor teachers that need to improve their practice" (Baldwin et al., 2006, p. 4).

As can be seen in the attendance data found in Table 1, Missouri Teacher Academy attendance rebounded again with greater than 100 teachers attending Missouri Teacher Academy in the 2006-2007 school year. However, after a few years, attendance tracking disappeared again. While no state-level attendance has been identified during 
2010 and 2014, evidence exists for a revitalization of Missouri Teacher Academy in the 2011-2012 school year when Missouri Teacher Academy was used to facilitate the advancement of the newly adopted Missouri Teacher Standards. It is uncertain as to the exact number of RPDCs who participated in this work in the 2011-2012 school year, however, there is documentation of five RPDC proposals being provided to Missouri DESE (Appendix E), each outlining a plan for the development of a regional teacher cohort wherein which the Missouri Teacher Standards would become a central focus of the experience.

The agreement between Missouri DESE Office of Educator Quality (OEQ) and the RPDCs included RPDC discretion in: (a) identifying a teacher network wherein to promote the teacher standards; (b) connecting the standards to network objectives; and (c) reporting of some form of pre- and post- data collections. Common non-negotiable elements within the contract included submission of a plan for linking the standards within the network and a proposed budget request and the sharing of data results, including participant feedback. Review of the RPDC teacher academy proposals revealed language referring to the program as a "pilot project [that] will provide a diverse teacher audience to learn about, reflect on, and react to, the newly adopted Missouri Teacher Standards" (Appendix E).

Based on an analysis of the 2011 RPDC proposals for the operation of teacher academy, the purposes of Missouri Teacher Academy were noted to be the: (a) provision of teacher support, (b) enhancement of teacher skills, and (c) instruction surrounding the new Missouri Teacher Standards. One out of the five proposals noted implementation of the Common Core State Standards as the purpose of Missouri Teacher Academy. While 
some variation was noted in 2011 regarding content objectives across the different RPDCs, statewide content consistency existed across all five of the RPDC proposals in their inclusion of (a) instructional practice, (b) engagement, (c) reflective practice, and (d) the Missouri Teacher Standards within their content objectives and/or program outcomes. Other than the addition of the Missouri Teacher Standards, the common commitments of the RPDCs were true to the original programming of Missouri Teacher Academy as well as the content intentions of the 2006 professional grant.

Missouri Teacher Academy again saw another time of renewal in the summer of 2015 when RPDC academy facilitators gathered to promote Missouri Teacher Academy. They worked to re-establish the benefits of having a statewide professional learning opportunity for teachers. They engaged in discussions to create frameworks for the program. These discussions included the generation of a list of benefits for a statewide model, program non-negotiables, and data collection agreements (Figure 3).

Additionally, program designers and facilitators at the time included the statement "statewide consistency with regional flexibility" regarding the implementation of Missouri Teacher Academy. This is a common value across the RPDC system which heralds the belief of the RPDCs in disseminating the same content statewide, while maintaining flexibility in delivery in order to meet the diverse needs of those they serve. The 2015 facilitator group met again in September, 2015 and continued their work on strengthening the framework for Missouri Teacher Academy. A common vocabulary (Appendix F) sheet was shared with program facilitators, which defined essential program components and common strategies. This support fostered increased content consistency statewide. Additionally, this group spent time thinking about the reason 
Missouri Teacher Academy existed and who it was for. Noted as "What is our WHY?"

(Appendix G), the group created a list of reasons for Missouri Teacher Academy to exist.

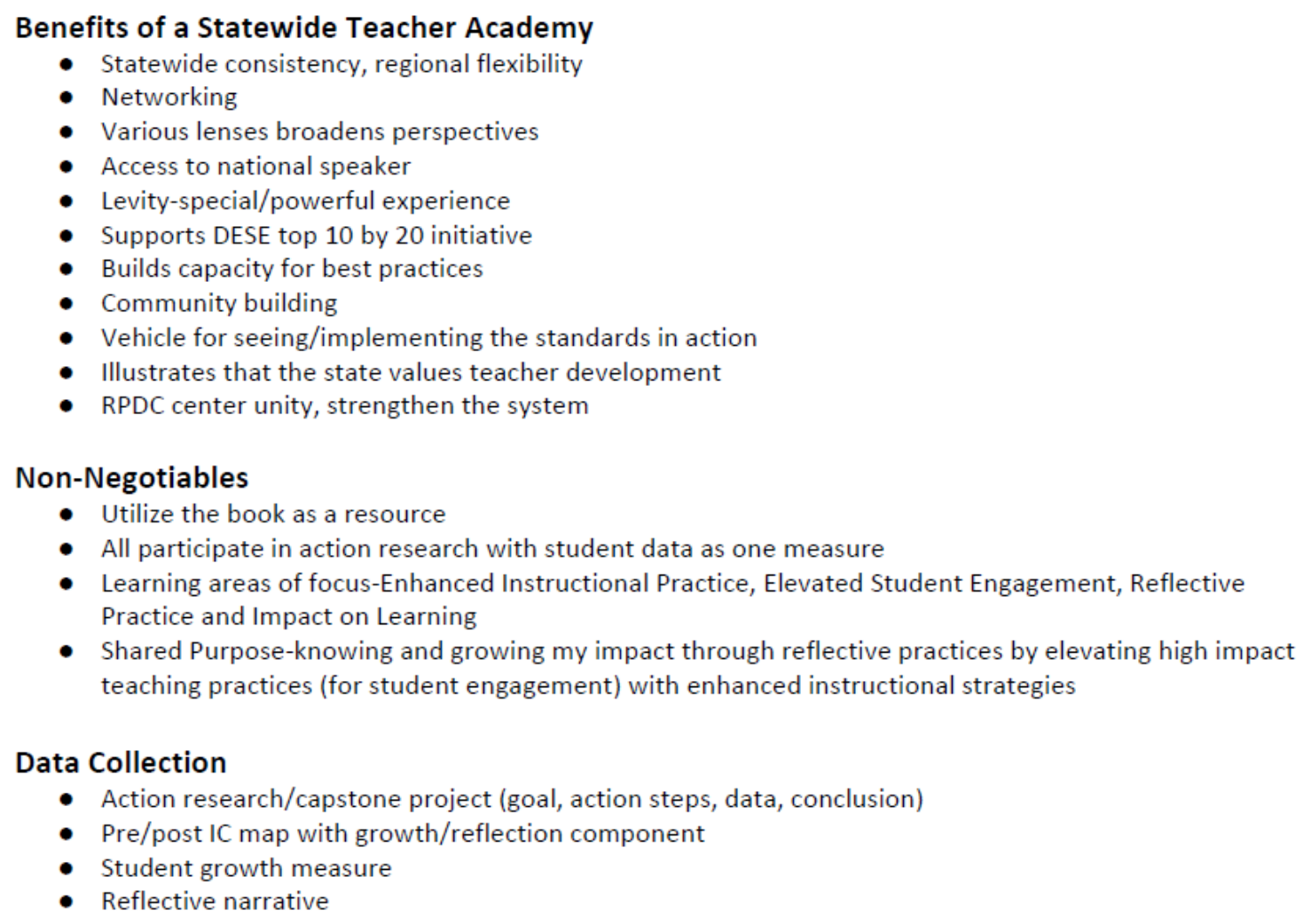

- Utilize the book as a resource

- All participate in action research with student data as one measure

- Learning areas of focus-Enhanced Instructional Practice, Elevated Student Engagement, Reflective Practice and Impact on Learning

- Shared Purpose-knowing and growing my impact through reflective practices by elevating high impact teaching practices (for student engagement) with enhanced instructional strategies

Data Collection

- Action research/capstone project (goal, action steps, data, conclusion)

- Pre/post IC map with growth/reflection component

- Student growth measure

- Reflective narrative

Figure 3. Artifact from the July, 2015 Statewide Teacher Academy facilitator's meeting showing the progression of the academy towards a more solidified statewide program.

Some key ideas from the list included: (a) celebrating teaching, (b) modeling best practice, (c) collaboration, (d) increases to student achievement, (e) teacher growth, (f) giving teachers time to reflect, and (g) developing highly effective teachers. The list from this facilitator session also made connections between collaboration and teacher growth as well as teacher learning and student growth. (Appendix G).

Beginning in the 2015-2016 school year, and continuing into 2019, Missouri Teacher Academy has maintained somewhat similar structures statewide with the Missouri DESE providing oversight and accountability for the (a) number of regional 
sessions required and (b) the submission of evidence of teacher academy participants' action research, including student growth data. Additionally, the completion of reflective perceptual participant and principal surveys has been a requirement or non-negotiable of the program. Content, while not standardized, has maintained consistency, which can be seen as far back as the original 1996 teacher academy with all regions agreeing to three common content focus areas: (a) Instructional Practice, (b) Student Engagement, and (c) Reflective Practice. These areas of focus were called "big rocks" and remain as centralizing components of Missouri Teacher Academy.

Structurally, all nine RPDC regions, and one additional Missouri DESE approved program provider, offer six full day sessions of cohort learning, which is in addition to the two statewide sessions where all teacher academy teachers gather together for conference-style learning with leading authors and speakers. Additional consistency across the state exists in adherence to teacher completion of an action-research classroom project, which is shared regionally and submitted to the Missouri DESE. Within this project, teachers identify an area of focus, plan and implement strategies, and gather student growth data, which is used by each teacher reflectively to evaluate the effectiveness of their instruction.

In the $2019-2020$ school year, after the 2015 revitalization, Missouri Teacher Academy is operational in ten geographic regions, covering the entire state of Missouri. While there are pockets of missing attendance data, comparing the current information to the first academy, attendance has grown greatly from the original 19 teachers in 1997 to post 2015 attendance occurring at consistent levels of greater than 100 teachers per year. The program continues to operate through collaborative alliances between the Missouri 
DESE, RPDCs, universities, and school districts with the RPDC network providing logistics and facilitation of the program.

Over time change has come to Missouri Teacher Academy, however, some elements of the program have remained fairly constant. The experience still includes time away in a lake retreat style setting, although it currently includes two separate oneday events rather than the three-day late summer and two-day fall retreats (Belcher \& Vinson, 1997) of the program's earliest days. The current academy framework still includes some of the original program's foundational structures, such as (a) opportunities for teachers to develop strong regional and state networking opportunities, (b) an emphasis on discussion and peer interactions, and (c) sharing of growth and celebration of success (Belcher \& Vinson, 1997). Interestingly, one thing that exists entirely in its original form is the cost of attending Missouri Teacher Academy. The tuition for the first academy year, twenty-three years ago, was, and still remains in many locations, set at $\$ 500$. Another aspect of the program, which has carried onward throughout the years is the focus on the action research component of academy, which continues to be a central mechanism for participant learning (Belcher \& Vinson, 1997). Fortunately, most notably unchanged, even across more than two decades of operation, are the original intentions of the first academy: (a) to help teachers "serve as knowledgeable change agents in their school districts and (b) the "creation of a network of outstanding teachers" (Belcher \& Vinson, 1997, p. 2), which continue to be realized with each successive teacher academy year.

While much has remained the same, one area that has seen great change over the last twenty-three years is the level of participant control over the program. Belcher and 
Vinson (1997) reported participant "complete control in developing the activities and areas of study" (p. 4) as "a fundamental philosophy of the academy" (p. 4). The current ideology regarding program development and delivery is aligned to the commitment of the RPDCs to statewide content consistency with regional flexibility. Additionally, with each revitalization, program frameworks have increased in consistency. Given the longstanding operation of Missouri Teacher Academy, attention has turned to efforts to identify the impacts of the program. Additionally, over the past three years there has been ongoing development of the Missouri Teacher Development System, which is a system of aligned learning that spans the teaching career. Given new information obtained from evaluations, as well as the continued movement towards a career-spanning learning system for teachers, it is likely Missouri Teacher Academy will once again face a period of restructuring and redefinition as it continues to strengthen its capacity to serve and support Missouri's teachers.

\section{Organizational Analysis}

As a state-level educational initiative, Missouri Teacher Academy operates under the authority and direction of the Missouri Department of Elementary and Secondary Education (DESE) in cooperation with the state's Regional Professional Development Centers (RPDCs). This organizational alliance represents a systemic networking of entities working jointly to fund, develop, facilitate, promote, support, and evaluate this teacher support program, which impacts teachers from all regions within Missouri. Both the Missouri DESE and the RPDCs, as well as Missouri Teacher Academy itself, have distinct internal organizational structures supporting the program with cross-organization units connecting through a dense web of state-wide relationships committed to the 
program's central purpose of building state-level support systems for Missouri's teachers. This section will: (a) provide an overview of the organizational structures and functioning of the Missouri DESE in relationship to Missouri Teacher Academy, (b) present some historical positional referencing of the RPDCs and define their organizational structures pertaining to their role in Missouri Teacher Academy, and (c) discuss ways in which these organizations have partnered in their efforts to provide high quality professional learning supports through Missouri Teacher Academy for the last 23 years.

\section{Missouri Department of Elementary and Secondary Education}

Missouri Teacher Academy is promoted and supported by the Missouri DESE. As a state-supported teacher development program, it is offered through the department's Division of Learning Services. In analyzing the program within the hierarchical structuring of the Missouri DESE (Figure 4), it resides within the Office of Educator Quality with program oversight and accountability provided by Assistant Commissioner, Paul Katnik, EdD. Direct program coordination and management is offered by the Missouri DESE's Director of Teaching, Linda Dooling. The Missouri DESE is a state educational organization, which functions "as a complex policy ecosystem" (Bolman \& Deal, p. 235) working to effectively manage and allocate resources to meet the needs of many different constituents. While some organizational units within the Missouri DESE contract with the RPDCs to provide consultants whose work is then managed through contractual conditions outlined through the Missouri DESE, Missouri Teacher Academy historically has not followed this model. Rather, the OEQ has offered teacher academy supports to the RPDCs, and one additional program provider, in the form of reimbursements for scholarships, program funding, and expense reimbursements. 
Additionally, they host the two state meetings, including the provision of a national expert speaker and a book for each teacher academy participant. This funding structure has presented a less directive approach with the Missouri DESE sharing control with the RPDCs, who directly oversee facilitator selection, program logistics, and content delivery; the program has operated through collaborative negotiations regarding program content and accountability requirements.

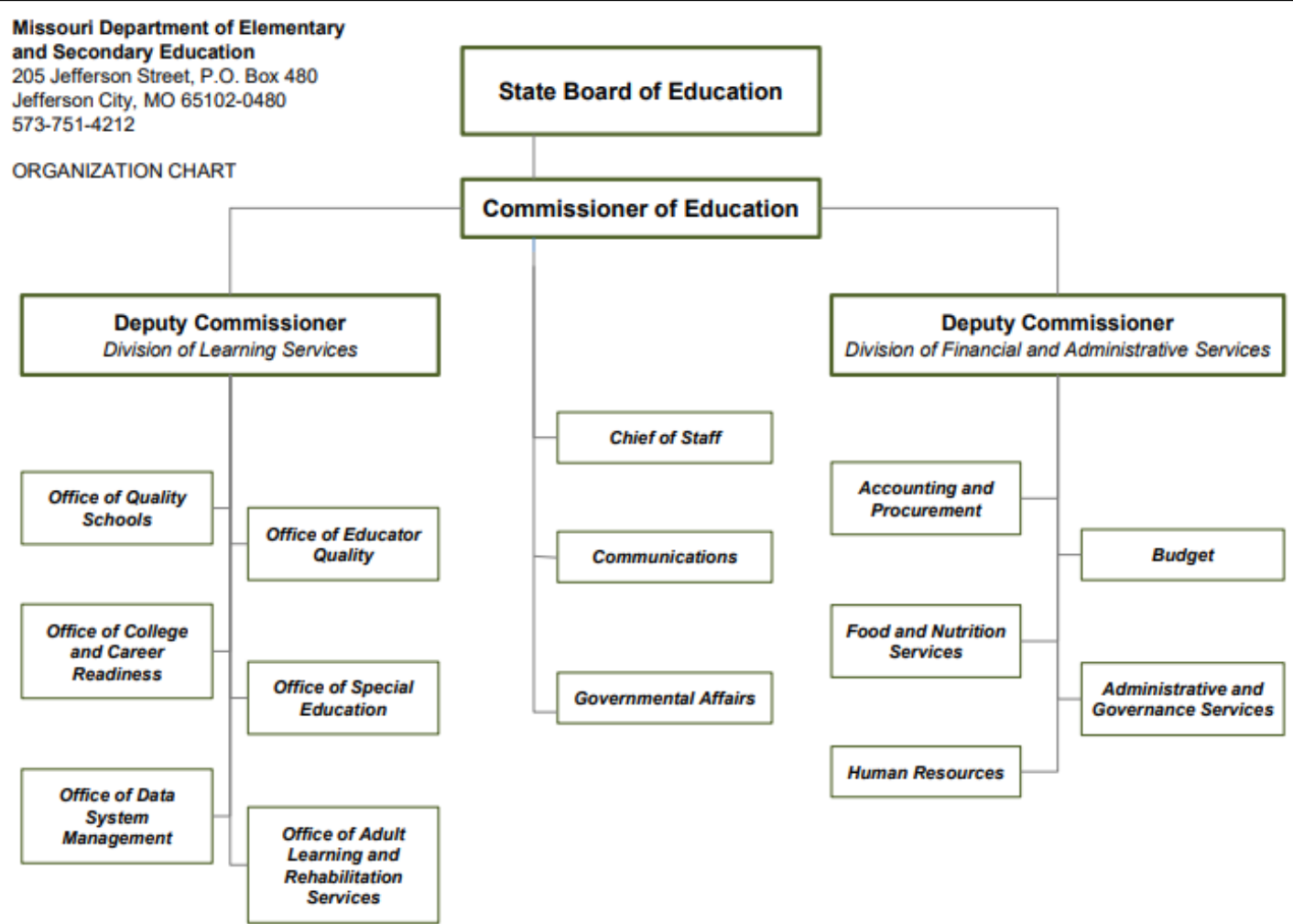

JANUARY 2019

Figure 4. Missouri Department of Elementary and Secondary Education Organizational Chart. Retrieved from: https://dese.mo.gov/sites/default/files/DESE_orgchart.pdf

In relationship to Missouri Teacher Academy, the Missouri DESE provides both vertical and lateral coordination. The Missouri DESE is the main authority over Missouri Teacher Academy and establishes protocols and operating procedures (Bolman \& Deal, 2016) needed to maintain the program. Additionally, the Missouri DESE presents 
accountability to the program, which encourages continual evaluation of effectiveness and monitoring of progress, both of which have contributed to ongoing program improvement and advancement. Laterally, the Missouri DESE has been instrumental in the formation and sustainability of Missouri Teacher Academy with its ability to connect the RPDCs, districts, and teachers throughout the entire state. In addition to the statewide teacher gatherings, the Missouri DESE hosts additional facilitator meetings throughout the year to connect facilitators, provide information, and encourage facilitator collaboration. Additionally, the Missouri DESE communicates program progress and success to stakeholders and obtains program funding to continue program operations.

Missouri Teacher Development System. While historically Missouri Teacher Academy has existed alone as a statewide teacher development support, Missouri has expanded its teacher supports, adding programs to meet the needs of beginning teachers and teacher leaders. In 2016, the Missouri DESE and six RPDCs began collaborating on developing statewide induction programs, which include training for new teachers and mentors. Work has continued to advance over the last three years with operational induction programs consisting of at least three days for beginning teachers, mentor training, and professional development committee training being offered in six RPDC regions. The work has expanded in its scope and has become known as the Missouri Teacher Development System (MTDS).

MTDS is being developed as a state-supported complement of sequenced careerspanning professional learning supports designed to promote teacher: (a) recruitment; (b) knowledge and skill development; (c) recognition; and (d) retention. Its design offers a progression of learning leading to thirty teacher competencies. There are plans for the 
development of learning experiences aligned to the competencies spanning across six levels of teacher development: (a) aspiring, (b) preparing, (c) emerging, (d) developing, (e) mastering, and (f) teacher leader. In fall 2019, the MTDS work focused on the development of system competencies to guide teacher learning across the career levels. A draft of the MTDS competencies was completed in January 2020, outlining thirty teaching competencies, which were clustered around six domains of teaching (Appendix H). Each competency was broken down and progressed across the six career-levels recognized within the system, which can be used to guide program development.

Future plans for the system include the development of competency-based learning opportunities anchored in delivery methods built on the guiding principles of transformative and holistic adult learning theories. These include both Taylor's (2009) core elements of transformative learning: (a) individual experience, (b) critical reflection, (c) dialogue, (d) holistic orientation, (e) awareness of content, and (f) authentic practice, as well as Dirkx's "sense of relationship [that] is critical to nurturing and caring for soul" (Dirkx, 1997, p.84). MTDS programs follow the Missouri Teacher Academy model in that they provide participants with long-term, cohort-style learning experiences, which promote: (a) state and regional teacher collaboration; (b) job-embedded learning with application of skills within classrooms and schools during experiences; and (c) the development of teacher reflective practice, which the design-team is considering as a potential system-wide focus for teacher learning. The design team understands that "the developmental span for both prospective and practicing teachers will vary considerably [and that] it is important for teachers to progress through the levels of reflective practice to ultimately become critically reflective teachers who pose the important questions of 
practice" (Laviree, 2008, p. 344). While it is currently unknown how MTDS will connect to Missouri Teacher Academy, it is likely that it will.

\section{Regional Professional Development Centers}

Although Missouri Teacher Academy is supported and promoted by the Missouri DESE, it has primarily been designed and facilitated by the nine regional professional development centers, along with one additional approved service provider. The RPDCs employ highly skilled educational consultants with extensive backgrounds in education. Many of the RPDC consultants throughout the state hold greater than 25 years of experience, serving Missouri’s schools as administrators, counselors, and teachers.

The RPDCs were established by the Missouri DESE in the 1995-1996 school year (Learning Forward, n.d.) and were determined through legislation to be spread across the state in order to provide equitable access to all Missouri schools (Jaquith, Mindich, Wei, \& Darling-Hammond, 2010). The infrastructure of Missouri's RPDC network was applauded in research as an effective method for providing professional learning and supports for teachers across the state (Jaquith et al., 2010). While originally established by the Missouri DESE, over time and with funding changes, the RPDCs have become more independent. Each of the nine RPDCs currently functions independently of the others, however, they are banded together through long-standing relationships and common working commitments and contracts through the Missouri DESE. Jaquith, et al. (2010) noted that:

Relationships are developed across the regional RPDCs because of formal communication channels, such as monthly director and program meetings, and because of the longevity of directors who have become friends and colleagues over 
many years of working together to lead common RPDC programs. Relationships are also built between program coordinators at DESE and the local RPDC directors. Of course, because of the formal partnership with and proximity of the centers to universities, relationships between higher education faculty and the RPDC staff are also formed. (p. 61)

The RPDCs maintain a collective mission to "build the capacity of educators through high quality professional learning to maximize student success" (Agency for Teaching, Leading, \& Learning, Central RPDC, South Central RPDC, 2019).

In addition to operating independently, yet dependently, with the Missouri DESE, the majority of the RPDCs are housed within universities, who serve as the financial agents for the RPDC. This positioning establishes a triad of connectivity between the Missouri DESE, the RPDCs, and home universities. Additionally, as the main work of the RPDCs resides within the K-12 public school system, the RPDCs function as a connector for the school districts to both the Missouri DESE and the university systems. Under this positioning, the RPDCs operate, "in the role of an intermediary organization, mediating between state policy and local needs, [which is] where the RPDCs are able to add the greatest value" (Jaquith \& McLaughlin, 2010, p. 59).

Each of the RPDCs employs a director or coordinator of programs who is responsible for the allocation and coordination of resources (Bolman \& Deal, 2013) for the operation of Missouri Teacher Academy regionally. This includes providing a training location and program facilitator as well as any other logistical needs of the program. Directors actively participate in the development of the program and many attend the Missouri DESE sponsored facilitator meetings. RPDC directors are critical to 
the relationships between the Missouri DESE and the RPDC network. They engage in on-going collaboration and negotiations regarding the operation of the program, both within the internal RPDC network as well as with the Missouri DESE. The RPDC directors promote the program throughout their respective regions and provide districts with program information.

\section{Policy and Funding}

Currently, Missouri Teacher Academy is primarily funded through Title II state funding. Missouri Teacher Academy is included in the state's consolidated state plan, which mentions "state-sponsored professional learning [that] includes a Teacher Academy that provides teachers the opportunity to improve their instructional practice within a statewide network of teachers.” Since 2015, the Missouri DESE has provided each of the program providers $\$ 3000$ for program funds, $\$ 1500$ to be used for regional teacher scholarships, and additional scholarships for each region for each teacher who has been selected as a Regional Teacher of the Year through the Missouri Teacher of the Year program. In 2018-2019 and 2019-2020, additional funds were provided by the Missouri DESE to promote the program. These funds were provided to the program providers in the form of scholarship reimbursements. In 2019, these funds included up to $\$ 10,000$ per location to be used for teacher scholarships. Additionally, the Missouri DESE reimburses the RPDCs for facilitator travel expenses when attending statewide program events and facilitator meetings. While each RPDC establishes the cost of teacher academy attendance, the majority charge the original registration fees of $\$ 500$. The RPDCs provide program facilitators and all logistics for the program delivery. While the Missouri DESE provides reimbursements for facilitator travel, the RPDCs are 
responsible for facilitator salaries for all time spent preparing and delivering the program, as well as for attendance at state-level gatherings.

\section{Leadership Analysis}

Within an inter-organization relationship web, leadership of Missouri Teacher Academy is a complex construct with program leadership and management occurring through distributed leadership. Both the Missouri DESE and the RPDCs, "step forward when situations warrant, provide the leadership necessary, and then step back to allow others to lead" (Northouse, 2016, p. 365). This partnership has provided the program with a multitude of diverse leaders from which to draw upon to maintain the program through challenges as well as lead it into new adaptations and through periods of change (Heifetz \& Laurie, 1997). The Missouri DESE, as well as the RPDCs, have remained committed since the program's first academy in 1996, to providing teachers with a transformational learning experience (Taylor, 2009), which nourishes and challenges teachers simultaneously, regardless of changing educational climates, and this shared commitment has both sustained and advanced the program over its 23 -year history.

The earliest years of Missouri Teacher Academy, 1998 - 2004, saw periods of program instability as evidenced by lack of systemic data collection, as well as reports from program developers and facilitators reporting diminished state supports during these years. This period was marked by an increase in RPDC-level leadership and support of Missouri Teacher Academy with an emphasis on maintenance of regional operations. This was most notable between 1998 and 2004. During this period, based on conversations with program directors and facilitators of the time, the program continued to exist in several regions even though there was a decrease in state funding. These years 
represented a period of servant leadership (Northouse, 2016) with many of the RPDCs dedicating to the continual operation of Missouri Teacher Academy regardless of shifts in funding and without wide-spread supports for the program. They determined to keep Missouri Teacher Academy going by, "put[ting] followers [teachers] first, empower[ing] them, and help[ing] them develop their full personal capacities" (Northouse, 2016, p. 225). During this time program leaders demonstrated many characteristics of servant leadership in their: (a) care about the personal well-being of their followers [teachers], (b) stewardship, holding, "the organization in trust for the greater good of society" (Northouse, 2016, p. 228), (c) "commitment to the growth of people" (Northouse, 2016, p. 228), and (d) building of community with many of the RPDCs strengthening relationships through their efforts to sustain teacher academy regionally. True to the tenants of a servant leader, early teacher academy leadership put the needs of others before their own (Northouse, 2016).

Missouri Teacher Academy was, and continues to be, driven by the force of servant leadership and unwavering dedication to the service of teachers. In addition to leaders with servant hearts, the Missouri DESE-RPDC partnership has continually provided Missouri Teacher Academy with leaders focused on the advancement of Missouri Teacher Academy and the securing of its position as a state-wide system. Missouri Teacher Academy transformations and times of expansion have been led by: (a) visionary leaders who set new directions for the program (Bolman \& Deal, 2013; Heifetz \& Laurie 1997; Kotter, 1990; Northouse, 2016) and inspired hope and motivation (Helland \& Winston, 2005) across the system; (b) political leaders who rallied stakeholders and constituents and campaigned and promoted the program (Bolman \& 
Deal, 2013); and (c) those who provided path-goal (Northouse, 2016) leadership to "remove obstacles and roadblocks to attaining the goal" (Northouse, 2016, p. 115). Through Missouri DESE-RPDC networking, Missouri Teacher Academy continues to have access to multiple frames of leadership. It is likely in this collaboration that all seven of Rooke and Torbert's (2005) action logics can be found working together across the system. These logics connect through networked relationships similar to those found within Helgesen's (1995) web of inclusion or an all-channel network (Bolman \& Deal, 2013) where "information flows freely; decisions sometimes require touching multiple bases" (Bolman \& Deal, 2013, 102). The availability and collaborative functioning of diverse leadership capacity has protected and promoted Missouri Teacher Academy since 1996, and as the system strengthens, movement towards additional teacher support programs modeled after Missouri Teacher Academy finds more potentiality.

Great strength exists in sharing leadership between organizational entities, however, challenges can also be found when working inter-organizationally and Missouri Teacher Academy may struggle within the current model with clarity in organizational roles in: (a) authority and leadership, (b) program direction-setting, (c) responsibility for decisions and communication, and (d) coping with change. Leaders are responsible for "deciding what needs to be done, creating networks of people and relationships that can accomplish an agenda, and then trying to ensure that those people actually do the job" (Kotter, 1990, p. 39). These key functions can be challenging when organizations are working in partnership, each with their own internal organizational policies and procedures. Additionally, as both the RPDCs and the Missouri DESE have varied in their involvement in taking the lead throughout Missouri Teacher Academy history, and in 
light of shared fiscal responsibility of the program operation, these challenges will likely continue as leadership functions fluctuate between the Missouri DESE and RPDCs. Given the program longevity and extensive favorable program perceptions statewide, the benefits from this partnership appear to supersede challenges, and Missouri Teacher Academy has continued to gain strength into its current operational year of 2020-2021.

\section{Implications for Research}

Missouri Teacher Academy is a program designed to support teachers who have the potential to become part of the Irreplaceables (Jacob, et al., 2012). Insights gained contribute to understanding the impacts of Missouri Teacher Academy on teacher self-efficacy, reflective practice, and/or job satisfaction. This program has the potential to serve as a model for states who are seeking to improve career development as a way to improve teacher retention (Sutcher,et al., 2016). Implications of this study include: (a) increased state and national interest in the program, including potential interest in replication of the program in other states; (b) additional research into the effectiveness of the program; (c) potential legislative actions to secure the future of Missouri Teacher Academy; (d) possible increases in state-level funding and program support; and (e) probable expansion of the framework into additional state-level teacher development programs through the MTDS.

\section{Summary}

This study was conducted within Missouri Teacher Academy, which is a statesponsored professional learning opportunity for teachers with more than three years of experience. The program operates through a cooperative partnership between the 
Missouri DESE and the RPDCs. Within this framework, Missouri Teacher Academy has experienced a long history of shared leadership between these organizations. While there have been multiple periods of revitalization and on-going movements associated with various educational initiatives, the core framework of Missouri Teacher Academy has remained fairly stable since its first year of operation in 1996.

Missouri Teacher Academy has been fully operational in 10 geographic regions throughout the State of Missouri since 2015 with teacher participation rates consistently reaching greater than 100 teachers in attendance statewide. All 10 locations have committed to providing teachers with on-going learning opportunities that emphasize (a) instructional strategies, (b) engagement strategies, and (c) reflective practice.

Additionally, all locations provide direction and support for participant completion of a classroom action research project. Teachers gather regionally for six cohort sessions throughout the Missouri Teacher Academy year and all regions join together twice a year for state-wide programming provided by nationally recognized speaker and author, John Antonetti. The results of this study inform stakeholders and program designers of the impacts of Missouri Teacher Academy on level of teacher self-efficacy and reflective practice, which can be used for future program design. Implications of the study also include potential increases to program funding, support for the program as a state-level support with research-based connections to teacher retention. 
SECTION THREE: SCHOLARLY REVIEW 


\section{Introduction}

This scholarly review of literature included an overview of research regarding: (a) the teacher shortage crisis; (b) professional development for teachers; (c) teacher selfefficacy; (d) and reflective practice. Missouri Teacher Academy is part of state-level efforts to improve teacher retention through professional development. The program focuses on increasing levels of teacher self-efficacy and reflective practice. Information regarding the current teacher shortage crisis and the positioning of professional development as an important retention strategy are shared. Additionally, connections between reflective practice, teacher self-efficacy, and job satisfaction will be made to support viewing this study through the lens of supporting teacher retention through professional development.

\section{Teacher Shortage Crisis}

The current teacher shortage crisis is "the result of multiple and interdependent drivers, all working simultaneously to cause the imbalance between the number of new teachers needed (demand) and the number of individuals available to be hired (supply)" (Garcia \& Weiss, 2019a, p. 11). While it would seem recruiting more teachers to the profession would be the simple solution, issues within the career itself have made retaining teachers a challenge as well. To further compound the problem, teachers are leaving the profession for reasons equally complex as the shortage itself, including factors such as dissatisfactions with the career (Goldring, Taie, \& Riddles, 2014; Guarino, et al., 2006; Ingersoll, 2003; Podolsky, et al., 2016; Strauss, 2015; Sutcher et al., 2016), inadequate preparation for the career (Podolsky et al., 2016; Redding \& Smith, 2016), high levels of attrition within the early part of the career (Allensworth, et al., 
2009; Carver-Thomas \& Darling-Hammond, 2019; Guarino, et al., 2006; Ingersoll, 2003;

Haushekt, Kain, \& Rivkin, 2004; Johnson \& Birkeland, 2003; Stinebricker, 2002), and poor on-going training and learning for teachers throughout their career (DarlingHammond, Hyler et al., 2017; Garcia \& Weiss, 2019e; Gates Foundation, 2014).

The shortage is a complex problem, which has a great impact on both human and economic capital (Carroll, 2007; Carver-Thomas \& Darling-Hammond, 2017; Garcia \& Weiss, 2019b). Not having enough teachers to fill America's classrooms comes with great costs to students, teachers, and the entire society (Garcia \& Weiss, 2019b; Strauss, 2015). Economically, costs associated with the teacher shortage crisis reach into the billions of dollars (Carroll, 2007; Garcia \& Weiss, 2019b) with the cost of filling a teacher vacancy averaging \$21,000 (Carver-Thomas \& Darling Hammond, 2017). Beyond the economic cost of the crisis, human effects are great given the known impact of teachers on student learning with Hattie (2003) referring to the teacher as "the greatest source of variance that can make the difference" (p. 3).

The lack of qualified teachers affects student learning (Allensworth Ponisciak, \& Mazzeo, 2009; Carroll, 2007; Darling-Hammond, 1999) with student outcomes being impacted by “a lower quality mix of teachers and loss of coherence within the school's educational program" (Sorenson \& Ladd, 2018, p. 1). Turnover effects teacher effectiveness (Carroll, 2007; Garcia \& Weiss, 2019a; Sorensen \& Ladd, 2018) with Sorensen and Ladd (2018) finding "evidence that turnover also moderately increases the share of those teaching out of their subject area of certification and those who score less well on teacher licensure tests" (p. 26) both of which they noted "signal lower quality of education for students" (Sorensen \& Ladd, 2018, p. 26). Beyond the effects of changing 
qualifications or effectiveness levels of teachers due to turnover, Ronfeldt, Loeg, \& Wyckoff (2013) found teacher turnover impacts the entire organization and "even when leaving teachers are equally as effective as those who replace them, turnover can still impact students' achievement" (p 7). It is important to note that "high poverty, high minority, urban, and rural public schools have among the highest rates of turnover" (Ingersoll, Merill, Stuckey, 2014, p. 18) and feel the effects of teacher turnover the most leading to educational inequities due to uneven distributions of qualified teachers (Garcia \& Weiss, 2019b).

Some argue the teacher shortage is not widespread, but rather only found in high poverty schools and targeted, hard-to fill areas such as special education, English language learner programs, technical content areas like math and science, and specialty courses such as foreign languages (Cowan, Goldhaber, Hayes, \& Theobald, 2016). However, Ingersoll et al. (2014) provides evidence of generalized systemic shortages even though they assert that the overall teacher force has actually increased (Ingersoll, et al., 2014). They attribute the shortages to increased demand for teachers due to: (a) increasing student enrollments (Ingersoll,et al., 2014; Garcia \& Weiss, 2019b), (b) movements towards smaller class sizes (Garcia \& Weiss, 2019b; Ingersoll, et al., 2014), (c) changes in student graduation requirements leading to program expansions (Ingersoll, et al., 2014), and (d) an increased need for teachers in the area of special education (Ingersoll, et al., 2014).

In addition to the increased demand for teachers (Ingersoll, et al., 2014) and noted difficulties associated with finding teachers for hard-to-fill vacancies (Cowan, et al., 2016), there has been a sharp decline in the number of people choosing to enter the 
teaching career (Sutcher, et al., 2016) as well as an increase in attrition from the profession for non-retirement reasons (Carver-Thomas \& Darling-Hammond, 2017; Ingersoll \& Smith, 2003; Reeves, 2018; Strunk \& Robinson, 2006; Gray, et al., 2015; Garcia, \& Weiss, 2019). The "shortage makes it more difficult to build a solid reputation for teaching and to professionalize it, which further contributes to perpetuating the shortage" (Garcia \& Weiss, 2019a, p.2).

Some of the main factors associated with decreasing recruitment and increasing attrition include: (a) low compensation or salary (Ingersoll, 2003; Garcia \& Weiss, 2019a; Podolsky et al., 2016); (b) challenging working conditions (Garcia \& Weiss, 2019a; Guarino, et al., 2006; Podolsky et al., 2016); (c) insufficient preparation for the career (Podolsky et al., 2016), including increases in alternative pathways to certification (Redding \& Smith, 2016); (d) inadequate professional development (Garcia \& Weiss, 2019; Ingersoll, 2003; Podolsky et al., 2016); and (e) lack of recognition (Garcia \& Weiss, 2019a). The combination of low recruitment into the profession and high levels of attrition from the field have exacerbated shortages and contributed to the everworsening teacher shortage crisis now affecting the majority of schools across the United States (Carroll, 2007; Carver-Thomas \& Darling-Hammond, 2017; Darling-Hammond, 1999; Darling-Hammond, 2003; Garcia \& Weiss, 2019a; Ingersoll, et al., 2014; Podolsky, et al., 2016; Sutcher et al., 2016). With the worsening crisis, the number of schools unable to fill openings tripled between 2011 and 2016 due to a lack of qualified teachers.

In combatting the teacher shortage crisis in the past, increasing the supply of teachers was the main focus with recruitment programs, such as Teach for America and 
Troops as Teachers, being designed to attract college graduates to the field (Ingersoll, 2003; Borman \& Dowling, 2008). Recruitment efforts also hoped to attract those looking for a career change with the expansion of alternative certification pathways (Borman \& Dowling, 2008). Recruitment efforts that lower expectations and/or provide entry shortcuts for those entering the field "simply exacerbate the root factors behind school staffing problems" (Ingersoll, 2003, p. 17). The above-mentioned programs are designed to increase the supply of teachers entering the profession, however, "attrition rates are found to be two to three times higher for those who enter the profession without full preparation...than for those who are comprehensively prepared (Podolsky et al., 2016, p.vi). Recruiting potential teachers to the profession is a critical part of solving the shortage crisis, but these efforts will not be successful without solutions focused on stopping the mass exodus of current teachers from the career(Carroll, 2007; Ingersoll, 2003; Podolsky et al, 2016). The importance of focusing on retention as a viable strategy for combatting the teacher shortage crisis cannot be understated as "reducing attrition by half could virtually eliminate shortages" (Sutcher et al., 2016, p. 4). Solving this crisis will require "urgent, comprehensive and sustainable policy solutions" (Garcia \& Weiss, 2019b, p.1), and understanding the reasons teachers are leaving the career at higher rates than other similar professional occupations (Ingersoll, et al., 2014) is crucial to stopping the exodus of America's teaching force.

\section{Factors Associated with Attrition}

Not all teacher attrition is bad. Attrition associated with ineffective teachers leaving the field is beneficial (Ingersoll, 2003) and attrition due to retirement as evidenced by higher levels of attrition of teachers over 50 (Carver-Thomas \& Darling Hammond, 2017) is expected. However, teachers are voluntarily abandoning the 
profession for non-retirement reasons other than those associated with normal labor market changes seen in most careers. One of the most concerning factors includes dissatisfaction with teaching as a career (Goldring, Taie, and Riddles, 2014; Guarino, et al., 2006; Ingersoll, 2003; Podolsky, et al., 2016; Strauss, 2015; Sutcher et al., 2016). Additionally, inadequate preparation for the profession (Podolsky et al., 2016; Redding and Smith, 2016), early career exit (Allensworth, et al., 2009; Carver-Thomas \& DarlingHammond, 2019; Guarino, et al., 2006; Ingersoll, 2003; Haushekt, Kain, \& Rivkin, 2004; Johnson \& Birkeland, 2003; Stinebricker, 2002), and weak professional growth opportunities (Darling-Hammond, Burns, et al., 2017; Garcia \& Weiss, 2019e; Gates Foundation, 2014; Podosky et al., 2018) are oft-reported factors associated with teacher shortages due to teacher attrition.

Dissatisfaction. Greater than $50 \%$ of teachers leaving the career note some form of dissatisfaction with teaching as a career (Carver-Thomas \& Darling-Hammond, 2017; Ingersol, 2003). A "2013 poll found that teacher satisfaction had declined 23 percentage points since 2008...the lowest level in 25 years" (Strauss, 2015, para 6). Dissatisfaction is further clarified within the research to reveal issues related to low compensation (Garcia \& Weiss, 2019; Goldring, et al., 2014; Guarino, et al., 2006; Ingersoll, 2003; Podolsky, et al., 2016), challenging working conditions (Darling-Hammond, 206; Garcia \& Weiss, 2019; Ingersoll, 2003; Podolsky et al., 2016), lack of administrative supports and resources for teaching (Ingersoll, 2003; Podolsky et al., 2016), low levels of autonomy (Ingersoll, 2003), and "lack of teacher influence over decision-making" (Ingersoll, 2003, p. 16; Podolsky et al., 2016). Dissatisfaction with teaching as a career is a factor associated with attrition from the field as teachers look for better career 
opportunities for themselves and their families, and " $51 \%$ who left report better manageability of their workload in their new position and 53\% reported better working conditions" (Goldring, et al., 2014). While dissatisfaction is widely noted among teachers leaving the profession, there is evidence to suggest the quality of the preparation of teachers for the career greatly impacts their decision to stay (Garcia \& Weiss, 2019a; Ingersoll, 2003; Podolsky et al., 2016; Redding \& Smith, 2016).

Preparation. Combatting teacher shortages requires addressing both the inflow of teachers to the profession as well as controlling the unwanted exodus of teachers from the career. Strategies associated with increasing the supply of teachers to the career that diminish the quality of the preparation of the teacher candidate can result in increases in attrition (Ingersoll, 2003) due to a lack of preparation for the demands of the career. It is common for new "teachers to feel less than very well prepared to handle all the tasks required in their classrooms in their first year on the job" (Garcia \& Weiss, 2019e, p. 9). Podolsky et al. (2016) report, "attrition rates are found to be two to three times higher for those who enter the profession without full preparation, including those without certification, than for those who are comprehensively prepared" (p. vi). Non-traditional entry teachers and those who have entered teaching through an alternative route have a higher likelihood of leaving the career (Redding \& Smith, 2016) and "teachers with stronger credentials are less likely to quit the profession or move to a different school" (Garcia \& Weiss, 2019, p. 6).

Early career exit. Teacher attrition data associated with the age of a teacher is often discussed in view of its U-shape (Ingersoll, 2001). High levels of attrition are seen in teachers who are under 30 years old and those over 50 years old (Carver-Thomas \& 
Darling-Hammond, 2017), sometimes leading to incorrect thinking of retirement as being a substantially driving factor in teacher attrition. However, Ingersoll (2001) countered this thinking when he reported high levels of teacher attrition in late career even when accounting for retirement. His work (2001) noted the importance of addressing attrition in both early and late career teachers. Ingersoll (2003) reported that "teaching is an occupation that loses many of its newly trained members very early in their careers long before retirement years" (p. 13) and coinciding with the loss of late career teachers to both retirement and non-retirement factors Ingersoll et al., (2014) revealed an "increase in inexperienced teacher force" (p. 11). Early career exit as a factor associated with teacher attrition is supported given the increases in the number of early career teachers and data revealing that early career teachers are more likely to quit than those with more experience (Allensworth et al., 2009; Guarino et al., 2006; Ingersoll, 2003).

Weak professional development. While, "there is a relationship between systems of professional supports - professional development, career-building supports, and teachers' autonomy and influence - and whether or not teachers stay in the profession" (Garcia \& Weiss, 2019e, p.8), teachers are largely unsatisfied with the professional development supports they receive (Gates Foundation, 2014). In fact, the Gates Foundation reports that only $29 \%$ of teachers are highly satisfied with the professional development they are offered and "teachers say that too many current professional development offerings are not relevant, not effective, and most important of all, not connected to their core work of helping students learn" (p.3). Not only are teachers reporting dissatisfaction with the professional development supports they are receiving, "research has shown that many PD initiatives appear ineffective in supporting 
changes in teacher practices and student learning (Darling-Hammond, Hyler, \& Gardner, 2017, p.v).

Ineffectiveness of traditional offerings for teachers is also reported by the Gates Foundation (2014) with teachers reporting a disconnect between what leaders think they are offering and what teachers are actually receiving and what they need (Garcia \& Weiss, 2019e; Gates Foundation, 2014). Both Garcia \& Weiss (2019) and the Gates Foundation (2014) report low teacher involvement in selecting and/or designing the learning they need, which may be associated with the perception of low levels of autonomy. Additionally, "most teachers receive PD of short duration (less than eight hours on a topic, usually in afterschool workshops)" (Darling-Hammond, et al., 2017). Without "broad access to effective training and professional development, as well as to learning communities where their professional judgement is considered, we hurt teachers' effectiveness, sense of purpose, and career advancement opportunities. This likely plays a role in the teacher shortage." (Garcia \& Weiss, 2019e, p. 3).

Further contributing to weak professional development for teachers are issues of resources and support for ongoing continuous learning. Teachers have limited access to effective professional development and many times the costs associated with attending professional development fall to the teacher. Garcia and Weiss (2019e) reported that "for all teachers, only half have released time from teaching to participate in professional development (50.9\%), less than a third are reimbursed for conferences or workshop fees (28.2\%) or receive a stipend for professional development accessed outside of regular work hours $(27.3 \%)$, and only one in 10 teachers $(9.4 \%)$ receives full or partial reimbursement of college tuition" (p.6). In addition to the high costs teachers bear for 
their own professional development, and the ineffectiveness of traditional modalities, professional development may be further weakened by factors associated to the school district where the teacher works.

Darling-Hammond et al. (2017) noted concerns with school policies that are not aligned to ongoing continuous learning, barriers to teacher learning due to school culture, and unresponsiveness to the needs of teachers. While there is understanding regarding professional development that works, many times, decisions about professional development are not based on "evidence of effectiveness" (Gates Foundation, 2014, p. 14), but rather, teacher learning is acquired through the use of "personal networks" (Gates Foundation, 2014, p. 14). Professional development is an important part of solving the teacher shortage crisis, and "professional development and continuous training opportunities and the learning climate - the lack thereof-can directly influence teacher retention and recruitment" (Garcia \& Weiss, 2019e, p. 5).

There are currently not enough teachers to fill the needs of America's schools (Carver-Thomas \& Darling-Hammond, 2017; Garcia \& Weiss, 2019a; Ingersoll, et al., 2014). The shortage has great human and economic impacts (Allensworth Ponisciak, \& Mazzeo, 2009; Carroll, 2007; Carver-Thomas \& Darling-Hammond, 2017; DarlingHammond, 1999P). The current shortage is due to many factors. Rising student enrollment, expansion of required programming, and greater needs in special education (Ingersoll, et al., 2014; Garcia \& Weiss, 2019b) have created a need for more teachers, however, the shortage has reached crisis levels due to decreases in teacher program enrollment and increasing non-retirement teacher attrition. Efforts focused on recruiting new teachers to the profession will not be effective in solving the crisis without also 
finding ways to keep teachers in the career (Carroll, 2007; Ingersoll, et al., 2016; Sutcher, et al., 2016). Some commonly noted factors associated with teacher attrition include: (a) dissatisfaction with the career (Carver-Thomas \& Darling-Hammond, 2017; Ingersol, 2003); (b) inadequate preparation (Redding \& Smith, 2016); (c) early career exit (CarverThomas \& Darling-Hammond, 2017; Ingersoll, 2001) and (d) weak professional development (Darling-Hammond et al., 2017; Garcia \& Weisse, 2019e; Gates Foundation, 2010).

\section{Professional Development for Teachers}

On-going continuous teacher development is an important part of supporting teacher retention as they navigate changes throughout the teaching career. As teachers enter the career, a collaborative community of learners can help teachers transition from their role as a student to that of teacher (Garcia \& Weiss, 2019e). Additionally, professional development provides an opportunity for teachers to increase their knowledge and skills, gaining important strategies for meeting the needs of their students (Garcia \& Weiss, 2019e). Just like other professional careers, there is an expectation that teachers would continue to learn and grow throughout their career, and professional development can increase levels of professionalism of the career and promote career advancement for teachers (Garcia \& Weiss, 2019e), "which would make teaching a more appealing profession (and may mitigate some of the other factors driving the teacher shortage, such as tough working environments)" (Garcia \& Weiss, 2019e, p. 8).

There is still a lot of unknowns about teacher professional development, specifically regarding how decisions are made about the learning teachers experience, the most effective duration for learning, and how needs of teachers change given various 
contexts (Garcia \& Weiss, 2019e). However, it is clear that effective professional development is an important part of recruitment and retention plans designed to decrease the teacher shortage (Guarino et al., 2006; Podolsky et al., 2016; Carroll, 2007), and "continuous learning via professional development helps teachers do their jobs more effectively and efficiently and advance their careers, increasing their sense of dedication, purpose, satisfaction, and professionalism and, significantly, helping their students' learning and performance as well" (Garcia \& Weiss, 2019e, p.6).

\section{Effective Professional Development}

In reviewing the research on effective professional development, there appears to be good agreement about essential elements associated with high-quality professional development for teachers. These were able to be clustered into three main themes associated with high-quality, effective professional development for teachers. These themes include: (a) the duration of learning with an understanding that effective teacher learning occurs over time and with opportunities for teachers to apply their new learning (Darling-Hammond, Hyler et al., 2017); (b) the importance of recognizing teachers as adult learners and providing teachers with professional development that is delivered through adult learning theory; and (c) job-embedded, classroom-focused professional development.

Sustained duration. "Professional learning must be sustained to have an impact" (Darling-Hammond, Hyler, et al., 2017, p. 15) and include "opportunities to apply learning in the classroom" (Darling-Hammond, Hyler, et al., 2017, p.15). While there is no specific definition of the best duration for professional learning, it is defined by Darling-Harmmond, Hyler et al. (2017) as allowing teachers "adequate time to learn, practice, implement, and reflect upon new strategies that facilitate changes in their 
practice" (Darling-Hammond, Hyler et al., 2017, p. vi). It is discussed in terms of weeks, months, or years (Darling-Hammond, Hyler et al., 2017). In addition to thinking about duration from the lens of a single learning experience, sustained duration can also be thought of systemically with the creation of "a coherent system that supports teachers across the entire professional continuum, [and] professional learning should link to their experiences in preparation and induction, as well as to teaching standards and evaluation. It should also bridge to leadership opportunities to ensure a comprehensive system focused on the growth and development of teachers" (Darling-Hammond, Hyler, et al., 2017, p.vii).

Adult learning theory. Effective professional development for teachers understands how teachers learn and provides active learning based on adult learning theories (Darling-Hammond, Hyler et al., 2017) that invite the "whole person into the [learning] environment" (Taylor, 2009, p. 11) and "treats teachers like professionals" (Gates Foundation, 2014, p.4). Professional development that recognizes, that as adults, teachers "are self-directed and their learning is optimized when their experience is recognized and utilized in the learning process" (Chen, 2014, p.407) will be more successful in supporting teachers as they adjust their teaching practice through reflection, "which leads to the determination that the learning material is disorienting (Chen, 2014, p. 414) allowing the teacher to experience self-identification of their needed areas of growth.

Within the understanding of recognizing teachers as self-directed professionals, it is not surprising that a main characteristic of effective teacher learning is that the professional development be relevant (Darling-Hammond, Hyler et al., 2017; Gates 
Foundation, 2014), teacher-lead (Darling-Hammond, Burns et al., 2017) and contentbased (Croft et al., 2010; Darling-Hammond, Burns et al., 2017; Darling-Hammond, Hirsh, 2016; Hyler, et al., 2017; Garcia \& Weiss, 2019e; Gates Foundation, 2014), including "learning activities that directly support teacher practice, such as planning and reflecting on instruction..., as they tap into their motivation to help students learn" (Gates Foundation, 2014, p. 11).

There is wide agreement on the inclusion of collaboration within discussions of effective professional development (Croft et al., 2010; Darling-Hammond, Burns et al., 2017; Darling-Hammond, Hyler et al., 2017; Gates Foundation, 2014; Hirsh, 2016) with "collective work in trusting environments provid[ing] a basis for inquiry and reflection into teachers' own practices, allowing teachers to take risks, solve problems, and attend to dilemmas in their practice" (Darling-Hammond, Hyler, et al., 2017, p. 10). This thinking aligns to Bruffee's (1999) thoughts on conversation as learning, however it is important for those working with teachers to understand that, "if the talk within the knowledge communities we are members of is narrow, superficial, biased, or limited to clichés, our thinking is almost certain to be so, too" (Bruffee, 1999,p. 134). Rather than seeking for teacher conformity, collaborative learning should seek to build, "a sense of trust in the process of dialogue with others, creating a setting that helps learners live with some discomfort while on the edge of knowing, in the process of gaining new insights and understanding" (Taylor, 2009, p.10). Part of creating the trust needed within a collaborative learning environment includes the development of a cultural awareness. Teacher professional development that recognizes teachers as adults, and provides learning experiences designed for them, will include some of Cueva's (2010) strategies 
for fostering cultural awareness in adult learning environments: (a) "learning as respectful engagement" (p. 83); (b) "sharing power" (p.83); (c) "talking story" (p.86); and (d) "embracing learning through laughter" (p. 87). Facilitators of effective professional development for teachers would understand that "learning involves growth and change which is often disoriented and painful" (Cueva, 2010, p. 81).

In addition to creating supportive and trusting collaborative learning environments for teachers, effective professional development allows the time and space needed for reflective processing and the use of lesson study frameworks (DarlingHammond, Burns et al., 2017; Darling-Hammond, Hyler et al., 2017; Gates Foundation, 2014). Given the relationships between level of teacher reflective capacity, teacher selfefficacy, and retention (Kelley, 2004; Yost, 2006), professional development structures that increase teacher reflective capacity will most likely support teacher retention as well as improve teacher practice (Kelley, 2004) as engaging in reflective practice has been found to increase teacher self-efficacy (Stallions, Murrill, \& Earp, 2012).

Job-embedded learning. Professional development that works for teachers is not only on-going and designed for adult learners, but it is also relevant to the work of the teacher so new learning can be applied and practiced within the classroom. It is jobembedded (Croft et al., 2010; Darling-Hammond, Hyler et al., 2017; Hirsh, 2016). Jobembedded learning includes a variety of strategies and modalities, including: (a) teacher action research (Croft et al., 2010; Darling-Hammond, Burns et al., 2017; Kelley, 2004; Yost, 2006); (b) coaching (Croft et al., 2010; Darling-Hammond, Burns et al., 2017; Darling-Hammond, Hyler et al., 2017; Garcia \& Weiss, 2019e; Gates Foundation, 2014) delivered by someone who "is not the same person who does my evaluation" (Gates 
Foundation, 2014, p.7); (c) mentoring (Garcia \& Weiss 2019e); (d) collaborative teams (Croft et al., 2010; Darling-Hammond, Hyler et al., 2017; Kraft, et al., 2018; Gates Foundation, 2014); (e) student work analysis (Croft et al., 2010; Darling-Hammond, Burns, et al., 2017); and (f) lesson study (Croft et al., 2016; Darling-Hammond, Burns et al., 2017). Incorporating job-embedded learning requires, "common effort across all three levels: states, districts, and schools" (Croft et al., 2010, p. 12) to create the conditions for teacher learning, including the identification and development of skilled facilitators, common vocabulary, development of systems for monitoring, and creating a culture of continued learning (Croft et al., 2010).

Effective teacher professional development is an important strategy for increasing teacher retention by providing supports for teachers, developing teacher knowledge and skill, and increasing the level of professionalism of the career (Carroll, 2007; Garcia \& Weiss, 2019e; Guarino et al, 2006; Podolsky et al, 2018). While more research is needed regarding the decision-making processes used to determine what professional development teachers need and how teacher needs change within different contexts (Garcia \& Weiss, 2019e), there is research-agreement of the characteristics of effective teacher professional development (Croft et al., 2010; Darling-Hammond, Burns et al., 2017; Darling-Hammond, Hyler et al., 2017; Gates Foundation, 2014; Hirsh, 2016). Professional development that: (a) is on-going and of sustained duration (DarlingHammond, Burns et al, 2017; Darling-Hammond, Hyler, et al., 2017); (b) recognizes teachers as adults and is delivered through adult learning frameworks (DarlingHammond, Burns et al., 2016; Gates Foundation, 2014); and (c) is job-embedded (Croft et al., 2010; Darling-Hammond, Hyler et al., 2017; Hirsh, 2016) is considered to be 
effective for teachers. Effective professional development includes time for teachers to develop their reflective practice (Darling-Hammond, Burns et al., 2017), which is known to be related to increases in teacher self-efficacy (Stallions, Murrill, and Earp, 2012), which further supports teacher development as an important teacher retention strategy.

\section{Teacher Self-efficacy}

Teacher self-efficacy (TSE) finds its origins in studies conducted by the RAND Corporation (Armor et al., 1976). These studies were based on Rotter's social learning theory with TSE being measured by an instrument of only two items (Tschannen-Moran, et al., 1998). In addition to studies of TSE “grounded in Rotter's (1966) theories... a second strand grew out of Bandura's (1977) social-cognitive theory" (Tschannen-Moran et al., 1998), which moved away from traditional thinking of human behavior as having "unidirectional causation, in which behavior is depicted as either being shaped and controlled by environmental influences or driven by internal dispositions" (Bandura, 1999, p. 23). Rather, Bandura's social cognitive theory viewed human functioning from a lens of "triadic reciprocal causation" (Bandura, 1999, p. 23) where "internal personal factors in the form of cognitive, affective, and biological events; behavioral patterns, and environmental events all operative as interacting determinants that influence on another bi-directionally" (Bandura, 1999, p. 23).

Bandura (1977) drews distinction between self-efficacy and locus of control (Rotter, 1966). While both emphasize human agency (Zee \& Koomen, 2016), Bandura (1977) separated efficacy expectations from outcome expectations. From his view, “an efficacy expectation is the conviction that one can successfully execute the behavior required to produce the outcomes" (Bandura, 1977, p. 193) whereas an outcome 
expectation is the expectation of a specific outcome from a certain behavior. This distinction moved the self-efficacy field from stimulation-response thinking to personal control through self-belief. These two conceptual strands of self-efficacy are still discussed together (Wheatley, 2002). However, "most researchers have underscored the need to differentiate between self-efficacy and outcome expectancies" (Zee \& Koomen, 2016, p. 984) with data showing the two strands of thinking as distinctly different with only self-efficacy strongly predicting behavior (Tschannen-Moran et al., 1998).

Teacher self-efficacy can be thought of as how much a teacher believes "s/he is able to teach even the most difficult and unmotivated students, and [it] involves many dimensions of teacher practices" (Aloe, Amo, Shanahan, 2014, p.105). Teacher selfefficacy affects teachers' sense of accomplishment (Brouwers, Evers, \& Tomic, 2001; Goddard, Hoy, \& Woolfolk Hoy, 2004), which then informs belief of self, leading to behaviors which impact students (Goddard et al., 2004), such as increases in the quality of classroom management (Woolfolk \& Hoy, 1990) and planning and organization (Allinder, 1994). Teacher self-efficacy affects the goals teachers have for students (Muijs \& Reynolds, 2002). Teachers with high levels of self-efficacy have been found to be less controlling (Woolfolk \& Hoy, 1990; Woolfolk, Rosoff, \& Hoy, 1990) and critical (Ashton \& Web, 1986) of students. Additionally, teacher self-efficacy is related to openness to innovation (Guskey, 1988) and the use of integrative (Smylie, 1988), creative (Thurlings, Evers, \& Vermeulen, 2015), and effective teaching methods, such as the use of grouping structures (Gibson \& Dembo, 1984).

A strong relationship exists between self-efficacy and burn-out (Skaalvik \& Skaalvik, 2007) with levels of teacher self-efficacy working to protect teachers from 
burning out (Aloe et al., 2014; Schwerdtfeger et al., 2008). Unfortunately, the extent of the connection between the mitigating effects of self-efficacy on teacher burn-out are not clear (Friedman, 2003), and more research is needed in this area. However, there is strong evidence supporting the connection between these constructs with Aloe et al. (2014) finding, "a significant relationship between classroom management self-efficacy and the three dimensions of burnout, suggesting that teachers with higher levels of CMSE are less likely to experience the feelings of burnout" (p. 101).

While higher levels of self-efficacy seem to support retention by protecting teachers from burnout (Aloe, Amo, \& Shanahan, 2014), the converse seems to also be true with lower levels of self-efficacy associated to higher levels of attrition (Jensen, Sandoval-Hernandez, Knoll \& Gonzalez, 2012). Although low levels of self-efficacy may contribute to a teacher leaving the profession, it is possible to increase teacher selfefficacy through teacher development, which positively impacts level of resilience (Gibson \& Dembo, 1984) and reduces thoughts of leaving the career (Pfitzner-Eden, 2016). Teacher self-efficacy beliefs are known to vary in relation to the wide variety of variables found within the classroom environment (Tschannen-Moran et al, 1998). Teacher self-efficacy is, additionally, impacted by years of experience, decreasing in the first few years of teaching (Woolfolk Hoy \& Burke Spero, 2005), rebounding mid-career, and then declining again towards career-end (Klassen \& Chiu, 2010). Given the abovementioned impacts of self-efficacy on teacher practice, it is not surprising that TSE is solidly linked to student achievement (Anderson, Greene and Loewen, 1988; Armor, et. al., 1976; Caprara, Barbaranelli, Steca, \& Malone, 2006; Gibson \& Dembo, 1984; 
Tschannen-Moran et al., 1998) and student engagement (Holzberger, Phillipp \& Kunter, 2013).

Teacher self-efficacy is a well-researched, well-established construct with strong associations to factors that impact both teachers and students. However, criticisms of the construct do exist. One criticism of TSE is that there are many definitions of the construct (Tschannen-Moran et al., 1998), which is not surprising given its foundational positioning in both Rotter's social learning theory and Bandura's (1977) social cognitive theory, each with distinct assumptions. Many researchers (Henson, 2002; Klassen, Tze, Betts, \& Gordon, 2011; Tschannen-Moran et al., 1998) have called for agreement in the conceptualization of TSE, as well as the development of valid measurements aligned to Bandura's (1977) construct of self-efficacy (Pfitzner-Eden, 2016; Skaalvik \& Skaalvik, 2010) rather than those which have been influenced by Rotter's (1966) locus of control theory (Gibson \& Dembo, 1984).

The work of Tschannen-Moran and Woolfolk Hoy (2001) responded to the above criticisms with the development of the Teacher Self-Efficacy Scale, which provides a three-dimensional framework of TSE aligned to Bandura's (1977) theory of self-efficacy. The instrument measures three distinct areas associated to teacher practice: (a) efficacy in instructional strategies, (b) efficacy in classroom management; and (c) efficacy in student engagement. It has been described as, "superior to previous measures of teacher efficacy in that it has a unified and stable factor structure" (Woolfolk Hoy \& Burke Spero, 2005, p. 354), and research has reported satisfactory reliability and construct validity evidence for this instrument (Tschannen-Moran \& Woolfolk Hoy, 2001). 
Teacher self-efficacy is a construct with connections to both social learning theory (Rotter, 1954) and social cognitive theory (Bandura, 1977). Given the distinct differences in these two theories, there have been calls for differentiation between these two distinct theoretical foundations (Wheatley, 2002; Zee \& Koomen, 2016) with thinking about self-efficacy shifting more towards Bandura's construct rather than Rotter's (Tschannen-Moran, 1998). Possibly due to the original theoretical duality of the construct of self-efficacy, there are criticisms of self-efficacy related to the lack of a unified construct definition (Tschanen-Moran et al., 1998; Henson, 2002; Klassen et al., 2011) and challenges in developing valid measurements (Pfitzner-Eden, 2016; Skaalvik \& Skaalvik, 2010). Tschannen-Moran and Woolfolk Hoy (2004) responded to calls for clarity in definition and validity in measurement, and they developed the TSES, which was based on Bandura's (1977) theory of self-efficacy and provided definition of three measurable dimensions of teacher self-efficacy (Tschannen-Moran \& Woolfolk Hoy, 2004).

Level of teacher self-efficacy describes the extent to which a teacher believes in their ability to impact the learning of even the most challenging students regardless of external circumstances (Alow, Amo, Shanahan, 2014). Teacher self-efficacy impacts teacher behavior (Aloe, Amo, Shanahan, 2014; Brouwers, Evers, \& Tomic, 2001; Goddard, Hoy, \& Woolfolk Hoy, 2004) which affects student learning (Anderson, Green, \& Loewen, 1988; Armor, et al., 1976; Caprara, Bararanelli, Steca, \& Malone, 2006; Gibson \& Dembo, 1984; Goddard et al., 2004; Tschannen-Moran et al., 1998). Levels of teacher efficacy vary within different contexts (Tschannen-Moran et al., 1998; Woolfold 
Hoy \& Burke Spero, 2005) as well as across the span of the teaching career (Klassen \& Chiu, 2010).

\section{Reflective Practice}

The concept of reflective teaching practice is grounded in the writings of Dewey (1933) and the foundational work of Schön (1983), who highlighted the ability to "reflect-in-action" (Schön, 1983), or "think about something while doing it" (Schön, 1983, p. 54). Dewey (1933) "characterizes reflection as deliberate thoughtfulness about teaching beliefs and practices without specifying that it has a predominantly retrospective focus" (Conway, 2001, p. 90). Even given the lack of directionality provided by Dewey (1933), the predominant thinking about reflection has emphasized looking backwards (Conway, 2001), however, it is clear within the research that reflection is more than reviewing the past. It includes thoughts of looking back, looking in the moment, looking to the future, and looking within. Reflection "enables teachers to stop, look, and discover where they are at that moment and then decide where they want to go (professionally) in the future" (Farrell, 2012, p.7).

\section{Temporal Dimensions}

The foundational work of Schön (1983) highlighted the active reframing of situations as they occur (Schön, 1983), noting the ability of practitioners to "reflect-inaction" (Schön, 1983, p. 62), or "think about something while doing it" (Schön, 1983, p. 54). Building upon this, van Manen (1995) highlights reflection as having multiple “temporal dimensions” (p. 2), expanding Schön’s work through the inclusion of “anticipatory reflection" (van Manen, 1995, p. 2), which is future-oriented reflection. In addition to considerations of reflection through the lens of time, the construct is further 
confounded by considerations of reflection as the processes involved in "turning inward, examining one's own remembered experiences and/or anticipated experiences, not exclusively looking back in time... looking toward the future with knowledge of the past from the viewpoint of the present" (Conway, 2001, p. 90). Reflective threading of past, present, and future actions through memory and imagination (Conway, 2001) allows one to learn about self (Freese, 2006; Urzúa \& Vásquez, 2008; Sutherland, Howard, \& Markauskite, 2010) and is an important part of understanding the role of reflection in identity development (Warin, et al., 2006).

\section{Levels of Reflection}

In addition to discussions regarding the temporal scope of reflection, much reflective practice research has been devoted to understanding levels of reflective practice with "references to numerous levels, stage, dimensions, or types of reflection are indicative that reflection is generally viewed as an incremental process" (Larrivee, 2008, p. 341-342). Reflection is understood to exist within three distinct levels of practice (Larrivee, 2008; Thompson \& Pascal, 2012). These progress from reflection on skills or techniques to a more critical form of reflecting including a teacher's consideration of "ethical, social, and political consequences of their teaching" (Larrivee, 2008, p. 342).

The work of both Schön (1983) and van Manen (1995) undergird dimensionality

of reflection, contributing to the understanding of degrees of reflective capacity one may engage in. Three levels seem to be agreed upon in research (Larrivee, 2008; Thompson \& Pascal, 2012), beginning with a technical rationality (Thompson \& Pascal, 2012), advancing to a "pedagogical practice" (Larrivee, 2008, p. 342), and then moving to a "higher order where teachers examine the ethical, social, and political consequences of 
their teaching" (Larrivee, 2008, p. 342). The concepts of these levels, as well as the idea of non-reflection, are seen in Larrivee's (2008) four levels: (a) pre-reflection; (b) surface; (c) pedagogical; (d) critical (p. 342).

Given the dimensionality of reflection, it is important to consider criticisms of the construct, the first of which is the lack of a clearly defined understanding of the concept (Beauchamp, 2014; Collin, et al., 2013; Galea, 2012; Larrivee, 2008; Thompson \& Pascal, 2012). There is a call for a more comprehensive definition of reflection (Beauchamp, 2014) to expand the focus from the individual to a broader social context (Thompson \& Pascal, 2012) with greater understanding and emphasis of critical reflection, which is often misunderstood (Beauchamp, 2014; Collin et al., 2013; Galea, 2012; Thompson \& Pascal, 2012). Not surprising, given the lack of clarity mentioned above, a second criticism of reflective practice is misalignment between conversations about teacher reflective practice and the actual implementation by teachers (Mena, Marcos, Sanchez, and Tillema, 2011). Some of this has been attributed to increases in accountability and the popularity of reflection resulting in the implementation of processes to artificially force the practice (Galea, 2012) along with the use of narrow approaches (Beauchamp, 2014). A third criticism of reflective practice is found in the questioning of the value of reflective practice for teaching as there are very few empirical studies (Collin et al., 2013) and "no evidence to show improved teacher or student performance resulting from reflective techniques" (Akbari, 2007, p. 192). Additionally, reflection has been found to be associated to decreases in confidence (Priddis \& Rogers, 2018), although the effects of this relationship are not fully understood (Priddis \& Rogers, 2018). 
In response to these criticisms, some solutions have been presented to strengthen the use of reflective practice as a way to support professional growth. It is noted that the context within the reflection takes place is very important (Beauchamp, 2014; Thompson \& Pascal, 2012). Research stresses the importance of reflection that is collaborative (Beauchamp, 2014) and is "both an individual and social process" (Noffke \& Brennan, 2005, p. 74). Building on the idea of reflection as a social process, researchers assert the importance of developing critically reflective practice (Beauchamp, 2014; Thompson \& Pascal, 2012) through skilled facilitation and explicit teaching of reflective processing (Beauchamp, 2014; Collin et al., 2013; Gün, 2011).

Reflective teaching practice, is a multidimensional construct that occurs through the merging of temporal thinking and identify formation through the use of visualization within temporal and contextual considerations. It involves teachers intentionally thinking about their own teaching practice (Dewey, 1933) and is not limited to reviewing past events (Conway, 2001). Rather it is inclusive of all temporal dimensions (van Manen, 1995) and involves looking at the past and present coupled with looking to the future (van Manen, 1995) through an active processing of all three simultaneously with conclusions used for decision-making and direct-setting (Farrell, 2012). The process includes understanding of the past, awareness of the moment (Schön,1983), and the ability to predict (van Manen, 1995). In addition to being able to adapt to and for situations, reflective practice includes ideas of understanding, adapting, and predicting self (Freese, 2006; Urzúa \& Vásquez, 2008; Sutherland, Howard, \& Markauskite, 2010) in light of considering past, present, and future experiences (Conway, 2001). The capacity for reflective practice is understood to exist not only across time, for action, 
adaptation, and predication, and as a process of knowing self, but also across levels or types of reflection (Larrivee, 2008; Schön,1983; \& van Manen, 1995).

Many definitions of reflection exist (Beauchamp, 2014; Collin, Karsenti, \& Komis, 2013; Galea, 2012; Larrivee, 2008; Thompson \& Pascal, 2012) with many researchers expressing a lack of understanding of real reflection and the need for greater emphasis on and understanding of critical reflection (Beauchamp, 2014; Collin et al., 2013; Galea, 2012; Thompson \& Pascal, 2012). Some questions have been raised about the value of reflective practice given a lack of empirical data (Akbari, 2007; Collin et al., 2013). Context is important for reflective practice (Beauchamp, 2014; Thompson \& Pascal, 2012), and researchers express value in reflection that: (a) is social and takes place within collaborative environments (Beauchamp, 2014; Noffke \& Brennan, 2005), (b) includes the development of critically reflective practice (Beauchamp, 2014;

Thompson \& Pascal, 2012), and (c) is guided by skilled facilitation that includes explicit teaching of reflective processing (Beauchamp, 2014; Collin et al., 2013; Gün, 2011).

It is clear within the research that there is a relationship between reflective practice and self-efficacy (Babaei, \& Abednia, 2016; Rahimi \& Weisi, 2018), however, it is unclear as to how these are reacting on each other. In Kelley (2004), participants were asked to engage in reflective processing during an action-research project with the outcomes of the study revealing increases in participant self-efficacy. The use of reflection as a mechanism to increase self-efficacy is further found in Awkard's (2017) work outlining suggestions on how to build self-efficacy through the use of reflective strategies. Just as reflective practice is noted to lead to increases in self-efficacy, the opposite can also be seen. This was seen in the study conducted by Thoonen, Sleegers, 
Oort, Peetsma, and Geijsel (2011), which connected teacher motivation, and specifically teacher self-efficacy, to teacher learning activities, which included reflection. This study revealed "when teachers believe stronger in their capabilities to achieve a desired result, they are more engaged in professional learning activities" (514), providing insights into the reversal effect of self-efficacy's influence on reflective practice. The seemingly circular influence of reflective practice on self-efficacy and vice versa is also seen in Kelley's (2004) study where engaging in reflective activities showing some connection to increases in self-efficacy. In this study, participants participated in the Partners In Education Program, which, like the Missouri Statewide Teacher Academy, engaged participants in reflective journaling and classroom-based inquiry. Participants were tracked over 10 years, and it was noted that these teachers remained "in the profession at much higher rates than the national statistics suggest is likely, with $94 \%$ of participants still teaching after 4 years" (Kelley, 2004). In evaluating the effects of the program on teacher growth, participant responses were analyzed, and Kelley (2004) noted "a heightened sense of self-as-teacher and a newly found appreciation for introspective practice emerged" (p. 445).

\section{Summary}

The United States is a currently facing a teacher shortage (Carroll, 2007; CarverThomas \& Darling-Hammond, 2017; Darling-Hammond, 1999; Darling-Hammond, 2003; Garcia \& Weiss, 2019a; Ingersoll, et al., 2014; Podolsky, et al., 2016; Sutcher et al., 2016), which is a complex issue arising from an increasing demand for teachers and a decreasing supply (Ingersoll, et al., 2014; Garcia \& Weiss, 2019b). Solutions to increasing the supply of teachers often focus on recruiting new teachers to the profession, 
however, the shortage will not be solved without addressing issues facing teachers already in the field who are rapidly leaving the career for non-retirement reasons. Many factors are associated with teacher attrition, however, "most teachers who voluntarily leave the classroom list some area of job dissatisfaction as very important or extremely important in their decision to leave the profession" (Sutcher et al., 2016, p.49) and level of job satisfaction has been found to be a reliable predictor of employee retention (Bobbitt, Faupel, \& Burns, 1991). Other factors associated with teacher attrition include insufficient preparation for the career, high levels of early career exits (Allensworth, et al., 2009; Carver-Thomas \& Darling-Hammond, 2019; Guarino, et al., 2006; Ingersoll, 2003; Haushekt, Kain, \& Rivkin, 2004; Johnson \& Birkelnad, 2003; Stinebricker, 2002), and weak professional development (Darling-Hammond, 2017; Garcia \& Weiss, 2019e; Gates Foundation, 2014).

Providing teachers with professional development is an important teacher retention strategy (Carroll, 2007; Garcia \& Weiss, 2019e; Guarino et al, 2006; Podolsky et al, 2016). Characteristics of effective professional development for teachers (Croft et al., 2010; Darling-Hammond, Burns et al., 2017; Darling-Hammond, Hyler et al., 2017; Gates Foundation, 2014; Hirsh, 2016) are widely known, and focus on learning that is: (a) sustained in duration, (b) embedded in adult learning theory, and (c) is job embedded. All of these characteristics include emphasizing the development of teacher reflective practice (Darling-Hammond, Burns et al., 2017). Teacher reflective practice is known to be related to increases in teacher self-efficacy (Stallions, Murrill, and Earp, 2012), and both teacher self-efficacy and reflective practice have been found to be related to teacher retention (Kelley, 2004; Yost, 2006). Teacher self-efficacy and reflective practice have 
also been found to have significant relationships to each other (Babaei, \& Abednia, 2016), and engaging in reflective practice fosters the development of professional selfefficacy in teachers (Stallions, Murrill, and Earp, 2012).

Given the strong relationships between reflective practice and self-efficacy and their connections to job satisfaction and retention, developing programs to increase teacher self-efficacy and/or reflective practice may indirectly support teacher retention. It is unclear as to whether reflective practice increases self-efficacy or if teachers with higher levels of efficacy are more reflective; it is clear that there is a relationship between these two ideas and both are associated to increases in teacher retention. There is overwhelming support for the relationship between self-efficacy and job satisfaction (Ingersoll, 2001; Johnson et al., 2005; Pfitzner-Eden, 2016).

This study cannot provide a direct relationship between the Missouri Statewide Teacher Academy and teacher retention. However, with well-established correlations between self-efficacy and factors associated with teacher retention: (a) job satisfaction (Klassen \& Chiu, 2010; Perrachione, Rosser, \& Peterson, 2008; Skaalvik \& Skaalvik, 2010; Viel-Ruma, et al., 2010; Zee \& Koomen, 2016); and (b) burnout (Aloe et al., 2014; Brown, 2012; Brouwers et al., 2001; Cherniss, 1993; Schwerdtfeger, et al., 2008; Skaalvik \& Skaalvik, 2007; Skaalvik and Skaalvik, 2010; Tschannen-Moran, et al., 1998); and (c) attrition (Pfitzner-Eden, 2016), as well as the known relationship between self-efficacy and reflective practice (Babaei, \& Abednia, 2016; Rahimi \& Weisi, 2018) a case can be made for combining these constructs when investigating the impacts of Missouri Statewide Teacher Academy on teacher self-efficacy, reflective capacity, and job satisfaction from the lens of identifying the program's potential as a state-level 
professional development intervention to indirectly support teacher retention through the development of teacher self-efficacy and reflective capacity. 
SECTION FOUR: CONTRIBUTION TO PRACTICE 


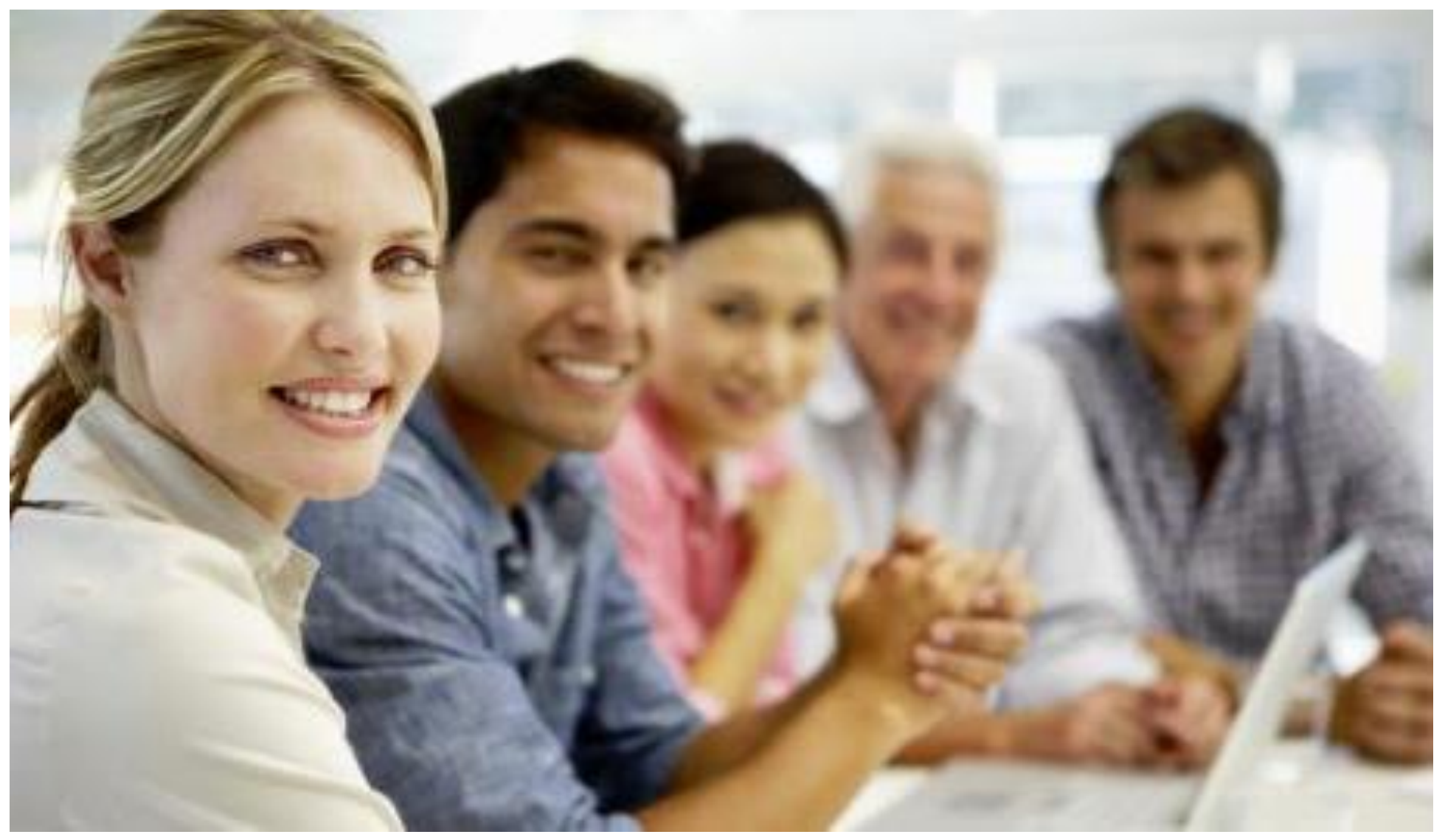

\title{
Building the Best
}

Missouri Teacher Academy Program Evaluation 2020

$$
\text { By Tracy Gross }
$$

\author{
Presented to
}

The Missouri Department of Elementary and Secondary Education's Office of Educator Quality 


\section{Problem of Practice}

\section{Executive Summary}

There is a teacher shortage crisis, which comes at a great cost to students, teachers, and society (Garcia \& Weiss, 2019b; Strauss, 2017). Costs associated with the crisis reach into the billions of dollars (Carroll, 2007; Garcia \& Weiss, 2019b). Fewer people are choosing to enter the career; there is an exodus of teachers from the classroom. Teachers are "the greatest source of variance that can make the difference" (Hattie, 2003, p. 3). Too often, those who leave are the best teachers we have; we cannot continue to lose them.

\section{Effective Professional Development as a State-Level Retention Strategy}

Effective professional development is an important part of recruitment and retention plans designed to decrease the teacher shortage (Guarino et al., 2006; Podolsky et al., 2016; Carroll, 2007).

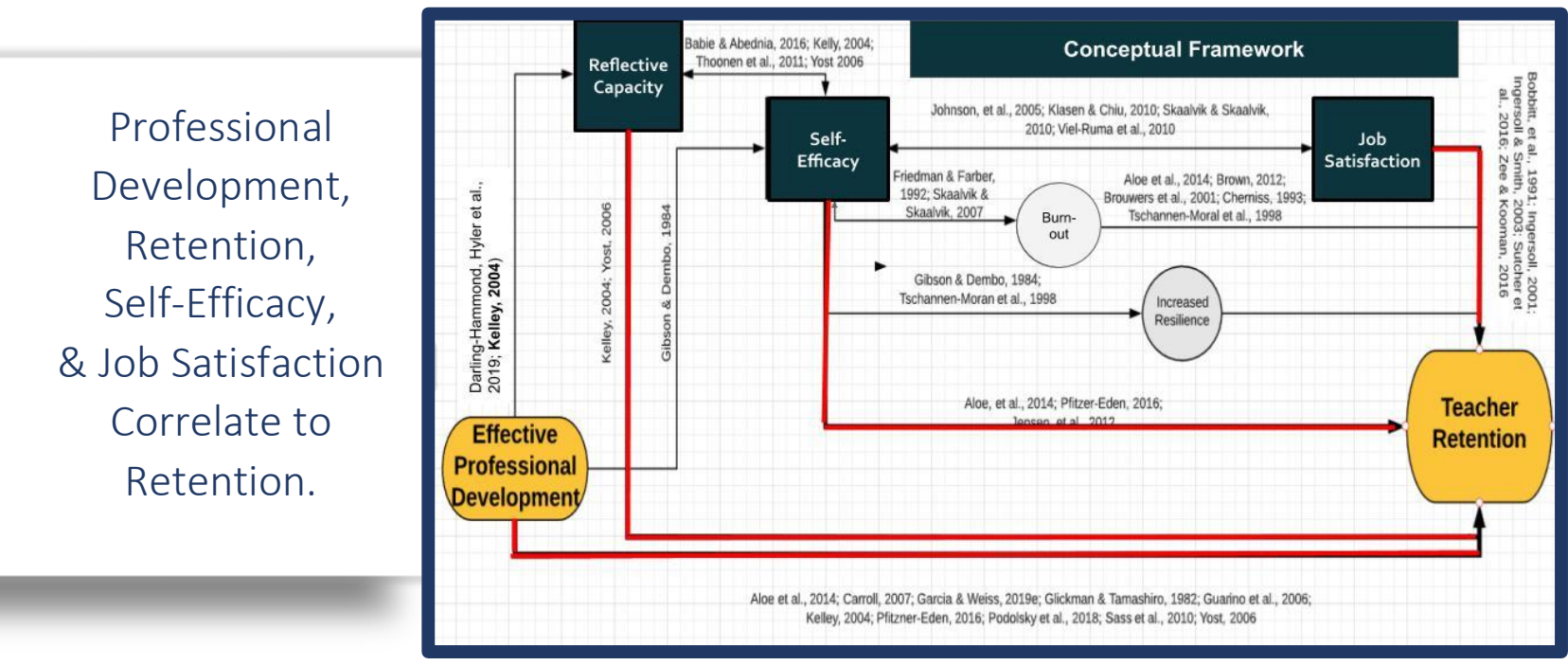

Purpose of Evaluation

Missouri Teacher Academy is a state-level program implemented as part of the workforce outreach plan to provide effective professional development for teachers as a retention strategy.

\section{Methods}

A quantitative impact evaluation utilizing a "one-group pretest-posttest survey design"
(Creswell, 2014, p. 172) was conducted. Analyses included whole group comparisons as well as investigations into a smaller subgroup of teachers of state-assessment content areas.

\section{Research Question}

This study was conducted to answer the question: Does Missouri Teacher Academy impact teacher (a) self-efficacy, (b) reflective capacity, and (c) job satisfaction? 
Participants - Comprehensive Purposive Sampling was Utilized (Ilker, Sulaiman, \& Rukayya, 2016)

Whole Group ( $n=95)$

$>$ Greater than 3 years of teaching experience

$>$ Teachers with a desire for continued growth

$>$ All grade levels, content areas, and years of experience

$>$ Greater than $70 \%$ from rural districts
Paired Sub-Group ( $\boldsymbol{n}=\mathbf{2 2}$ )

Teach in Tested Areas

ELA (50\%)

Math (22.7\%)

Science $(27.3 \%)$

Analyses

Whole Group ( $n=95)$

Independent Samples $t$-test

Paired Sub-Group ( $n=22)$

Paired Samples $t$-test

Key Results

$>$ Participants of Missouri Teacher Academy increased scores in self-efficacy, reflective capacity, and job satisfaction between the beginning and end of the program.

Statistically significant differences ( $p \leq$.001) were found in all three constructs within whole group and subgroup analyses (see full report for details).

$>$ A large effect size was noted for differences in level of self-efficacy (whole group, $d=.93$; sub-group, $d=2.26$ ). The greatest effect sizes seen with the instructional strategies subscale (whole group, $d=.95$; subgroup, $d=1.67$ ).

$>$ Differences in effect sizes were noted across whole/subgroup results with all three constructs showing larger effect sizes within the subgroup. Of interest, the job satisfaction effect size within the whole group was small (.46) whereas it was noted to be large (.80) within the subgroup.

\section{Recommendations}

$>$ Given known relationship between level of teacher self-efficacy and teacher retention (Glickman \& Tamashiro, 1982; Pfitzner-Eden, 2016; Sass et al., 2010; \& Yost, 2006), findings of this study support the inclusion of Missouri Teacher Academy in the state's human capital development plan. Support for including Missouri Teacher Academy within the Missouri Workforce Out-reach Plan as an effective professional development program is also supported.

$>$ Further studies into the impacts of Missouri Teacher Academy are suggested, including qualitative studies to identify program components contributing to the results of this study. Longitudinal studies to determine program impact and/or effectiveness over time may be valuable to determine direct correlations between attending Missouri Teacher Academy and a teacher's decision to stay in the career. 


\section{Introduction \& Background}

The number of schools unable to fill teacher openings tripled between 2011 and 2016 (Garcia \& Weiss, 2019b, p.1) due to the "insufficient number of credentialed teachers to fill vacancies at schools" (Garcia \& Weiss, 2019b, p.1). With crisis-level teacher shortages, recruiting more teachers to the field is an obvious mitigation strategy. However, "attrition is a much greater problem in the overall teacher supply picture than is producing enough teachers to fill the nation's needs" (Darling-Hammond, 2003, p. 7).

It is tempting to think those who leave are retiring or are simply not a good fit for teaching, but that is not the case, and non-retirement attrition is one of the main drivers of the teacher shortage crisis (Carver-Thomas \& Darling-Hammond, 2017; Darling-Hammond, 2003; Garcia \& Weiss, 2019a; Gray, Taie, \& O’Rear, 2015; Ingersoll \& Smith, 2003; Reeves, 2018; Sutcher, DarlingHammond, \& Carver-Thomas, 2016; Strunk \& Robinson, 2006; Gray, et al., 2015; Garcia, \& Weiss, 2019a). Unfortunately, many who leave are considered to be "so successful that they are nearly impossible to replace" (Jacob, et al., p. 2). The five-year attrition rate for all teachers is $17 \%$, this increases to $50 \%$ for "irreplaceables" (Jacob et al., 2012). Sadly, the impact of losing the best teachers is felt most by low-performing schools where "it can take 11 hires to find one teacher of comparable quality" (Jacob et al., 2012, p.4). Keeping the best teachers in the career is central to solving the current teacher shortage crisis (Darling-Hammond, 2003).

The Missouri Department of Elementary and Secondary Education (DESE) workforce outreach plan includes effective professional development as a state-level teacher retention strategy. Missouri Teacher Academy is a research-based professional development program within the scope of this strategy. This study was conducted to evaluate the effects of Missouri Teacher Academy in supporting teacher retention through impact on teacher: (a) self-efficacy, (b) reflective capacity, and (c) job satisfaction through effective professional development.

\section{What impact does Missouri Teacher Academy have on level of teacher self-Efficacy, reflective capacity, and job satisfaction?}

\section{Teacher Shortage Crisis}

The current teacher shortage crisis is "the result of multiple and interdependent drivers, all working simultaneously to cause the imbalance between the number of new teachers needed (demand) and the number of individuals available to be hired (supply)" (Garcia \& Weiss, 2019a, p. 11). The crisis impacts human and economic capital (Carroll, 2007; Carver-Thomas \& DarlingHammond, 2017; Garcia \& Weiss, 2019b). Not having enough teachers comes at a cost to 
students, teachers, and society (Garcia \& Weiss, 2019b; Strauss, 2017). Economically, costs associated with the crisis reach into the billions of dollars (Carroll, 2007; Garcia \& Weiss, 2019b) with filling one teacher vacancy averaging \$21,00o (Carver-Thomas \& Darling-Hammond, 2017). Human effects are great given the impact of teachers on student learning with Hattie (2003) referring to the teacher as "the greatest source of variance that can make the difference" (p. 3).

\section{Systemic Shortages}

Some argue the teacher shortage is not widespread, but rather only found in high poverty schools and targeted, hard-to fill areas such as special education, English language learner programs, technical content areas like math and science, and specialty courses such as foreign languages (Cowan, Goldhaber, Hayes, \& Theobald, 2016). However, Ingersoll, Merrill, and Stuckey (2014) provided evidence of generalized systemic shortages even though they asserted the overall teacher force has actually increased (Ingersoll et al., 2014) due to: (a) Increasing enrollments (Ingersoll et al., 2014; Garcia \& Weiss, 2019b); (b) Smaller class sizes (Garcia \& Weiss, 2019b; Ingersoll et al., 2014); (c) Changes in graduation requirements; program expansions (Ingersoll, et al., 2014); and (d) Increased need in special education (Ingersoll, et al., 2014).

\section{Lack of Qualified Teachers}

There has been a sharp decline in the number of people choosing to enter the teaching career (Sutcher, et al., 2016) and too many are exiting long before retirement (Carver-Thomas \& DarlingHammond, 2017; Ingersoll \& Smith, 2003; Reeves, 2018; Strunk \& Robinson, 2006; Gray, et al., 2015; Garcia, \& Weiss, 2019). The lack of qualified teachers impacts student learning (Allensworth, Ponisciak, \& Mazzeo, 2009; Carroll, 2007; Darling-Hammond, 1999) with "a lower quality mix of teachers and loss of coherence within the school's educational program" (Sorensen \& Ladd, 2018, p. 1). Turnover hurts the entire system and even if a teacher is replaced by one of equivalent effectiveness, “turnover can still impact students' achievement” (Ronfeldt, Loeg, \& Wyckoff , 2013, p 7). It is important to note that "high poverty, high minority, urban, and rural public schools have among the highest rates of turnover" (Ingersoll et al., 2014, p. 18) and feel the effects of teacher turnover the most, leading to educational inequities due to uneven distributions of qualified teachers (Garcia \& Weiss, 2019b). Teacher turnover results in decreases in teacher effectiveness (Carroll, 2007; Garcia \& Weiss, 2019a; Sorensen \& Ladd, 2018) with teachers teaching outside of their certification area and increases in hiring of teachers who score lower on certification tests, both of which "signal lower quality of education for students" (Sorensen \& Ladd, 2018, p. 26 ). 


\section{Combating the Shortage}

In the past, increasing the supply of teachers was the main focus of policy-makers (Ingersoll, 2003; Borman \& Dowling, 2008) with efforts focused on recruitment programs such as Teach for America and Troops-to-Teachers and the expansion of alternative certification pathways designed to promote teaching to those seeking a career change (Borman \& Dowling, 2008). Unfortunately, "recruitment strategies involv[ing] lowering teacher standards...simply exacerbate root factors behind school staffing problems" (Ingersoll, 2003, p. 17) and "attrition rates are two to three times higher for those who enter the profession without full preparation than for those who are comprehensively prepared” (Podolsky, Kini, Bishop, \& Darling-Hammond, 2016, p. vi).

Efforts "focus[ed] on the hiring of new teachers won't stem the costly exodus of teachers" (Carroll, 2007, p. 2) and retention must be a central strategy for combatting the teacher shortage crisis. The shortage of high quality teachers needs "urgent, comprehensive and sustainable policy solutions" (Garcia \& Weiss, 2019b, p.1). In order to stop the exodus of America's teaching force, it is crucial to understand why teachers are leaving the career at higher rates than similar professional occupations (Ingersoll, et al., 2014). Recruiting potential teachers is critical, however, "pouring more water into the bucket will not be the answer if the holes are not first patched" (Ingersoll, 2003, p. 17).

\section{Reducing attrition by half could virtually eliminate shortages (Sutcher et al., 2016, p. 4)}

\section{Understanding Why Teachers Leave}

The reasons teachers leave are complex and compounding. Some challenges teachers face within the career include: (a) low compensation or salary (Ingersoll, 2003; Garcia \& Weiss, 2019a; Podolsky et al., 2016); (b) challenging working conditions (Garcia \& Weiss, 2019a; Guarino, Santibáñez,„\& Daley, 2006; Podolsky et al., 2016); and (d) a lack of recognition (Garcia \& Weiss, 2019a). Attrition is also noted to be related to insufficient preparation for the teaching career (Podolsky et al., 2016), including increases in alternative pathways to certification (Redding \& Smith, 2016) with the quality of preparation greatly impacting a teacher's decision to stay in the profession (Garcia \& Weiss, 2019a; Ingersoll, 2003; Podolsky et al., 2016; Redding \& Smith, 
2016). Many teachers leave early in their career (Allensworth, et al., 2009; Carver-Thomas \& Darling-Hammond, 2017; Guarino, et al., 2006; Ingersoll, 2003; Haushekt, Kain, \& Rivkin, 2004; Johnson \& Birkeland, 2003; Stinebricker, 2002), but later career non-retirement attrition is also high (Ingersoll, 2001).

\section{Dissatisfactions with the Career}

Dissatisfaction with teaching as a career is a main factor of attrition (Carver-Thomas \& DarlingHammond, 2017; Goldring, Taie, \& Riddles, 2014; Guarino, et al., 2006; Ingersoll, 2001; Ingersoll \& Smith, 2003; Podolsky, et al., 2016; Strauss, 2017; Sutcher et al., 2016) with greater than 50\% of teachers leaving the career noting some form of dissatisfaction with teaching as a career (Carver-Thomas \& Darling-Hammond, 2017; Ingersol, 2003). Teacher dissatisfaction arises from the factors noted above, but also from lack of administrative supports and resources for teaching (Ingersoll, 2003; Podolsky et al., 2016), low levels of autonomy (Ingersoll, 2003), and "lack of teacher influence over decision-making" (Ingersoll, 2003, p. 16; Podolsky et al., 2016). When deciding to continue in the career, teachers evaluate if the career "remains the most attractive in terms of compensation, working conditions, and intrinsic rewards" (Guarino et al., 2006, p. 186). As work loses importance and meaning for a teacher, burnout occurs (Maslach \& Leiter, 2008; Skaalvik \& Skaalvik, 2010) and teacher self-efficacy erodes (Chang, 2009).

\section{Weak professional development}

Although "there is a relationship between systems of professional supports - professional development, career-building supports, and teachers' autonomy and influence - and whether or not teachers stay in the profession" (Garcia \& Weiss, 2019e, p.8), teachers are largely unsatisfied with the professional development supports they receive (Gates Foundation, 2014). They report professional development as "not relevant, not effective, and most important of all, not connected to their core work of helping students learning" (Gates Foundation, 2014, p. 3). Teachers report a disconnect between what leaders think they are offering and what teachers are actually receiving and what they need (Garcia \& Weiss, 2019e; Gates Foundation, 2014). Characteristics of effective professional development are widely known (Croft et al., 2010; Darling-Hammong, Burns et al., 2017; Darling-Hammond, Hyler, \& Gardner, 2017; Gates Foundataion, 2014; Hirsh, 2019), however, many times decisions about professional development are not based on, but rather, teacher learning is acquired through relationships and networking (Gates Foundation, 2014). 
Professional development plays an important role in solving the teacher shortage crisis, with "professional development and continuous training opportunities and the learning climate - the lack thereof-can directly influence teacher retention and recruitment" (Garcia \& Weiss, 2019e, p. 5). Without "broad access to effective training and professional development, as well as to learning communities where their professional judgement is considered, we hurt teachers' effectiveness, sense of purpose, and career advancement opportunities. This likely plays a role in the teacher shortage" (Garcia \& Weiss, 2019e, p. 3).

\section{Factors of Weak PD}

○ Low Teacher Involvement in Selecting/Designing Learning

(Garcia \& Weiss, 2019; Gates Foundation, 2014)

- Short duration

(Darling-Hammond, et al., 2017)

- Lack of alignment in school policies \& ongoing continuous learning

(Darling-Hammond et al., 2017)

- Barriers from school culture and unresponsiveness to teacher needs

(Darling-Hammond et al., 2017)

○ High Personal Costs \& Limited Access

(Garcia \& Weiss, 2019e)

\section{Retention through Professional Development}

Effective professional development is an important part of recruitment and retention plans designed to decrease the teacher shortage (Guarino et al., 2006; Podolsky et al., 2016; Carroll, 2007). Professional development provides an opportunity for teachers to increase their knowledge and skills and gain important strategies for meeting the needs of their students. Highquality, professional development for teachers is sustained in duration, recognizes teachers as adult learners, and is job-embedded. 
Continuous learning via professional development helps teachers do their jobs more effectively and efficiently and advance their careers, increasing their sense of dedication, purpose, satisfaction, and professionalism and, significantly, helping their students' learning and performance as well. (Garcia \& Weiss, 2019e, p.6)

\section{Sustained Duration}

Sustained duration can be thought of systemically with the creation of "a coherent system that supports teachers across the entire professional continuum, [and] professional learning should link to [teacher] experiences in preparation and induction, as well as to teaching standards and evaluation. It should also bridge to leadership opportunities to ensure a comprehensive system focused on the growth and development of teachers" (Darling-Hammond, Hyler, et al., 2017, p. vii). There is no specific definition of the best duration for professional learning, but learning takes time and sustained duration is discussed in literature in terms of weeks, months, or years (Darling-Hammond, Hyler et al., 2017).

\section{Adult Learning Theory}

Effective professional development for teachers is designed with an understanding of how teachers learn and provides active learning based on adult learning theories (Darling-Hammond, Hyler et al., 2017) that invite the "whole person into the [learning] environment" (Taylor, 2009, p. 11) and "treats teachers like professionals" (Gates Foundation, 2014, p.4). Effective professional development recognizes, that teachers "are self-directed" (Chen, 2014, p.407) and allows the teacher to experience self-identification of their needed areas of growth.

\section{Collaboration}

There is wide agreement on the inclusion of collaboration within discussions of effective professional development (Croft et al., 2010; Darling-Hammond, Burns et al., 2017; DarlingHammond, Hyler et al., 2017; Gates Foundation, 2014; Hirsh, 2019) with "collective work in trusting environments provid[ing] a basis for inquiry and reflection into teachers' own practices, allowing teachers to take risks, solve problems, and attend to dilemmas in their practice" (DarlingHammond, Hyler, et al., 2017, p. 10). This thinking aligns to Bruffee's (1999) thoughts on conversation as learning, however it is important for those working with teachers to understand that, "if the talk within the knowledge communities we are members of is narrow, superficial, biased, or limited to clichés, our thinking is almost certain to be so, too" (Bruffee, 1999, p. 134). Rather than seeking for teacher conformity, collaborative learning should seek to build, "a sense of trust in the process of dialogue with others, creating a setting that helps learners live with some 
discomfort while on the edge of knowing, in the process of gaining new insights and understanding" (Taylor, 2009, p.10).

\section{Cultural Awareness}

Creating trust within a collaborative learning environment includes the development of a cultural awareness. Teacher professional development that recognizes this will include strategies such as Cueva's (2010) strategies for fostering cultural awareness in adult learning environments: (a) "learning as respectful engagement” (p. 83); (b) "sharing power" (p.83); (c) “talking story” (p.86); and (d) "embracing learning through laughter" (p. 87). Facilitators of effective professional development for teachers would understand that "learning involves growth and change which is often disoriented and painful" (Cueva, 2010, p. 81). In addition to creating supportive and trusting collaborative learning environments for teachers, effective professional development allows job-embedded time and space needed for reflective processing and the use of lesson study frameworks (Darling-Hammond, Burns et al., 2017; Darling-Hammond, Hyler et al., 2017; Gates Foundation, 2014).

\section{Job-Embedded Learning}

Professional development that works for teachers is not only on-going and designed for adult learners, but also relevant to the work of the teacher so new learning can be applied and practiced within the classroom. It is job-embedded (Croft et al., 2010; Darling-Hammond, Hyler et al., 2017; Hirsh, 2019). Incorporating job-embedded learning requires, "common effort across all three levels: states, districts, and schools" (Croft et al., 2010, p. 12) to create the conditions for teacher learning, including the identification and development of skilled facilitators, common vocabulary, development of systems for monitoring, and creating a culture of continued learning (Croft et al., 2010).

\section{Proper professional development not only validates teachers' professional standing and strengthens the teaching workforce... it also correlates with teacher retention and thus could contribute to ameliorating the national teacher shortage}

(Garcia \& Weiss, 2019e, p. 28) 


\section{Job Embedded Modalities \& Strategies}

\author{
Teacher Action Research \\ (Croft et al., 2010; Darling-Hammond, Burns et al., 2017; Kelley, \\ 2004; Yost, 2006) \\ Mentoring \\ (Garcia \& Weiss 2019e) \\ Student Work Analysis \\ (Croft et al., 2010; Darling-Hammond, Burns, et al., 2017) \\ Lesson Study \\ (Croft et al., 2016; Darling-Hammond, Burns et al., 2017)
}

\section{Coaching}

(Croft et al., 2010; Darling-Hammond, Burns et al., 2017; DarlingHammond, Hyler et al., 2017; Garcia \& Weiss, 2019e; Gates Foundation, 2014)

...by someone who "is not the same person who does my evaluation" (Gates Foundation, 2014, p.7).

Collaborative Teams

(Croft et al., 2010; Darling-Hammond, Hyler et al., 2017; Gates Foundation, 2014; Kraft et al., 2018)

\section{Purpose of Evaluation}

Various levels of factors lead to attrition, including state-level contributions (Strunk \& Robinson, 2006). Missouri Teacher Academy is a program within The Missouri Teacher Development System (MTDS) and falls within the scope of Missouri DESE's Teacher Workforce Outreach Plan (2020), which includes "high quality professional learning opportunities" (Missouri DESE, 2020) as a strategy for increasing teacher retention. MTDS consists of a complement of state-supported, career-spanning teacher development programs. All MTDS programs provide participants with long-term, cohort-style learning experiences, which promote: (a) state and regional teacher collaboration and networking, (b) job-embedded learning with application of knowledge and skills within classrooms during experiences, and (c) the development of teacher reflective capacity through reflective supervision supports.

Missouri Teacher Academy was recently included in the National Council on Teacher Quality (2019) state analyses of teacher leadership development where the program was noted to "provide a strong model for leadership development” (p. 6). The program has the potential to serve as a national model for states seeking ways to use career development to support teacher retention (Sutcher et al., 2016), which could "make a greater difference in balancing supply and demand than any other intervention" (Sutcher et al., 2016, p. 37). 
Program impact has been measured in the past through participant and principal surveys with data consistently revealing evidence of perceived changes in teacher practice. Prior collections and analysis of qualitative data, including open-ended survey questions and evaluation of participant projects revealed improvement in teacher practice, specifically in teacher use of: (a) instructional strategies, (b) engagement strategies, and (c) reflective practice. These data supported the rationale that Missouri Teacher Academy meets the definition of a "promising program" under the Every Student Succeeds Act (ESSA), which "requires states to reference a positive evaluation of some kind in relationship to a chosen intervention and to track its effects in the field" (Chiefs for Change, 2016, p. 4). Other than a presentation paper (Belcher \& Vinson, 1997) discussing the first year of Missouri Teacher Academy, no peer-reviewed published research studies specifically evaluating statistical relationships between participation in Missouri Teacher Academy and level of teacher self-efficacy, reflective capacity, and/or job satisfaction were found. This study was conducted in order to evaluate the impact of Missouri Teacher Academy on factors related to teacher retention: (a) teacher self-efficacy (Sass, Seal, \& Martin, 2010; Yost, 2006), (b) reflective practice (Kelley, 2004; Yost, 2006), and (c) job satisfaction (Ingersoll \& Smith, 2003; Sutcher, et al., 2016; Strunk \& Robinson, 2006; Zee \& Koomen, 2016).

\section{Program Description}

Missouri Teacher Academy adheres to research-based teacher development structures aligned with the Every Student Succeeds Act (ESSA) suggestions for building systems of professional learning, as well as learning modalities designed to empower educators, such as lesson study, action research, appraisal, and feedback, (Darling-Hammond, Burns, Campbell, Goodwin, Hammerness, Ee-Ling Low, McIntyre, Sata, \& Zeichner, 2017). Program outcomes include: (a) supporting teacher retention through development of self-efficacy, reflective capacity, and job satisfaction; (b) promoting teacher empowerment; and (c) creating regional and state-level teacher networks.

Missouri Teacher Academy content is competency-based with priority learning areas including: (a) using data to make decisions, (b) engaging in on-ongoing reflective practice, (c) working in a community of practice, and (d) engaging students in content. Reflective journaling, questioning, and a classroom-based action research project conducted from a lesson study cycle framework are used by teachers to evaluate the effectiveness of their use of instructional and engagement strategies. Teachers implement their learning within the classroom, use multiple sources of data to evaluate the effectiveness of instruction, reflect upon their impact on student learning, and adapt practices based on new learning. Teachers reflect on the efficacy of their own practice while 
simultaneously engaging in risk-taking with the use of emerging research and innovative practices. The experience offers opportunities for teachers to build communities of practice both regionally and state-wide.

Missouri Teacher Academy has been in operation in some regions of the state since 1996 and reached full state-wide implementation in 2015. The program is currently offered at ten geographic locations throughout the state by nine Regional Professional Development Centers (RPDCs) and one additional approved program provider. While the RPDCs are networked with each other, as well as with the Missouri Department of Elementary and Secondary Education (DESE), each program location is a separate entity contracting with the Missouri DESE to facilitate the Missouri Teacher Academy program, which is partially funded by the Missouri DESE through participant scholarships and program funds. Program providers select their own facilitators, session dates, and locations in alignment to the contractual requirements of the Missouri DESE, which require participants to attend two days of state meetings and six regional sessions for a total of eight full days (48 hours) of participant learning. All program facilitators are highly skilled and experienced educational consultants.

\section{Conceptual Framework}

Effective professional development is directly related to: (a) reflective capacity (DarlingHammong, Hyler et al., 2019; Kelley, 2004), (b) self-efficacy (Gibson \& Dembo, 1984), and (c) teacher retention (Aloe, Amo, \& Shanahan, 2014; Carroll, 2007; Garcia \& Weiss, 2019e; Glickman \& Tamashiro, 1982; Guarino et al., 2006; Kelley, 2004; Pfitzner-Eden, 2016; Podolsky et al., 2016; Sass et al., 2010; and Yost, 2006). Additionally, reflective capacity (Kelley, 2004; Yost, 2006) and self-efficacy (Aloe et al., 2014; Pfitzer-Eden, 2016; Jensen, Sandoval-Hernandez, Knoll \& Gonzalez, 2012) are both directly related to teacher retention, as well as to each other (Babie \& Abednia, 2016; Kelly, 2004; Thoonen, Sleegers, Oort, Peetsma, and Geijsel, 2011; Yost, 2006). Furthermore, teacher self-efficacy correlates to job satisfaction (Johnson et al., 2006; Klassen \& Chiu, 2010; Skaalvik \& Skaalvik, 2010; Viel-Ruma, Houchins, Jolivette, \& Benson, 2010), which also relates to teacher retention (Bobbitt, Faupel, \& Burns, 1991; Ingersoll, 2001; Ingersoll \& Smith, 2003; Sutcher et al., 2016; Zee \& Kooman, 2016). Finally, teacher self-efficacy is directly related to teacher burnout (Fridman \& Farber, 1992; Skaalvik \& Skaalvik, 2007), which impacts teacher job satisfaction (Aloe et al., 2014; Brown, 2012; Brouwers, Evers, \& Tomic, 2001; Cherniss, 1993; Tschannen-Moran, Woolfolk Hoy, \& Hoy, 1998). 
Given the interwoven and overlapping relationships noted above, high quality professional development programs leading to increases in these constructs may help support retention efforts as well as improve teacher practice.

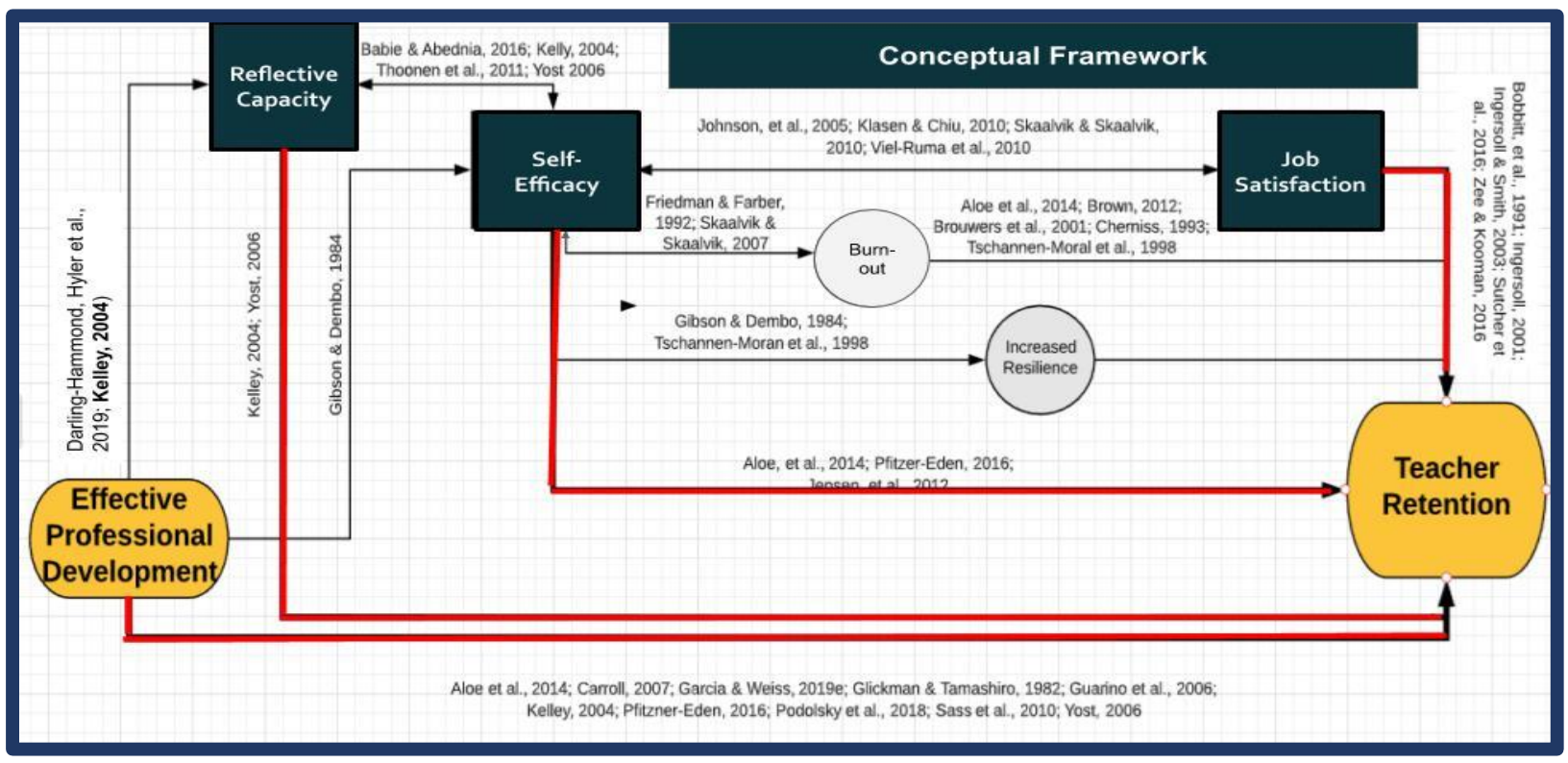

Figure 1. Conceptual framework showing the relationships among constructs

\section{Teacher Self-Efficacy}

Teacher self-efficacy (TSE) is a well-researched, well-established construct describing one's level of personal control obtained through self-belief (Bandura, 1977). Level of teacher self-efficacy refers to the extent to which a teacher believes in their ability to impact the learning of even the most challenging students regardless of external circumstances (Alow, Amo, Shanahan, 2014). Teacher self-efficacy impacts teacher behavior (Aloe et al., 2014; Brouwers et al., 2001; Goddard, Hoy, \& Woolfolk Hoy, 2004) which affects student learning (Anderson, Green, \& Loewen, 1988; Armor, Conry-Oseguera, Cox, King, McDonnell, Pascal, Pauly, \& Zellman, 1976; Caprara, Bararanelli, Steca, \& Malone, 2006; Gibson \& Dembo, 1984; Goddard et al., 2004; TschannenMoran et al., 1998). Teachers with high levels of self-efficacy have been found to be less controlling (Woolfolk \& Hoy, 1990; Woolfolk, Rosoff, \& Hoy, 1990) and critical (Ashton \& Web, 1986) of students. Teacher self-efficacy affects teachers' sense of accomplishment (Brouwers et al., 2001; Goddard et al., 2004), which then informs belief of self, leading to behaviors which impact students (Goddard et al., 2004). 
Teacher self-efficacy is impacted by years of experience, decreasing in the first few years of teaching (Woolfolk Hoy \& Burke Spero, 2005), rebounding mid-career, and then declining again towards career-end (Klassen \& Chiu, 2010). While higher levels of self-efficacy seem to support retention by protecting teachers from burnout (Aloe et al., 2014), the converse seems to also be true with lower levels of self-efficacy associated to higher levels of attrition (Jensen et al, 2013). Although low levels of self-efficacy may contribute to a teacher leaving the profession, it is possible to increase teacher self-efficacy through teacher development, which positively impacts level of resilience (Gibson \& Dembo, 1984) and reduces thoughts of leaving the career (Pfitzner-Eden, 2016).

\section{Reflective Practice}

Effective professional development emphasizes reflective practice (Darling-Hammond, Hyler et al., 2019; Kelley, 2004; Yost, 2006). Although some question the value of reflective practice for teaching as there are very few empirical studies (Collin, Karsenti, \& Komis, 2013) and "no evidence to show improved teacher or student performance resulting from reflective techniques" (Akbari, 2007, p. 192), it is clear within the research that there is a relationship between reflective practice and self-efficacy (Babaei \& Abednia, 2016; Rahimi \& Weisi, 2018; Thoonen et al., 2011; Yost, 2006). In Kelley (2004), reflective processes, including action research, were noted contribute to increased levels of self-efficacy and retention with 94\% of participants remaining in the classroom after four years (Kelley, 2004). The use of reflection as a mechanism to increase self-efficacy is further found in Awkard's (2017) work outlining suggestions on how to build selfefficacy through the use of reflective strategies. However, just as reflective practice is noted to lead to increases in self-efficacy, the opposite can also be seen (Thoonen et al., 2011).

Reflective practice is grounded in the writings of Dewey (1933) and Schön (1983), who highlighted the ability to "reflect-in-action" or "think about something while doing it" (Schön, 1983, p. 54). Schön's (1983) views were expanded to include "anticipatory reflection" (van Manen, 1995, p. 2), connecting reflective thinking through memory and imagination (Conway, 2001) as a form of selfdiscovery and identity formation (Warin, Maddock, Pell, \& Hargreaves, 2006). Reflection includes looking at the past and present coupled with looking to the future (van Manen, 1995) through active processing of all three simultaneously with conclusions used for decision-making and direction-setting (Farrell, 2012).

Reflective practice is understood to exist not only across time, for action, adaptation, predication, and as a process of knowing self, but also across levels or types of reflection (Larrivee, 2008; 
Schön,1983; van Manen, 1995). Reflective practice research "references to numerous levels, stage, dimensions, or types of reflection are indicative that reflection is generally viewed as an incremental process" (Larrivee, 2008, p. 341-342). Larrivee's (2008) four levels: (a) prereflection; (b) surface; (c) pedagogical; (d) critical (p. 342) progress from non-reflection to reflection on skills or techniques to a more critical form of reflecting including a teacher's consideration of "ethical, social, and political consequences of their teaching” (Larrivee, 2008, p. 342). Context is important for reflective practice (Beauchamp, 2014; Thompson \& Pascal, 2012) with value placed on reflection that: (a) is social and takes place within collaborative environments (Beauchamp, 2014; Noffke \& Brennan, 2005),

(b) includes the development of critically reflective practice (Beauchamp, 2014; Thompson \& Pascal, 2012), and (c) is guided by skilled facilitation that includes explicit teaching of reflective processing (Beauchamp, 2014; Collin et al., 2013; Gün, 2011).

\section{Job Satisfaction}

Job satisfaction is directly related to teacher retention (Bobbitt et al., 1991; Ingersoll \& Smith, 2003; Klassen \& Chiu, 2010; Perrachione, Peterson, \& Rosser, 2008; Skaalvik \& Skaalvik, 2010; Sutcher, et al., 2016; Strunk \& Robinson, 2006; Viel-Ruma, et al., 2010; Zee \& Koomen, 2016), and the impact of self-efficacy on job satisfaction is well known in the literature (Ingersoll, 2001; Johnson, Berg, \& Donaldson, 2005; Perrachione et al., 2008; Pfitzner-Eden, 2016). For this study job satisfaction was defined as (a) the level of fulfilment gained through participation in teaching, (b) the value of the work beyond the extrinsic motivation of monetary gain, (c) how much enjoyment was received from engaging in the work of teaching, and (d) level of motivation for attending the job (Priddis \& Rogers, 2018; Rogers et al., 2019).

\section{Methods}

From an impact evaluation approach, this quantitative study was conducted utilizing a one-group pretest-posttest survey design (Creswell, 2014). Survey data were compared to archival data collected from an identical survey taken by participants $(n=148)$ in Fall 2019 prior to attending Missouri Teacher Academy.

\section{Participants}

Comprehensive purposive sampling (Ilker, Sulaiman, \& Rukayya et al., 2016) was employed with all 2019-2020 Missouri Teacher Academy candidates asked to complete a survey at the completion of the Missouri Teacher Academy. Informed consent was completed, which outlined that participation was voluntary and did not affect the participant's position in Missouri Teacher Academy, relationship with their facilitator, or their employment in any way. 
Greater than $60 \%$ of candidates responded resulting in $n=97$ for the whole group sample.

All participants had > 3 years of teaching experience and had been identified as effective teachers with a desire for continued growth. The sample included teachers of all grade levels and content areas. The majority of the participants (83.5\%) were women. While the study included participants from urban, suburban, and rural districts, greater than $70 \%$ of participants indicated teaching in a rural district. See Data Appendix B for full demographic data charts.

\section{- Paired Subgroup}

The archival survey data included identifying information from a subgroup of teachers who teach in tested areas (ELA, Math, and Science). This allowed for the addition of a small paired subgroup sample $(n=22)$ to be included in this study. Subgroup participants included teachers who identified as teaching ELA (50\%), Math (22.7\%), and/or Science (27.3\%). While the paired sample demographics, such as experience level and age, were similar to the whole group in most respects, given the content-specific distinction, the sample included a larger concentration of grade 6-8 (45.5\%) and 9-12 (31.8\%) than the whole group representation of 6-8 (21.9\%) and grade 9-12 (25\%) teachers.

\section{Data Collection \& Instruments}

Data were collected using an instrument (Appendix D) comprised of two subscales from the Teacher Self-Efficacy Scale (TSES) (Tschannen-Moran \& Woolfolk Hoy, 2001): (a) efficacy in instructional strategies, and (b) efficacy in student engagement; and four subscales included in the dimension of reflective capacity, as well as the job satisfaction subscale, from the Reflective Practice Questionnaire (RPQ) (Priddis \& Rogers, 2018; Rogers et al., 2019). The reflective capacity subscales included were: (a) reflecting-on-action, (b) reflecting-in-action, (c) reflecting with others, and (c) self-appraisal.

Heneman, Kimball, and Milanowski (2006) tested the construct validity and reliability of the TSES (Tschannen-Moran \& Woolfolk Hoy, 2001) and asserted "the TSES should be the preferred measure of teachers' sense of efficacy in future research" (Heneman et al., 2006, p. 13). The RPQ closely aligns to the study conceptual framework and "can be utilized for education where students and practitioners complete the questionnaire as part of their own self-reflection and professional development" (Rogers, et al., 2019, p 8). The tool "was designed for flexible use across different professions" (Rogers, et al., 2019, p. 4). The RPQ is a new instrument, however, it has been found to be reliable in initial studies across different career contexts (Priddis \& Rogers, 2018; Rogers et al., 2019), as well as within the general population (Priddis \& Rogers, 2018), with the tool 
revealing acceptable internal consistency with each administration. Instrument subscales are directly aligned with the body of research and factor analysis has been conducted (Rogers et al., 2019).

\section{Data Analysis}

Archival and study data sets were analyzed. Descriptive statistics were used to evaluate the distribution of the data. Independent samples $t$-tests were conducted to compare pre- and postattendance means of self-efficacy, reflective capacity, and job satisfaction with level of significance established as $p<0.05$ (Fields, 2018). Given the differences in sample sizes between the pre ( $n$ $=148)$ and post $(n=95)$ data, Hedges' g was conducted to evaluate effect size. However, when compared to Cohen's $d$, differences were negligible, so only Cohen's $d$ was reported.

Additionally, paired-sample $t$-tests were conducted to analyze the subgroup ( $n=22)$ of ELA, Math, and Science teachers to compare pre- and post- attendance means of self-efficacy, reflective capacity, and job satisfaction. To control for Type I error within this small sample, as well as given that a total of nine analyses were performed on the same data set, a Bonferronicorrected level of significance for all analyses was established as $p<0.006$.

\section{Independent Samples $T$-Test Results}

Self-Efficacy

An independent-samples $t$-test was conducted to compare pre-academy self-efficacy and postacademy self-efficacy. There was a statistically significant difference between pre-academy selfefficacy $(M=3.86, S D=0.46)$ and post-academy levels of self-efficacy $(M=4.27, S D=0.43)$; $t(240)=-7.03, p<.001$. Cohen's $d=.93$, which is considered a large effect size based on Cohen's (1992) guidelines (McLeod, 2019). Results indicate that there was a statistically significant

increase in self-efficacy scores before and after the intervention. Data were further analyzed by subscale to provide additional insights into the impact of Missouri Teacher Academy on level of teacher self-efficacy (See Table 2).

Reflective Capacity

An independent-samples $t$-test was conducted to compare pre-academy reflective capacity and post-academy reflective capacity. There was a statistically significant difference between preacademy reflective capacity $(M=4.80, S D=0.57)$ and post-academy reflective capacity $(M=5.12$, $S D=0.50) ; t(241)=-5.00, p<.001$. Cohen's $d=.67$, which is considered a medium effect size based on Cohen's (1992) guidelines (McLeod, 2019). Results indicate that there was a statistically significant increase in reflective capacity scores before and after the intervention. Teacher 
reflective capacity subscale data were also analyzed to provide additional insights into the impact of Missouri Teacher Academy on level of teacher reflective capacity (table 3).

Table 2

Independent Sample T-test Subscales Results Comparing Pre-Post Academy Self-Efficacy(SE)

\begin{tabular}{lccccccc}
\hline & $n$ & $M$ & $S D$ & $t$ & $d f$ & $p$ & $d$ \\
\hline $\begin{array}{l}\text { (Pre)SE-Instructional Strategies } \\
\text { (Post)SE-Instructional Strategies }\end{array}$ & 148 & 3.84 & .49 & -7.20 & 240 & $<.001$ & .95 \\
(Pre)SE-Student Engagement & 148 & 3.88 & .52 & -5.48 & 241 & $<.001$ & .72 \\
(Post)SE-Student Engagement & 95 & 4.24 & .49 & & & & \\
\end{tabular}

Note. Cohen's $d>0.8$, considered to show a large effect size (McCleod, 2019) is noted for self-efficacy as well as the subscale self-efficacy in instructional strategies. The subscale self-efficacy in student engagement is noted to have a Cohen's $d>0.5$, which is noted to be a medium effect size.

Job Satisfaction

An independent-samples $t$-test was conducted to compare pre-academy job satisfaction and postacademy job satisfaction. There was a statistically significant difference between pre-academy job satisfaction $(M=5.05, S D=0.63)$ and post-academy job satisfaction $(M=5.31, S D=0.51)$; $t(241)=-3.40, p=.001$. Cohen's $d=.46$, which is considered a small effect size based on Cohen's (1992) guidelines (McLeod, 2019). Results indicate that there was a statistically significant increase in job-satisfaction scores before and after the intervention.

\section{Paired Samples $T$-Test Results}

Self-Efficacy

A paired-samples $t$-test was conducted to compare pre-academy self-efficacy and post-academy self-efficacy. Given the small sample size of $n=21$, the assumption of normally distributed difference was confirmed with Shapiro Wilk of $p=.242$. The assumption of normality was further satisfied, as skew and kurtosis levels were 0.001 and -1.177 , respectively. Furthermore, strong, positive correlation was noted between pre-academy and post-academy level of self-efficacy with $r=0.74, p<0.001$, suggesting paired samples $t$-test was appropriate. There was a significant difference between pre-academy self-efficacy $(M=3.62, S D=0.40)$ and post-academy selfefficacy $(M=4.3, S D=0.37) ; t(20)=-10.37, p<.001$. Cohen's $d=2.263$, which is considered a large effect size based on Cohen's (1992) guidelines (McLeod, 2019). Results indicate that there was a statistically significant increase in self-efficacy scores before and after the intervention. 
Data were further analyzed by subscale to provide additional insights into the impact of Missouri Teacher Academy on level of teacher self-efficacy (table 4).

Table 3

Independent Sample T-test Subscale Results Pre-Post Academy Reflective Capacity (RC)

\begin{tabular}{lccccccc}
\hline & $n$ & $M$ & $S D$ & $t$ & $d f$ & $p$ & $d$ \\
\hline (Pre)Reflecting-in-Action & 148 & 4.40 & .73 & -4.48 & 242 & $<.001$ & .56 \\
(Post)Reflecting-in-Action & 96 & 4.83 & .74 & & & & \\
(Pre)Reflecting-on-Action & 148 & 4.83 & .91 & & & & .43 \\
*(Post)Reflecting-on-Action & 96 & 5.18 & .68 & -3.38 & 238 & .001 & .51 \\
(Pre)Reflecting-with-Others & 148 & 4.91 & .59 & -3.79 & 241 & $<.001$ & \\
(Post)Reflecting-with-Others & 95 & 5.24 & .64 & & & & \\
(Pre)Self-Appraisal & 148 & 4.90 & .55 & -3.97 & 242 & $<.001$ & .53 \\
(Post)Self-Appraisal & 96 & 5.22 & .63 & & & & \\
\hline
\end{tabular}

Note. Cohen's $d>0.5$, considered to show a medium effect size (McCleod, 2019), is noted for reflecting-in-action, reflecting-with-others, and self-appraisal subscales.

*equal variances were not assumed for reflecting on-action

Table 4

Paired Sample T-test Subscale Results Comparing Pre-Post Academy Self-Efficacy (SE)

\begin{tabular}{|c|c|c|c|c|c|c|c|}
\hline & $n$ & $M$ & $S D$ & $t$ & $d f$ & $p$ & $d$ \\
\hline (Pre)SE - Instructional Strategies & 22 & 3.63 & .44 & -7.81 & 21 & $<.001$ & 1.67 \\
\hline (Post)SE- Instructional Strategies & 22 & 4.30 & .38 & & & & \\
\hline (Pre)SE - Student Engagement & 22 & 3.65 & .50 & -5.63 & 21 & $<.001$ & 1.20 \\
\hline (Post)SE - Student Engagement & 22 & 4.2502 & .48 & & & & \\
\hline
\end{tabular}




\section{Reflective Capacity}

A paired-samples $t$-test was conducted to compare pre-academy reflective capacity and postacademy reflective capacity. Given the small sample size of $n=22$, the assumption of normally distributed difference was confirmed with Shapiro Wilk of $p=.164$. The assumption of normality was further considered to be satisfied, as skew and kurtosis levels were estimated at 0.379 and 1.030, respectively. However, weak positive correlation between pre-academy reflective capacity and post-academy reflective capacity was noted with $r=0.336$. There was significant difference between pre-academy reflective capacity $(M=4.73, S D=0.51)$ and post-academy reflective capacity $(M=5.16, \mathrm{SD}=0.45) ; t(21)=-3.59, p=.002$. Cohen's $d=.765$, which is considered to be a medium effect size based on Cohen's (1992) guidelines (McLeod, 2019). Results indicate that there was a statistically significant increase in reflective capacity scores before and after the intervention. Reflective capacity data were further analyzed by subscale (table 5 ).

Job Satisfaction

A paired-samples $t$-test was conducted to compare pre-academy job satisfaction and postacademy job satisfaction. Given the small sample size of $n=22$, the assumption of normally distributed difference was confirmed with Shapiro Wilk of $p=.125$. The assumption of normality was further considered to be satisfied, as skew and kurtosis levels were estimated at .442 and .039, respectively. Furthermore, strong positive correlation between pre-academy job satisfaction and post-academy job satisfaction was noted with $r=.775, p<.001$. There was a significant difference between pre-academy job satisfaction $(M=4.9, S D=0.72)$ and post-academy job satisfaction $(M$ $=5.26, S D=0.57) ; t(21)=-3.751, p=.001$. Cohen's $d=.8$, which is considered to be a large effect size based on Cohen's (1992) guidelines (McLeod, 2019). Results indicate that there was a statistically significant increase in job satisfaction scores before and after the intervention.

\section{Discussion}

This study was conducted to evaluate the potential impact of Missouri Teacher Academy, which is part of a state-level retention strategy focused on providing effective professional development to increase teacher self-efficacy, reflective capacity, and job satisfaction. Findings support the conclusion that Missouri Teacher Academy may be effective in increasing teacher self-efficacy, reflective capacity, and job satisfaction. Statistically significant differences were found in all three constructs within whole group and subgroup analyses. 


\section{Key Findings}

- Increased Pre/Post Level of Self-Efficacy with Large Effect Size

Results demonstrate a statistically significant increase in teacher self-efficacy in teachers who attended Missouri Teacher Academy. Differences in level of self-efficacy were statistically significant with a large effect size noted. These results were consistent across both whole group and subgroup samples. Additionally, when evaluating self-efficacy subscales, a large effect size was noted for level of self-efficacy in use of instructional strategies (seen in both whole group and subgroup data sets). Results indicate that there was a statistically significant increase in selfefficacy scores before and after the intervention.

Table 5

Paired Sample T-test Subscale Results Comparing Pre-Post Academy Reflective Capacity (RC)

\begin{tabular}{lccccccc}
\hline & $n$ & $M$ & $S D$ & $t$ & $d f$ & $p$ & $d$ \\
\hline (Pre)Reflecting-in-Action & 22 & 4.33 & .70 & -4.798 & 21 & $<.001$ & 1.04 \\
(Post)Reflecting-in-Action & 22 & 5.05 & .48 & & & & \\
(Pre)Reflecting-on-Action & 22 & 4.86 & .95 & -1.685 & 21 & .107 & .359 \\
(Post)Reflecting-on-Action & 22 & 5.16 & .65 & & & & \\
(Pre)Reflecting-with-Others & 22 & 4.93 & .60 & -1.715 & 21 & .101 & .366 \\
(Post)Reflecting-with-Others & 22 & 5.23 & .56 & & & & \\
(Pre)Self-Appraisal & 22 & 4.81 & .54 & -3.184 & 21 & .004 & .679 \\
(Post)Self-Appraisal & 22 & 5.20 & .52 & & & & \\
\hline
\end{tabular}

Note. Cohen's $d>0.5$, considered a medium effect size (McCleod, 2019) is noted for reflective capacity as well as for the self-appraisal subscale. Cohen's $d>0.8$, considered to show a large effect size (McCleod, 2019) is noted for reflecting-in-action.

\section{- Statistically Significant Increase in Pre/Post Level of Reflective Capacity}

Results demonstrated an increase in teacher reflective capacity in teachers who attended Missouri Teacher Academy. Differences in level of reflective capacity were statistically significant. There was a moderate effect size noted for the whole group and a large effect size noted for the subgroup. In evaluating subscales, the greatest effect size was noted on teacher reflection-in-action with a large effect size noted for the sub group and a moderate effect size noted for the whole group. 
These results support concluding that attending Missouri Teacher Academy may contribute to increases in reflective capacity, although it is unclear as to how great of an effect there is. Given the large effect size seen in the subgroup, additional research with paired data would be needed to substantiate these findings within a larger sample.

\section{- Statistically Significant Increase in Pre/Post Level of Job Satisfaction}

Results show increases in level of teacher job satisfaction in teachers who attended Missouri Teacher Academy and the effect was large within the paired subgroup. Again, research with paired data is needed to substantiate these findings within a larger sample. Further studies are needed confirm these findings. Additionally, qualitative studies, such as focus groups, may be helpful in providing insights into program structures and/or activities, which may be contributing to the program's impact on teacher self-efficacy.

\section{Study Limitations}

Although statistically significant differences between pre- and post- program groups were identified, random sampling was not utilized and individual participant growth was only able to be evaluated for a small subgroup. Further analysis of individual participant growth within a larger sample would benefit the program and strengthen understanding of impact. Participants represent typical teacher academy participants, who are thought to have a strong desire for improvement; one may even question the mitigating effects of teacher academy participant characteristics on any study results obtained. Additionally, with $70 \%$ of participants representing rural schools, the findings of this study may be specific to teachers within rural settings. Future studies comparing impacts across district settings may increase the generalizability of these findings to include suburban and/or urban settings.

Of note, the data collection window for this study occurred during the beginning of the Covid-19 crisis. It is unclear as to what effect the disruptions due to the crisis may have had on participant responses. It is thought there was some effect on the number of whole group responses received given the fall archival survey data represented $n=148$ as compared $n=95$ seen during the data collection for this study, which occurred in Spring 2020.

\section{Study Impacts}

This study serves as an important first step in understanding potential impacts of Missouri Teacher Academy. ESSA requires states to submit a plan for the development of human capital, which 
“address[es] systems of educator development, retention, and advancement..." (Chiefs for Change, 2017, p. 19). Given the findings of this study and the known relationship between level of teacher self-efficacy and teacher retention (Glickman \& Tamashiro, 1982; Pfitzner-Eden, 2016; Sass et al., 2010; \& Yost, 2006), this study supports the inclusion of Missouri Teacher Academy in the state's human capital development. Additionally, this study supports the continuation of the work of Missouri Teacher Development System Teams, including program development and further program evaluation efforts.

This study contributes to current understanding within the research, specifically regarding the use of effective professional development as a state level retention strategy by providing a conceptual framework connecting effective professional development intentionally focused on the development of reflective capacity, self-efficacy, and job satisfaction as mechanisms for increasing teacher retention. Future replication of this study could provide additional information about the reliability of findings. Additionally, longitudinal studies to determine program impact and/or effectiveness over time may be valuable to determine whether or not there is a direct correlation between attending Missouri Teacher Academy and a teacher's decision to stay in the career. 


\section{Practitioner Report Slides}

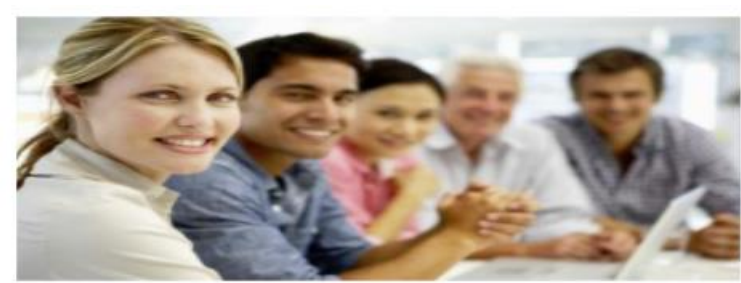

\section{Building the Best}

Missouri Teacher Academy Program Evaluation 2020

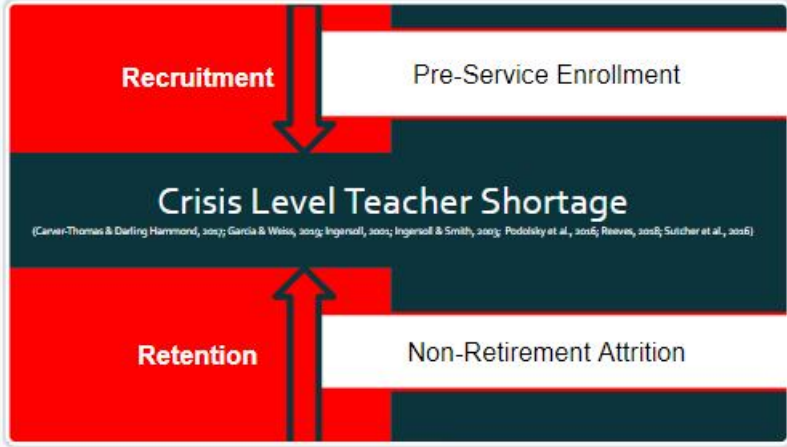

$3 \theta$

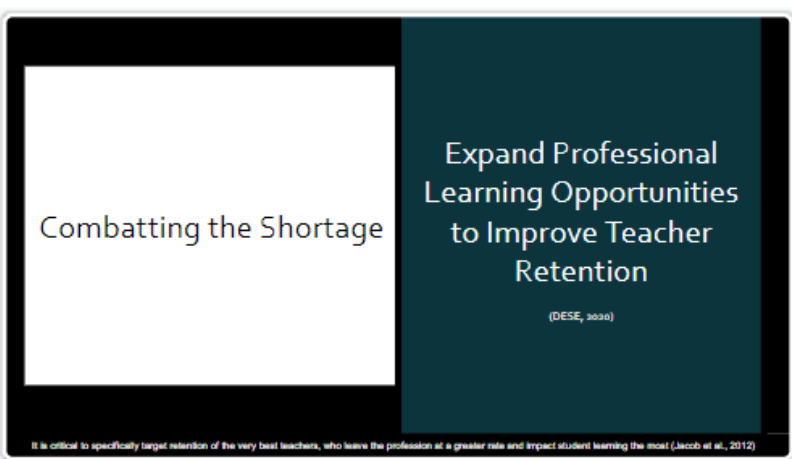

5 \&

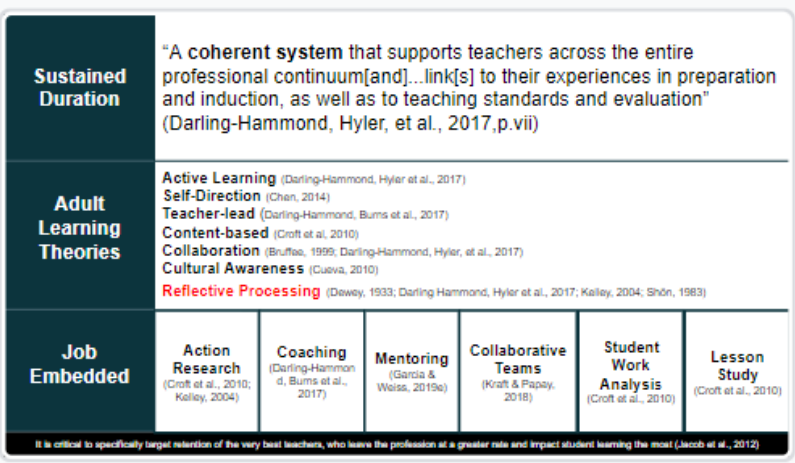

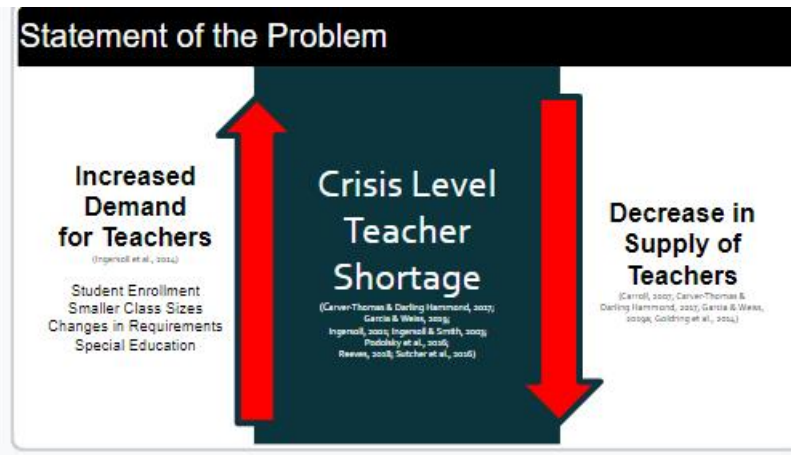

$2 \theta$

"Reducing attrition in half could virtually eliminate shortages"

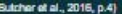

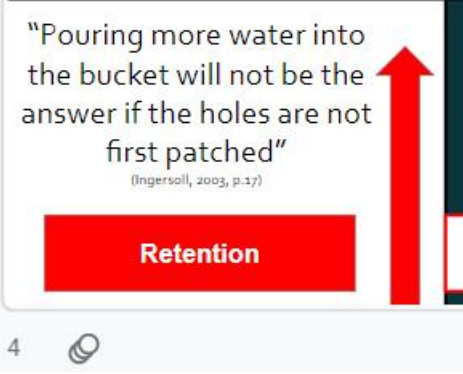

Crisis Level Teacher Shortage inting

Non-Retirement Attrition

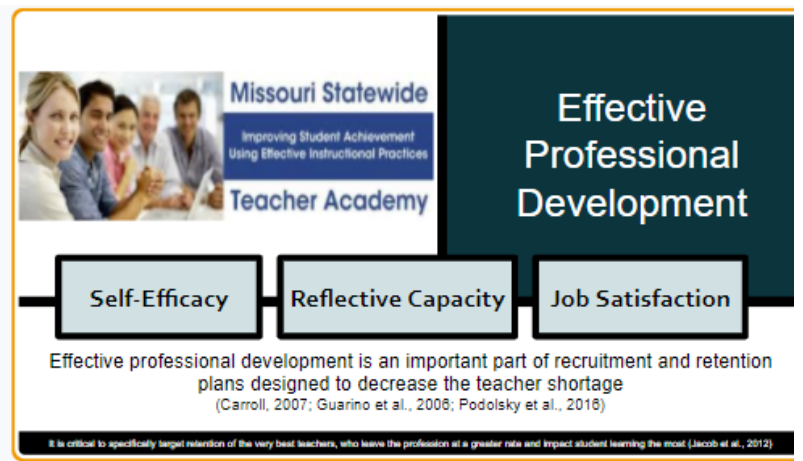

$6 \otimes$

How is effective professional development related to

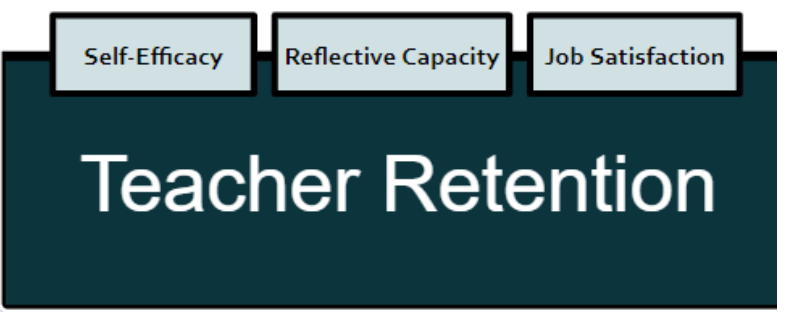




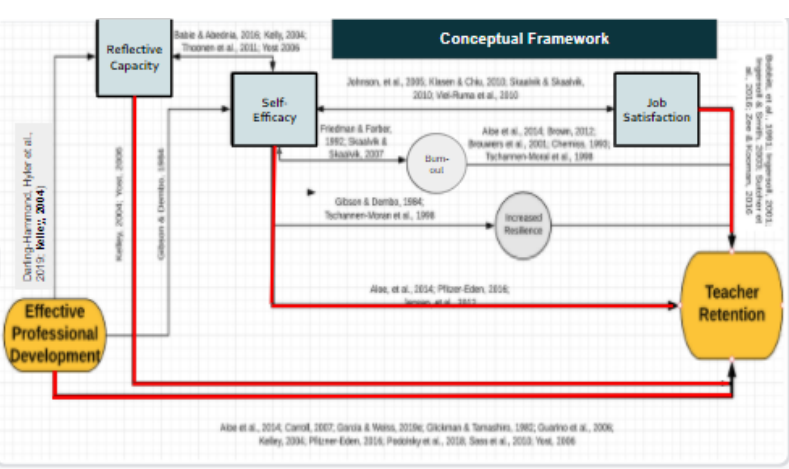

$9 \theta$

\section{Research Question}

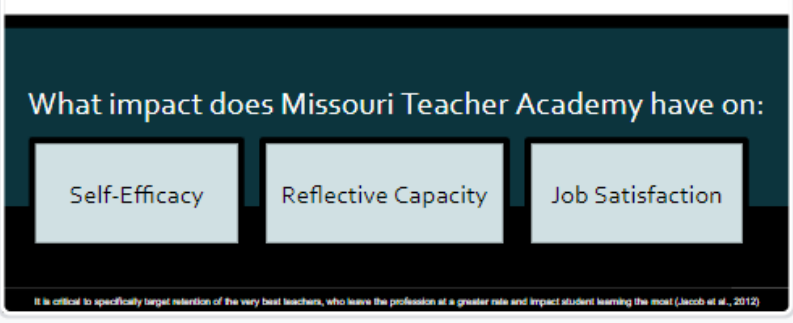

$11 \otimes$

\section{Participants} Cohort 2019-2020

- $>3$ years of teaching experience

- Effective teachers with a desire for continued growth

- All Grade Levels and Content Areas Sub-group (n=22) included only math, science, and ELA

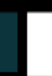

$13 \theta$

Study Limitations

Non-Random Sampling

Sample Bias

Selection \& Access

Researcher Positionality

\section{Purpose of Evaluation}

Evaluation of Program Impact on Factors Related to Teacher Retention

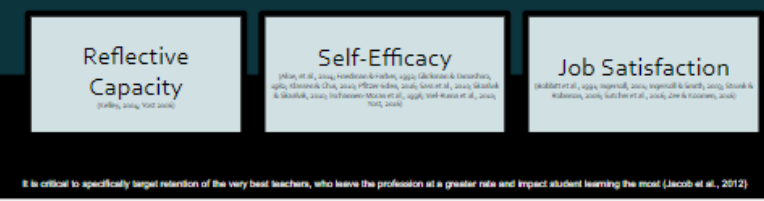

$10 \otimes$

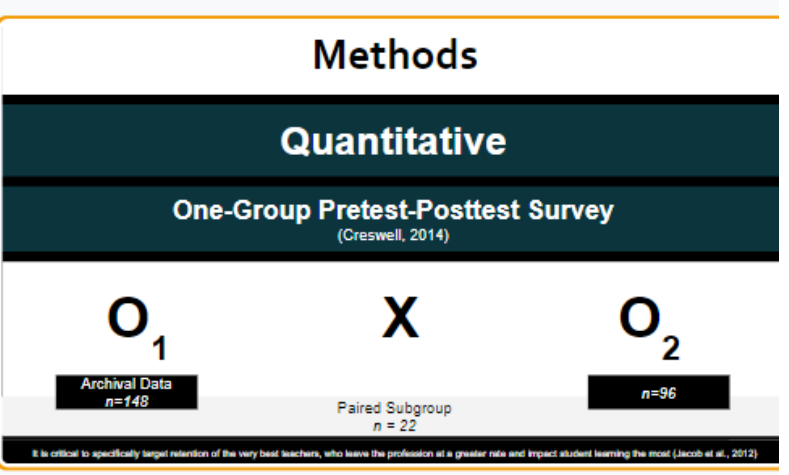

$12 \theta$

\section{Data Collection \& Instruments}

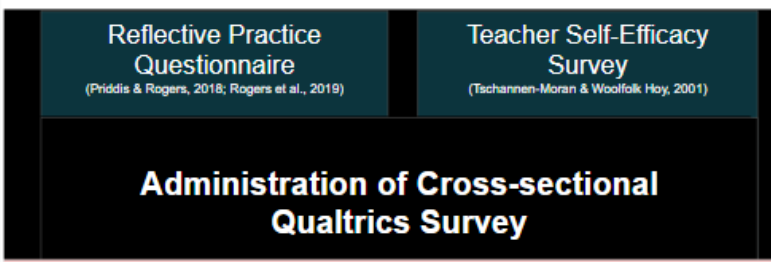

Data Collection Window: March 19, 2020 to June 1, 2020

$14 \ominus$

Assumptions of the Study

Participant Honesty

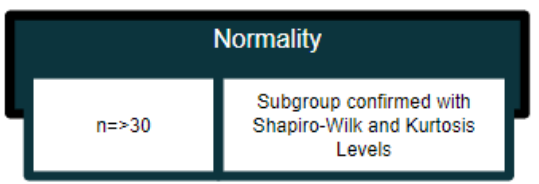

$16 \theta$ 


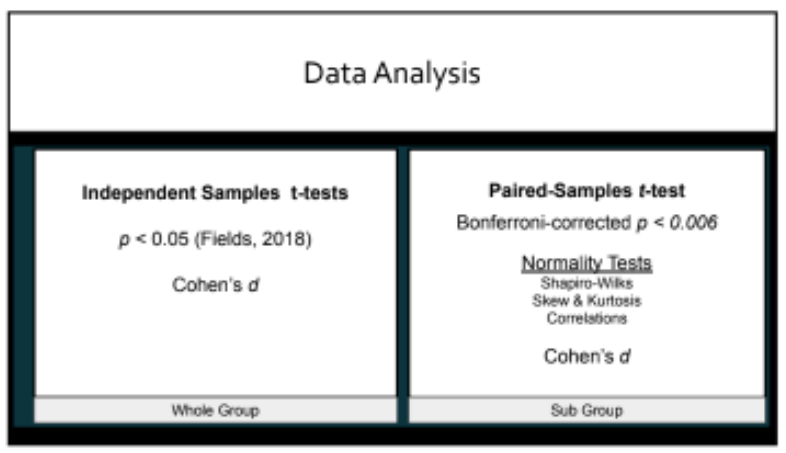

Independent Samples T-Test Results
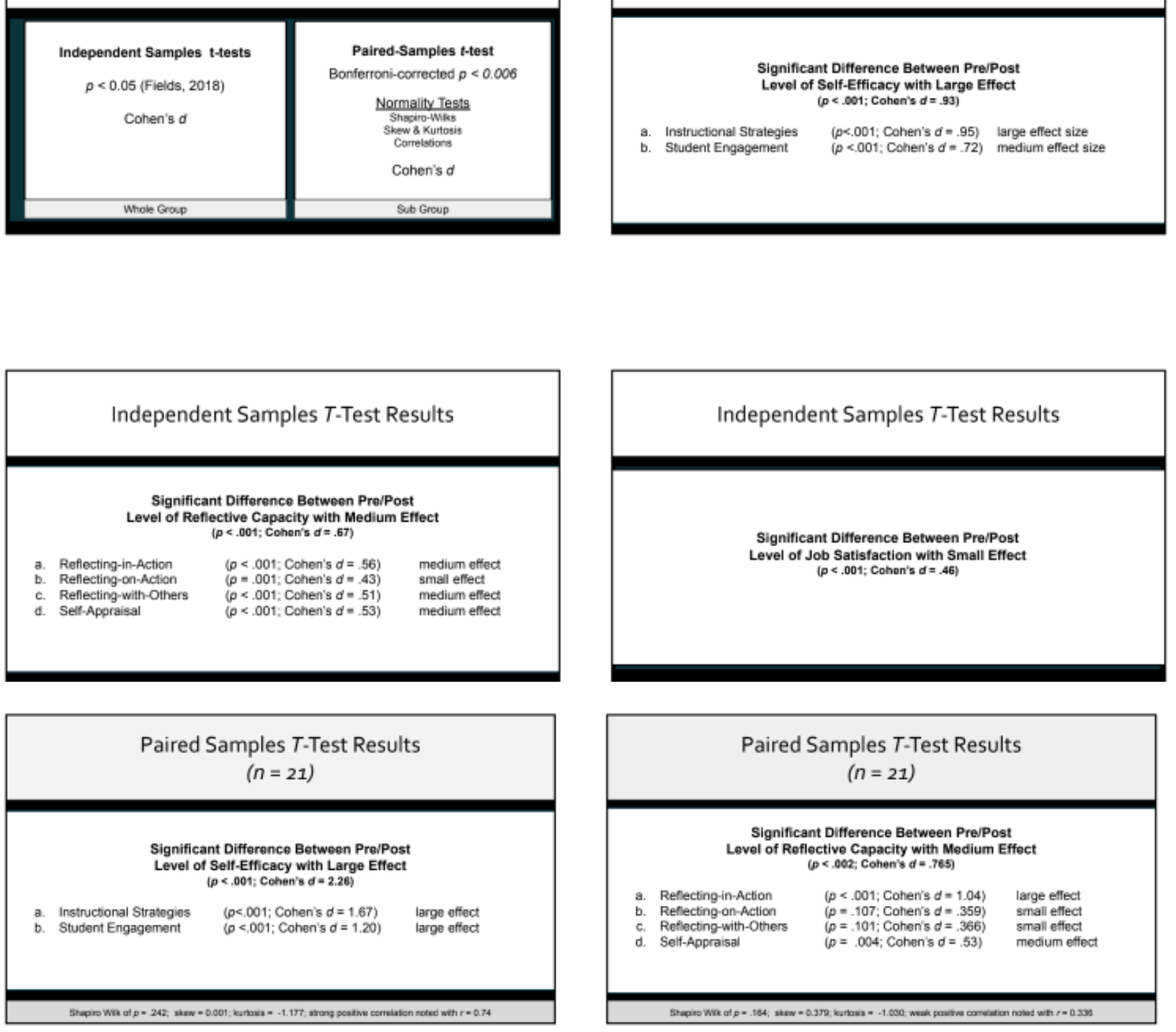

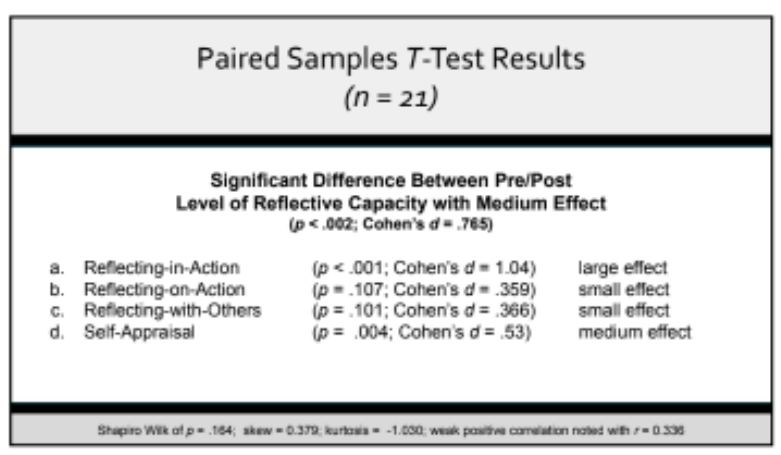

\section{Paired Samples T-Test Results}

$$
(n=22)
$$

Significant Difference Between Pre/Post Level of Job Satisfaction with Large Effect $(p=.001 ;$ Cohen's $d=, 8)$ 


\section{References}

Allensworth, E., Ponisciak, S., \& Mazzeo, C. (2009). The schools teachers leave: Teacher mobility in Chicago Public Schools. Chicago, IL: Consortium on Chicago School Research at the University of Chicago.

Aloe, A., Amo, L., \& Shanahan, M. (2014). Classroom management self-efficacy and burnout: a multivariate meta-analysis. Educational Psychology Review, 26(1), 101-126.

Anderson, R. N., Greene, M. L., \& Loewen, P. S. (1988). Relationships among teachers' and students' thinking skills, sense of efficacy, and student achievement. Alberta Journal of Educational Research, 34(2), 148-165.

Armor, D., Conry-Oseguera, P., Cox, M., King, N., McDonnell, L., Pascal, A., Pauly, E., \& Zellman, G. (1976). Analysis of the school preferred reading program in selected Los Angeles minority schools. Santa Monica, CA: Rand Corporation.

Ashton, P., \& Webb, R. (1986). Making a difference: Teachers' sense of efficacy and student achievement. New York, NY: Longman.

Awkard, T. (2017). The power of reflective action to build teacher efficacy. Kappan, 98(6), 5357.

Babaei, M., \& Abednia, A. (2016). Reflective teaching and self-efficacy beliefs: Exploring relationships in the context of teaching EFL in Iran. Australian Journal of Teacher Education, 41(9), 1-26.

Bandura, A. (1977). Toward a unifying theory of behavioral change. Psychological Review, 84, $1919-215$.

Beauchamp, C. (2014). Reflection in teacher education: Issues emerging from a review of current literature. Reflective Practice, 16(1), 123-141. 
Belcher, C., \& Vinson, G. (1997, August) The Teachers' Academy: A Collaborative Approach to Preparing Teachers for Leadership Roles in the Public Schools. Paper presented at the Summer Workshop of the Association of Teacher Educators, Las Vegas, NV. Retrieved from https://files.eric.ed.gov/fulltext/ED412192.pdf

Bobbitt, S., Faupel, E., \& Burns, S. (1991). Stayers, movers, and leavers: Results of the 1988-89 teacher follow-up survey. Washington, DC: National Center for Education Statistics.

Borman, G., \& Dowling, N. (2008). Teacher attrition and retention: A meta-analytic and narrative review of the research. Review of Educational Research, 78(3), 367-409.

Brouwers, A., Evers, W., \& Tomic, W. (2001). Self-efficacy in eliciting social support and burnout among secondary school teachers. Journal of Applied Social Psychology, 31, 1474-1491.

Brown, C. (2012). A systematic review of the relationship between self-efficacy and burnout in teachers. Educational and Child Psychology, 29(4), 47-63.

Bruffee, K. (1999). Collaborative Learning: Higher Education, Interdependence, and the Authority of Knowledge (2nded.). Baltimore, MD: The Johns Hopkins University Press.

Caprara, G., Barbaranelli, C., Steca, P., \& Malone, P. (2006). Teachers' self-efficacy beliefs as determinants of job satisfaction and students' academic achievement: A study at the school level. Journal of School Psychology, 44(6), 473-490.

Carroll, T. (2007). Policy Brief: The high cost of teacher turnover. Washington, D.C.: National Commission on Teaching and America's Future.

Carver-Thomas, D., \& Darling-Hammond, L. (2017). Teacher turnover: Why it matters and what we can do about it. Palo Alto, CA: Learning Policy Institute. 
Chang, M. (2009). An appraisal perspective of teacher burnout: Examining the emotional work of teachers. Educational Psychology Review, 21(3), 193-218.

Chen, J. (2014). Teaching nontraditional adult students: Adult learning theories in practice. Teaching in Higher Education, 19(4), 406-418.

Cherniss, C. (1993). Role of professional self-efficacy in the etiology and amelioration of burnout. In W. B. Schaufeli, C. Maslach, \& T. Marek (Eds.), Series in applied psychology: Social issues and questions. Professional burnout: Recent developments in theory and research (pp. 135-149). Philadelphia, PA, US: Taylor \& Francis.

Chiefs for Change. (2017). Evidence and funding: Connecting the dots. Retrieved from: chiefsforchange.org/policy-paper/4105/

Chiefs for Change. (2016). ESSA and evidence: Why it matters. Retrieved from: chiefsforchange.org/policy-paper/3096/

Collin, S., Karsenti, T., \& Komis, V. (2013). Reflective practice in initial teacher training: Critiques and perspectives. Reflective Practice: International and Multidisciplinary Perspectives, 14, 104-117.

Conway, P. (2001). Anticipatory reflection while learning to teach: From a temporally truncated to a temporally distributed model of reflection in teacher education. Teaching and Teacher Education, 17, 89-106.

Cowan, J., Goldhaber, D., Hayes, K., Theobald, R. (2016). Missing elements in the discussion of teacher shortages. Educational Researcher, 45(8), 460-462. doi.10.3102/0013189X16679145

Creswell, J. (2014). Research design: Qualitative, quantitative, and mixed methods approaches (4th ed.). Los Angeles, CA: Sage. 
Cueva, M. (2010). A living spiral of understanding: Community-based adult education. New Directions for Adult and Continuing Education, 125, 79-90.

Darling-Hammond, L. (1999). Teacher quality and student achievement: A review of state policy evidence. Seattle, WA: Center for the Study of Teaching and Policy, University of Washington.

Darling-Hammond, L. (2003). Keeping good teachers: Why it matters and what leaders can do. Educational Leadership, 60(8), 6-13.

Darling-Hammond, L., Burns, D., Campbell, C., Goodwin, A., Hammerness, K., Low, E., McIntyre, A., Sato, M., \& Zeichner, K. (2017). Empowered educators: How highperforming systems shape teaching quality around the world. San Francisco, CA: Jossey Bass.

Darling-Hammond, L., Hyler, M., \& Gardner, M. (2017). Effective teacher professional development. Palo Alto, CA: Learning Policy Institute.

Dewey, J. (1933). How we think: A restatement of the relations of reflective thinking to the educative process (2nd revised ed.). Boston, MA: D.C. Heath.

Farrell, T. (2012). Reflecting on reflective practice: (Re)visiting Dewey and Schön. TESOL Journal, 3(1), 7-16.

Fields, A. (2018). Discovering statistics using IBM SPSS statistics (5th ed.). Thousand Oaks, CA: Sage.

Garcia, E., \& Weiss, E. (2019a). The teacher shortage is real, large and growing, and worse than we thought: The first report in 'the perfect storm in the teacher labor market' series. Washington, D.C.: Economic Policy Institute. 
Garcia, E., \& Weiss, E. (2019b). U.S. schools struggle to hire and retain teachers: The second report in 'the perfect storm in the teacher labor market' series. Washington, D.C.: Economic Policy Institute.

Garcia, E., \& Weiss, E. (2019e). The role of early career supports, continuous professional development, and learning communities in the teacher shortage: The fifth report in 'the perfect storm in the teacher labor market' series. Washington, D.C.: Economic Policy Institute.

Gibson, S., \& Dembo, M. (1984). Teacher efficacy: A construct validation. Journal of Educational Psychology, 76(4), 569-582.

Glickman, C., \& Tamashiro, R. (1982). A comparison of first-year, fifth-year, and former teachers on efficacy, ego development, and problem solving. Psychology in the Schools, $19(4), 558-562$.

Goddard, R., Hoy, W., \& Woolfolk Hoy, A. (2004). Collective efficacy beliefs: Theoretical developments, empirical evidence, and future directions. Educational Researcher, 33, 313.

Goldring, R., Taie, S., \& Riddles, M. (2014). Teacher attrition and mobility: Results from the 2012-13 teacher follow-up survey (NCES 2014-077). U.S. Department of Education. Washington, DC: National Center for Education Statistics. Retrieved from http://nces.ed.gov/pubsearch

Gray, L., Taie, S., \& O’Rear, S. (2015). Public school teacher attrition and mobility in the first five years: Results from the first through fifth waves of the 2007-08 beginning teacher longitudinal study (NCES 2015-337). U.S. Department of Education. Washington, DC: National Center for Education Statistics. Retrieved from: http://nces.ed.gov/pubsearch 
Guarino, C., Santibáñez,, L., \& Daley, G. (2006). Teacher recruitment and retention: A review of the recent empirical literature. Review of Educational Research 76(2), 173-208.

Gün, B. (2011). Quality self-reflection through reflection training. ELT Journal, 65(2), 126 134.

Hattie, J. (2003). Teachers make a difference: What is the research evidence? Paper presented at the Building Teacher Quality: What does the research tell us? Acer Research Conference, Melbourne, Australia. Retrieved from: research.acer.edu.au/research_conference_2003/4/

Heneman, H., Kimball, S., \& Milanowski, A. (2006). The Teacher sense of efficacy scale: Validation evidence and behavioral prediction. WCER Working Paper No. 2006-7, Madison, WI: University of Wisconsin-Madison, Wisconsin Center for Education Research.

Hirsh, S. (2019). 4 cornerstones of professional learning: Fundamental principles pave the way for educators' actions. Oxford, OH: Learning Forward.

Ilker E, Sulaiman A., Rukayya S. (2016). Comparison of convenience sampling and purposive sampling. American Journal of Theoretical and Applied Statistics, 5(1), 1-4. 10.11648/j.ajtas.20160501.11

Ingersoll, R. (2001). Teacher turnover and teacher shortages: an organizational analysis. American Educational Research Journal, 38, 499-534.

Ingersoll, R. (2003). Is There Really a Teacher Shortage?. Retrieved from https://repository.upenn.edu/gse_pubs/133

Ingersoll, R., \& Smith, T. (2003). The wrong solution to the teacher shortage. Educational Leadership, 60(8), 30-33. 
Ingersoll, R., Merrill, L., \& Stuckey, D. (2014). Seven trends: The transformation of the teaching force. Philadelphia, PA: Consortium for Policy Research in Education, University of Pennsylvania.

Jacob, A., Vidyarthi, E., \& Carroll, K. (2012). The irreplaceables: Understanding the real retention crisis in America's urban schools. New York, NY: The New Teacher Project.

Jensen, B., Sandoval-Hernandez, A., Knoll, S., \& Gonzalez, E. (2012). The Experience of new teachers: Results from TALIS 2008. OECD Publishing. Retrieved from: http://www.oecd.org/education/school/49846877.pdf

Johnson, S., Berg, J., \& Donaldson, M. (2005). Who stays in teaching and why: A review of the literature on teacher retention. Washington, DC: NRTA.

Kelley, L. (2004). Why induction matters. Journal of Teacher Education, 55(5). 438-448.

Klassen, R., \& Chiu, M. (2010). Effects on teachers' self-efficacy and job satisfaction: Teacher gender, years of experience, and job stress. Journal of Educational Psychology, 102(3), 741-756.

Larrivee, B. (2008). Development of a tool to assess teachers' level of reflective practice. Reflective Practice, 9(3), 341-360.

Maslach, C., \& Leiter, M. (2008). Early predictors of job burnout and engagement. Journal of Applied Psychology, 933, 498-512.

McLeod, S. A. (2019, July 10). What does effect size tell you? Simply psychology: https://www.simplypsychology.org/effect-size.html

Missouri Department of Elementary and Secondary Education. (2020). State board of education outreach plan update. Retrieved from: dese.mo.gov 
National Council on Teacher Quality. (2019). NCTQ data burst: Teacher leadership opportunities. Retrieved from: nctq.org

Noffke, S., \& Brennan, M. (2005). The dimensions of reflection: A conceptual and contextual analysis. International Journal of Progressive Education, 1, 58-78.

Perrachione, B., Petersen, G., Rosser, V. (2008). Why do they stay? Elementary teachers' perceptions of job satisfaction and retention. The Professional Educator, 32(2), 25-41.

Pfitzner-Eden F. (2016). Why do I feel more confident? Bandura's sources predict preservice teachers' latent changes in teacher self-efficacy. Frontiers in Psychology, 7, 1486.

Podolsky, A., Kini, T., Bishop, J., \& Darling-Hammond, L. (2016). Solving the Teacher Shortage: How to Attract and Retain Excellent Educators. Palo Alto, CA: Learning Policy Institute.

Priddis, L., \& Rogers, S. (2018). Development of the reflective practice questionnaire: preliminary findings. Reflective Practice, 19(1), 89-104.

Rahimi, M., \& Weisi, H. (2018). Reflective practice, self-efficacy, and research practice of EFL teachers: Examining possible relationships. Issues in Educational Research, 28(3), 756780.

Redding, C., \& Smith, T. (2016). Easy in, easy out: Are alternatively certificated teachers turning over at increased rates? American Educational Research Journal, 53(4), 10861125. doi.10.3102/0002831216653206

Reeves, D. (2018) Seven keys to restoring the teacher pipeline. Educational Leadership, 75(8). Retrieved from ascd.org/publications/educational leadership/may18/vol75/num08/SevenKeys-to-Restoring-the-Teacher-Pipeline.aspx 
Rogers, S. Priddis, L., Michels, M., Tieman, M., \& Van Winkle, L. (2019). Applications of the reflective practice questionnaire in medical education. BMC Medical Education,19(47), $1-11$.

Ronfeldt, M., Loeb, S., \& Wyckoff, J. (2013). How teacher turnover harms student achievement. American Educational Research Journal, 50(1), 4-36. doi.10.3102/0002831212463813

Sass, D., Seal, K., \& Martin, N. (2010). Predicting teacher retention using stress and support variables. Journal of Educational Administration, 49(2), 200-215.

Schön, D. (1983). The reflective practitioner: How professionals think in action. London: Temple Smith.

Skaalvik, E., \& Skaalvik, S. (2007). Dimensions of teacher self-efficacy and relations with strain factors, perceived collective teacher efficacy and teacher burnout. Journal of Educational Psychology, 99, 611-625.

Skaalvik, E., \& Skaalvik, S. (2010). Teacher self-efficacy and teacher burnout: a study of relations. Teaching and Teacher Education, 26, 1059-1069.

Sorensen, L., \& Ladd,H. (2018). The hidden costs of teacher turnover (Working Paper No. 2030918-1). Retrieved from: files.eric.ed.gov/fulltext/ED591843.pdf

Strauss, V. (2017, November 27). Why it's a big problem that so many teachers quit-and what to do about it. Washington Post. Retrieved from: washingtonpost.comm/news/answersheet/wp/2017/11/27/why-its-a-big-problem-that-so-many-teachers-quit-and-what-to-doabout-it/

Strunk, K., \& Robinson, J. (2006). Oh won't you stay: A multilevel analysis of the difficulties in retaining qualified teachers. Peabody Journal of Education, 81(4), 65-94. 
Sutcher, L., Darling-Hammond, L., \& Carver-Thomas, D. (2016). A coming crisis in teaching? Teacher supply, demand, and shortages in the USA. Palo Alto, CA: Learning Policy Institute.

Taie, S., \& Goldring, R. (2018). Characteristics of public elementary and secondary school teachers in the United States: Results from the 2015-16 national teacher and principal survey first look (NCES 2017-072rev). U.S. Department of Education. Washington, DC: National Center for Education Statistics. Retrieved: nces.ed.gov

Taylor, E. (2009). Fostering transformative learning. In J. Mezirow, E. Taylor, \& Associates (Eds.), Transformative learning in practice: Insights from community, workplace, and higher education (pp. 3-1731). San Francisco, CA: Jossey-Bass.

Thompson, N., \& Pascal, J. (2012). Developing critically reflective practice. Reflective Practice: International and multidisciplinary perspectives, 13, 311-325.

Thoonen, E., Sleegers, P., Oort, F., Peetsma, T., \& Geijsel, F. (2011). How to improve teaching practices: The role of teacher motivation, organizational factors, and leadership practices. Educational Administration Quarterly, 47(3), 496-536.

Tschannen-Moran, M., Woolfolk Hoy, A., \& Hoy, W. (1998). Teacher efficacy: Its meaning and measure. Review of Educational Research, 68(2), 202-248.

Tschannen-Moran, M., \& Woolfolk Hoy, A. (2001). Teacher efficacy: Capturing an elusive construct. Teaching and Teacher Education, 17, 783-805.

van Manen, M. (1995). On the epistemology of reflective practice. Teachers and Teaching: Theory and Practices, 1(1), 33-50

Viel-Ruma, K., Houchins, D., Jolivette, K., \& Benson, G. (2010). Efficacy beliefs of special educators: The relationships among collective efficacy, teacher self-efficacy, and job 
satisfaction. Teacher Education and Special Education: The Journal of the Teacher Education Division of the Council for Exceptional Children, 33, 225-233.

Warin, J., Maddock, M., Pell, A., \& Hargreaves, L. (2006). Resolving identity dissonance through reflective and reflexive practices in teaching. Reflective Practice, 7, 233-245.

Woolfolk, A., \& Hoy, W. (1990). Prospective teachers' sense of efficacy and beliefs about control. Journal of Educational Psychology, 82(1), 81-91.

Woolfolk, A., Rosoff, B., \& Hoy, W. (1990) Teachers' sense of efficacy and their beliefs about managing students. Teaching and Teacher Education, 6, 137-148.

Woolfolk Hoy, A. \& Burke Spero, R. (2005) Changes in teacher efficacy during the early years of teaching: A comparison of four measures. Teaching and Teacher Education, 21, 343356.

Yost, D. (2006). Reflection and self-efficacy: Enhancing the retention of qualified teachers from a teacher education perspective. Teacher Education Quarterly, 33(4), 59-76.

Zee, M., \& Koomen, H. (2016). Teacher self-efficacy and its effects on classroom processes, student academic adjustment, and teacher well-being: A synthesis of 40 years of research. Review of Educational Research, 86(4), 981-1015. 
SECTION FIVE: CONTRIBUTION TO SCHOLARSHIP 
Missouri Teacher Academy: Supporting teacher retention by increasing self-efficacy, reflective capacity, and job satisfaction through effective professional development

Proposed submission to: Teaching and Teacher Education 


\begin{abstract}
Teacher attrition is a main contributor to teacher shortages; providing effective professional development leading to increases in self-efficacy, reflective capacity, and job satisfaction may support teacher retention. Effective professional development, self-efficacy, reflective practice, and job satisfaction are all directly related to teacher retention. This study evaluated the Missouri Teacher Academy, which is a state-level program implemented to provide effective professional development for teachers. The study evaluated the impact of Missouri Teacher Academy on level of teacher (a) self-efficacy, (b) reflective capacity, and (c) job satisfaction. The results indicated Missouri Teacher Academy increased levels of teacher self-efficacy, reflective capacity, and job satisfaction with large effect sizes seen for all three constructs.

\section{Keywords}

professional development, teacher efficacy, reflective capacity, job satisfaction, and retention
\end{abstract}




\section{Introduction}

Teacher shortage solutions often focus on recruiting more teachers to the career (Borman \& Dowling, 2008; Ingersoll, 2003). Many recruitment strategies lead to lowering career entry criteria or decreasing standards of quality in order to increase the pool of teachers from which to fill teacher vacancies (Borman \& Dowling, 2008; Redding \& Smith, 2016). Regardless of the number of teachers joining the profession, those dissatisfied with the career continue to leave (Carver-Thomas \& Darling-Hammond, 2017; Ingersoll, 2001; Ingersoll \& Smith, 2003; Sutcher, Darling-Hammond, \& Carver-Thomas, 2016) with non-retirement attrition a main driver of the teacher shortage crisis (Carver-Thomas \& Darling-Hammond, 2017; Darling-Hammond, 2003; Garcia \& Weiss, 2019a; Gray, Tai, \& O’Rear, 2015; Ingersoll \& Smith, 2003; Reeves, 2018; Sutcher et al., 2016; Strunk \& Robinson, 2006). Teachers leaving the career is a greater concern than recruiting more people to it (Darling-Hammond, 2003); the very best teachers are the most likely to exit classrooms well before retirement (Jacob, Vidyarthi, \& Carroll, 2012). When deciding to continue in the career, teachers, like other professionals, evaluate if the career "remains the most attractive in terms of compensation, working conditions, and intrinsic rewards” (Guarino, Santibáñez,„\& Daley, 2006, p. 186). As challenges outweigh rewards, teachers leave looking for a better challenge-reward balance (Borman \& Dowling, 2008).

Valuing quantity at the expense of quality weakens systemic structures, affects the quality of education students receive, and "won't stem the costly exodus of teachers that is undercutting our nation's ability to provide every child with quality teaching in a school organized for success" (Carroll, 2007, p. 2). Strategies for retaining teachers must be included in efforts aimed at solving the teacher shortage. Effective professional development, self-efficacy, reflective practice, and job satisfaction all correlate to teacher retention. Programs focused on increasing teacher self-efficacy, reflective capacity, and job satisfaction may provide protections 
against burn-out and support teacher retention in a career of constantly changing challenges (Garcia \& Weiss, 2019; Ingersoll, 2003; and Podolsky, Kini, Bishop, \& Darling-Hammond, 2016). Missouri's Teacher Academy is one such program included in Missouri's consolidated state plan, which mentions "state-sponsored professional learning [that] includes a Teacher Academy that provides teachers the opportunity to improve their instructional practice within a statewide network of teachers" (Missouri DESE, 2017, p. 46-47). The program also falls under the Missouri DESE's Teacher Workforce Outreach Plan (2020) with included effective professional development as a state-level teacher retention strategy. As a state-level educational initiative, Missouri Teacher Academy operates under the authority and direction of the Missouri Department of Elementary and Secondary Education (DESE) in cooperation with the state's Regional Professional Development Centers (RPDCs). This inter-organizational alliance represents a systemic networking of entities working jointly to fund, develop, facilitate, promote, support, and evaluate this teacher support program, which impacts teachers from all regions within Missouri.

\section{Context of the Evaluation}

Missouri Teacher Academy is supported and promoted by the Missouri DESE with program facilitation occurring through Missouri's nine RPDCs, which were applauded in research as an effective method for providing professional learning and supports for teachers across the state (Jaquith et al., 2010). The RPDCs employ educational consultants with extensive backgrounds in education, many with $>25$ years of experience serving Missouri's schools as administrators, counselors, and teachers. Missouri Teacher Academy is an intensive eight to nine month long transformational learning experience for mid-career teachers.

Participants attend two state conference sessions, learning with national author and speaker, John 
Antonetti. The experiences provide a retreat-like setting to promote personal and group reflection while participating in engaging and rigorous professional learning. Additionally, each RPDC region offers six full days (48 hours) of regional cohort learning and guidance for the completion of an action-research classroom project, which is shared regionally and submitted to the Missouri DESE.

Missouri Teacher Academy aligns to research-based teacher development structures of the Every Student Succeeds Act (ESSA), including building systems of professional learning and using modalities designed to empower educators, such as lesson study, action research, appraisal, and feedback, (Darling-Hammond, Burns, Campbell, Goodwin, Hammerness, Ee-Ling Low, McIntyre, Sata, \& Zeichner, 2017). Current program outcomes include: (a) supporting teacher retention through development of self-efficacy, reflective capacity, and job satisfaction; (b) promoting teacher empowerment; and (c) creating regional and state-level teacher networks. Program learning is competency-based with priority areas including: (a) using data to make decisions, (b) engaging in on-ongoing reflective practice, (c) working in a community of practice, and (d) engaging students in content. Increasing teacher self-efficacy in instructional strategies and engaging students in content are central to academy learning, as is fostering reflective practice with an emphasis on building teacher reflection in- and for- practice. Reflective journaling, questioning, and a classroom-based action research project conducted from a lesson study cycle framework are used by teachers to evaluate the effectiveness of their use of instructional and engagement strategies. Teachers implement their learning within the classroom, use multiple sources of data to evaluate the effectiveness of instruction, reflect upon their impact on student learning, and adapt practices based on new learning. Teachers reflect on the efficacy of their own practice while simultaneously engaging in risk-taking with the use of 
emerging research and innovative practices. The experience offers opportunities for teachers to build communities of practice both regionally and state-wide.

\section{Theoretical Framework}

Providing teachers with professional development is an important teacher retention strategy (Carroll, 2007; Garcia \& Weiss, 2019e; Guarino et al, 2006; Podolsky et al, 2016). Characteristics of effective professional development for teachers (Croft et al., 2010; DarlingHammond, Burns et al., 2017; Darling-Hammond, Hyler et al., 2017; Gates Foundation, 2014; Hirsh, 2019) are widely known, and focus on learning that is: (a) sustained in duration, (b) embedded in adult learning theory, and (c) is job embedded. These characteristics include emphasizing the development of teacher reflective practice (Darling-Hammond, Burns et al., 2017).

Teacher reflective practice is known to be related to increases in teacher self-efficacy (Stallions, Murrill, and Earp, 2012), and both teacher self-efficacy and reflective practice have been found to be related to teacher retention (Kelley, 2004; Yost, 2006). Teacher self-efficacy and reflective practice have also been found to have significant relationships to each other (Babaei, \& Abednia, 2016), and engaging in reflective practice fosters the development of professional self-efficacy in teachers (Stallions, Murrill, and Earp, 2012). There is overwhelming support for the relationship between self-efficacy and job satisfaction (Ingersoll, 2001; Johnson, Berg, \& Donaldson, 2005; Pfitzner-Eden, 2016). Given the strong relationships between reflective practice and self-efficacy and their connections to job satisfaction and retention (see Figure 1) developing programs to increase teacher self-efficacy and/or reflective practice may indirectly support teacher retention. 


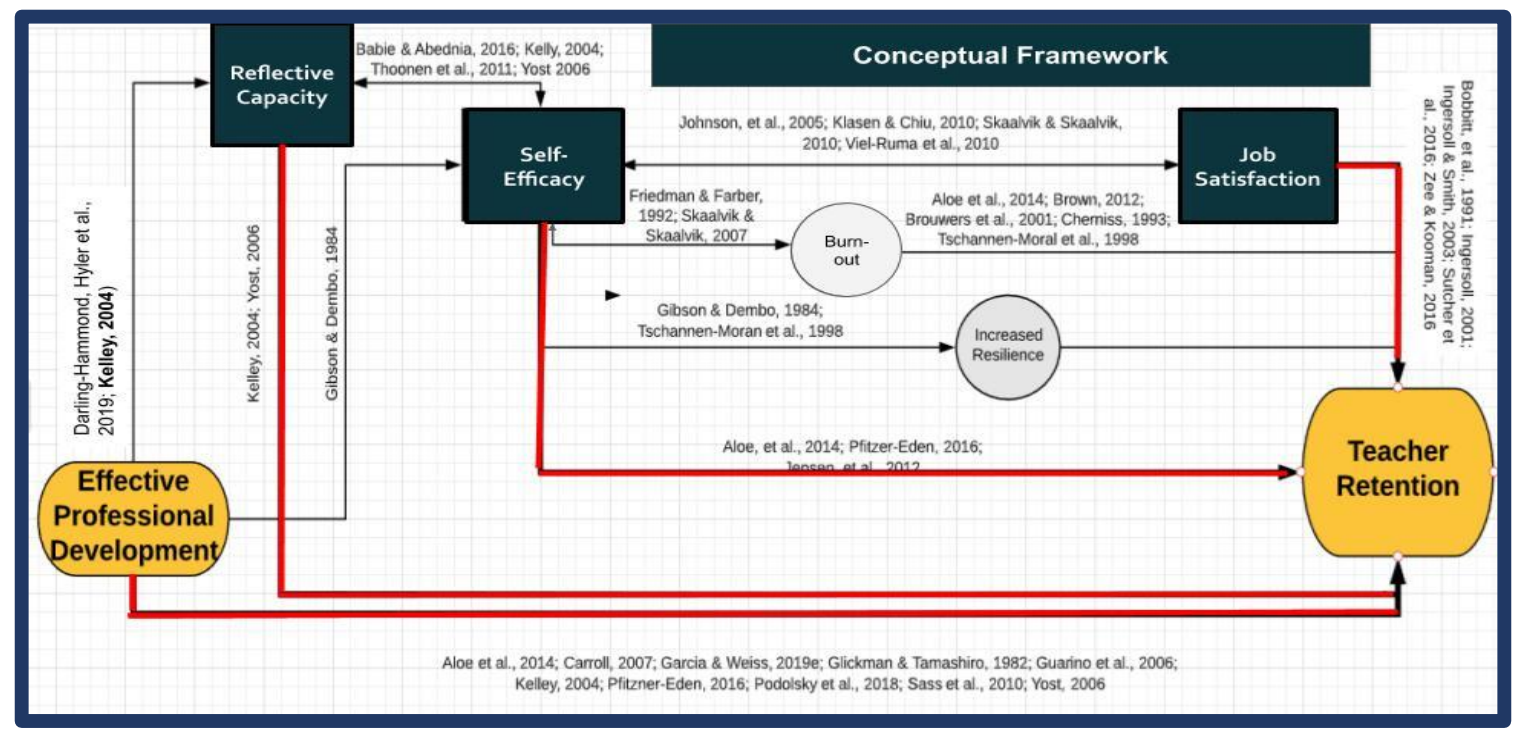

Figure 1. Conceptual framework showing the relationships among constructs

\section{Effective Professional Development}

Effective professional development is an important part of recruitment and retention plans designed to decrease the teacher shortage (Garcia \& Weiss, 2019e; Guarino et al., 2006;

Podolsky et al., 2016; Carroll, 2007) by "strengthening the teaching workforce" (Garcia \&

Weiss, 2019e, p.28). Professional development provides an opportunity for teachers to increase their knowledge and skills and gain important strategies for meeting the needs of their students (Garcia \& Weiss, 2019e). Like other professional careers, there is an expectation of continual learning and growth throughout the teaching career. Professional development increases levels of professionalism of the career and promotes career advancement for teachers (Garcia \& Weiss, 2019e), "which would make teaching a more appealing profession (and may mitigate some of the other factors driving the teacher shortage, such as tough working environments)" (Garcia \& Weiss, 2019e, p. 8).

Sustained duration. "Professional learning must be sustained to have an impact" (Darling-Hammond, Hyler, et al., 2017, p. 15) and include "opportunities to apply learning in the classroom" (Darling-Hammond, Hyler, et al., 2017, p.15). While there is no specific definition 
of the best duration for professional learning, it is defined by Darling-Harmmond, Hyler et al. (2017) as allowing teachers "adequate time to learn, practice, implement, and reflect upon new strategies that facilitate changes in their practice" (Darling-Hammond, Hyler et al., 2017, p. vi). It is discussed in terms of weeks, months, or years (Darling-Hammond, Hyler et al., 2017). In addition to thinking about duration from the lens of a single learning experience, sustained duration can be thought of systemically with the creation of progressive, connected learning that spans across the career and aligns to teacher preparation and evaluation, as well as to school leadership learning systems (Darling-Hammond, Hyler, et al., 2017).

Adult learning theory. Effective professional development for teachers is designed with an understanding of how teachers learn and provides active learning based on adult learning theories (Darling-Hammond, Hyler et al., 2017) that invite the "whole person into the [learning] environment" (Taylor, 2009, p. 11) and "treats teachers like professionals" (Gates Foundation, 2014, p.4). Effective professional development recognizes, that teachers "are self-directed" (Chen, 2014, p.407) and allows the teacher to experience self-identification of their needed areas of growth. Within the understanding of recognizing teachers as self-directed professionals, it is not surprising effective teacher learning is: (a) relevant (Darling-Hammond, Hyler et al., 2017; Gates Foundation, 2014); (b) teacher-lead (Darling-Hammond, Burns et al., 2017); and (c) content-based (Croft et al., 2010; Darling-Hammond, Burns et al., 2017; Darling-Hammond, Hirsh, 2019; Hyler, et al., 2017; Garcia \& Weiss, 2019e; Gates Foundation, 2014), including "learning activities that directly support teacher practice, such as planning and reflecting on instruction..., as they tap into their motivation to help students learn" (Gates Foundation, 2014, p. 11). 
Collaboration. Wide agreement exists on the inclusion of collaboration within discussions of effective professional development (Croft et al., 2010; Darling-Hammond, Burns et al., 2017; Darling-Hammond, Hyler et al., 2017; Gates Foundation, 2014; Hirsh, 2019) with "collective work in trusting environments provid[ing] a basis for inquiry and reflection into teachers' own practices, allowing teachers to take risks, solve problems, and attend to dilemmas in their practice" (Darling-Hammond, Hyler, et al., 2017, p. 10). This thinking aligns to Bruffee's (1999) thoughts on conversation as learning, however it is important for those working with teachers to understand that, "if the talk within the knowledge communities we are members of is narrow, superficial, biased, or limited to clichés, our thinking is almost certain to be so, too" (Bruffee, 1999, p. 134). Rather than seeking for teacher conformity, collaborative learning should seek to build, "a sense of trust in the process of dialogue with others, creating a setting that helps learners live with some discomfort while on the edge of knowing, in the process of gaining new insights and understanding" (Taylor, 2009, p.10).

Cultural awareness. Creating trust within a collaborative learning environment includes the development of a cultural awareness. Teacher professional development recognizing this will include strategies such as Cueva's (2010) strategies for fostering cultural awareness in adult learning environments: (a) "learning as respectful engagement" (p. 83); (b) "sharing power" (p.83); (c) "talking story” (p.86); and (d) "embracing learning through laughter" (p. 87). Facilitators of effective professional development for teachers would understand that "learning involves growth and change which is often disoriented and painful" (Cueva, 2010, p. 81). In addition to creating supportive and trusting collaborative learning environments for teachers, effective professional development allows job-embedded time and space needed for reflective 
processing and the use of lesson study frameworks (Darling-Hammond, Burns et al., 2017; Darling-Hammond, Hyler et al., 2017; Gates Foundation, 2014).

Job-embedded learning. Professional development that works for teachers is not only on-going and designed for adult learners, but also relevant to the work of the teacher so new learning can be applied and practiced within the classroom. It is job-embedded (Croft et al., 2010; Darling-Hammond, Hyler et al., 2017; Hirsh, 2019), including a variety of strategies and modalities, including: (a) teacher action research (Croft et al., 2010; Darling-Hammond, Burns et al., 2017; Kelley, 2004; Yost, 2006); (b) coaching (Croft et al., 2010; Darling-Hammond, Burns et al., 2017; Darling-Hammond, Hyler et al., 2017; Garcia \& Weiss, 2019e; Gates Foundation, 2014) delivered by someone who "is not the same person who does my evaluation" (Gates Foundation, 2014, p.7); (c) mentoring (Garcia \& Weiss 2019e); (d) collaborative teams (Croft et al., 2010; Darling-Hammond, Hyler et al., 2017; Kraft, et al., 2018; Gates Foundation, 2014); (e) student work analysis (Croft et al., 2010; Darling-Hammond, Burns, et al., 2017); and (f) lesson study (Croft et al., 2016; Darling-Hammond, Burns et al., 2017). Incorporating jobembedded learning requires, "common effort across all three levels: states, districts, and schools" (Croft et al., 2010, p. 12) to create the conditions for teacher learning, including the identification and development of skilled facilitators, common vocabulary, development of systems for monitoring, and creating a culture of continued learning" (Croft et al., 2010).

\section{Teacher Self-Efficacy}

Teacher self-efficacy can be thought of as how much a teacher believes "s/he is able to teach even the most difficult and unmotivated students, and [it] involves many dimensions of teacher practices" (Aloe, Amo, Shanahan, 2014, p.105). Teacher self-efficacy affects teachers' sense of accomplishment (Brouwers, Evers, \& Tomic, 2001; Goddard, Hoy, \& Woolfolk Hoy, 
2004), which then informs belief of self, leading to behaviors which impact students (Goddard et al., 2004), such as increases in the quality of classroom management (Woolfolk \& Hoy, 1990) and planning and organization (Allinder, 1994). Teacher self-efficacy affects the goals teachers have for students (Muijs \& Reynolds, 2002). Teachers with high levels of self-efficacy have been found to be less controlling (Woolfolk \& Hoy, 1990; Woolfolk, Rosoff, \& Hoy, 1990) and critical (Ashton \& Web, 1986) of students. Additionally, teacher self-efficacy is related to openness to innovation (Guskey, 1988) and the use of integrative (Smylie, 1988), creative (Thurlings, Evers, \& Vermeulen, 2015), and effective teaching methods, such as the use of grouping structures (Gibson \& Dembo, 1984).

A strong relationship exists between self-efficacy and burn-out (Skaalvik \& Skaalvik, 2007) with levels of teacher self-efficacy working to protect teachers from burning out (Aloe et al., 2014; Schwerdtfeger et al., 2008). Unfortunately, the extent of the connection between the mitigating effects of self-efficacy on teacher burn-out are not clear (Friedman, 2003), and more research is needed in this area. However, evidence supports the connection between these constructs with Aloe et al. (2014) finding, "a significant relationship between classroom management self-efficacy and the three dimensions of burnout, suggesting that teachers with higher levels of [classroom management self-efficacy] CMSE are less likely to experience the feelings of burnout" (p. 101).

While higher levels of self-efficacy seem to support retention by protecting teachers from burnout (Aloe et al., 2014), the converse seems to also be true with lower levels of self-efficacy associated to higher levels of attrition (Jensen, Sandoval-Hernandez, Knoll \& Gonzalez, 2012). Although low levels of self-efficacy may contribute to a teacher leaving the profession, it is possible to increase teacher self-efficacy through teacher development, which positively impacts 
level of resilience (Gibson \& Dembo, 1984) and reduces thoughts of leaving the career (PfitznerEden, 2016). Teacher self-efficacy beliefs are known to vary in relation to the wide variety of variables found within the classroom environment (Tschannen-Moran, Woolfolk-Hoy, \& Hoy, 1998). Teacher self-efficacy is known to be positively related to job satisfaction (Caprara, Barbaranelli, Steca, \& Malone, 2006; Collie, Shapka, \& Perry, 2012; Skaalvik \& Skaalvik, 2010; Zee \& Koomen, 2016) as "high TSE beliefs, and in particular those that go beyond the instructional domain, seem to help teachers stay motivated, satisfied, and consequently on the job" (Zee \& Koomen, 20016, p. 1009).

\section{Reflective Practice}

Reflection "enables teachers to stop, look, and discover where they are at that moment and then decide where they want to go (professionally) in the future" (Farrell, 2012, p.7). Reflective teaching practice, is multidimensional with the merging of temporal thinking and identify formation through the use of visualization within temporal and contextual considerations. It involves teachers intentionally thinking about their own teaching practice (Dewey, 1933) and is not limited to reviewing past events (Conway, 2001). Rather it is inclusive of all temporal dimensions and involves looking at the past and present coupled with looking to the future (van Manen, 1995) through an active processing of all three simultaneously with conclusions used for decision-making and direct-setting (Farrell, 2012). The process includes understanding of the past, awareness of the moment (Schön,1983), and the ability to predict (van Manen, 1995). In addition to being able to adapt to and for situations, reflective practice includes ideas of understanding, adapting, and predicting self (Freese, 2006; Urzúa \& Vásquez, 2008; Sutherland, Howard, \& Markauskite, 2010) in light of considering past, present, and future experiences (Conway, 2001). 
Reflective practice is positively correlated to self-efficacy (Babaei, \& Abednia, 2016; Rahimi \& Weisi, 2018), however, it is unclear as to how they are reacting on each other. In Kelley (2004), participants were asked to engage in reflective processing during an actionresearch project with the outcomes of the study revealing increases in participant self-efficacy. The use of reflection as a mechanism to increase self-efficacy is further found in Awkard's (2017) work outlining suggestions on how to build self-efficacy through the use of reflective strategies. Reflective practice is noted to lead to increases in self-efficacy, however, the opposite has also been noted. Thoonen, Sleegers, Oort, Peetsma, and Geijsel (2011) connected teacher motivation, specifically teacher self-efficacy, to teacher learning activities, which included reflection, revealing "when teachers believe stronger in their capabilities to achieve a desired result, they are more engaged in professional learning activities" (514). These findings provided insights into the reversal effect of self-efficacy's influence on reflective practice.

\section{Summary}

With well-established correlations between self-efficacy and factors associated with teacher retention: (a) job satisfaction (Klassen \& Chiu, 2010; Perrachione, Rosser, \& Peterson, 2008; Skaalvik \& Skaalvik, 2010; Viel-Ruma, Houchins, Jolivette, \& Benson, 2010; Zee \& Koomen, 2016); and (b) burnout (Aloe et al., 2014; Brown, 2012; Brouwers et al., 2001; Cherniss, 1993; Schwerdtfeger, et al., 2008; Skaalvik \& Skaalvik, 2007; Skaalvik and Skaalvik, 2010; Tschannen-Moran, et al., 1998); and (c) attrition (Pfitzner-Eden, 2016), as well as the known relationship between self-efficacy and reflective practice (Babaei, \& Abednia, 2016; Rahimi \& Weisi, 2018) a case can be made for combining these constructs when investigating the impacts of Missouri Statewide Teacher Academy on teacher self-efficacy, reflective capacity, and job satisfaction from the lens of identifying the program's potential as a state-level 
professional development intervention to indirectly support teacher retention through the development of teacher self-efficacy and reflective capacity.

\section{Purpose of Current Study}

Missouri Teacher Academy was recently included in the National Council on Teacher Quality (2019) state analyses of teacher leadership development where the program was noted to "provide a strong model for leadership development" (p. 6). The program has the potential to serve as a national model for states seeking ways to use career development to support teacher retention, which could "make a greater difference in balancing supply and demand than any other intervention" (Sutcher et al., 2016, p. 37). Program impact has been measured in the past through participant and principal surveys with data consistently revealing evidence of perceived changes in teacher practice. Prior informal collections and analysis of qualitative data by program facilitators, including open-ended survey questions and evaluation of participant projects revealed improvement in teacher practice, specifically in teacher use of: (a) instructional strategies, (b) engagement strategies, and (c) reflective practice.

Other than a presentation paper (Belcher \& Vinson, 1997) discussing the first year of Missouri Teacher Academy, no peer-reviewed published research studies specifically evaluating statistical relationships between participation in Missouri Teacher Academy and level of teacher self-efficacy, reflective capacity, and/or job satisfaction were found. This study was conducted in order to evaluate the impact of Missouri Teacher Academy on factors related to teacher retention: (a) teacher self-efficacy (Sass, Seal, \& Martin, 2010; Yost, 2006), (b) reflective practice (Kelley, 2004; Yost, 2006), and (c) job satisfaction (Ingersoll \& Smith, 2003; Sutcher, et al., 2016; Strunk \& Robinson, 2006; Zee \& Koomen, 2016). The following research question 
was addressed: What impact does Missouri Teacher Academy have on level of teacher selfefficacy, reflective capacity, and job satisfaction?

\section{Methods}

From an impact evaluation approach, this quantitative study was conducted utilizing a one-group pretest-posttest survey design (Creswell, 2014). Data were compared to archival data collected from an identical survey taken by participants $(n=22)$ in Fall 2019 prior to attending Missouri Teacher Academy. Informed consent was completed, which outlined that participation was voluntary and did not affect the participant's position in Missouri Teacher Academy, relationship with their facilitator, or their employment in any way.

\section{Participants}

Purposive sampling (Fink, 2017) was employed with candidates asked to complete a survey at the completion of the Missouri Teacher Academy in Spring 2020. Missouri Teacher Academy participants are required to have at least three years of teaching experience and have been identified as effective teachers with a desire for continued growth. The study included 22 Missouri Teacher Academy participants of tested content areas, which included teachers of English Language Arts (50\%), Math (22.7\%), and Science (27.3\%). The majority of participants (86.4\%) were women. Greater than $70 \%$ of participants indicated teaching in a rural district with $13.6 \%$ teaching in suburban, and only $9.1 \%$ teaching in an urban district. Additionally, greater than $75 \%$ of the teachers were noted to be middle (45.5\%) or high school teachers $(31.8 \%)$. Missouri Teacher Academy is intended to be a mid-career teacher support, so it is not surprising that $54.5 \%$ of the participants had between six and 15 years of experience. 


\section{Data Collection \& Instruments}

Data were collected using an instrument (Appendix D) comprised of two subscales from the Teacher Self-Efficacy Scale (TSES) (Tschannen-Moran \& Woolfolk Hoy, 2001): (a) efficacy in instructional strategies, and (b) efficacy in student engagement; and four subscales included in the dimension of reflective capacity, as well as the job satisfaction subscale, from the Reflective Practice Questionnaire (RPQ) (Priddis \& Rogers, 2018; Rogers et al., 2019). The reflective capacity subscales included were: (a) reflecting-on-action, (b) reflecting-in-action, (c) reflecting with others, and (c) self-appraisal.

Heneman, Kimball, and Milanowski (2006) tested the construct validity and reliability of the TSES (Tschannen-Moran \& Woolfolk Hoy, 2001) and asserted "the TSES should be the preferred measure of teachers' sense of efficacy in future research" (Heneman et al., 2006, p. 13). The RPQ closely aligns to the study conceptual framework and "can be utilized for education where students and practitioners complete the questionnaire as part of their own self-reflection and professional development" (Rogers et al., 2019, p 8). The tool "was designed for flexible use across different professions” (Rogers et al., 2019, p. 4). The RPQ is a new instrument, however, it has been found to be reliable in initial studies across different career contexts (Priddis \& Rogers, 2018; Rogers et al., 2019), as well as within the general population (Priddis \& Rogers, 2018), with the tool revealing acceptable internal consistency with each administration. Instrument subscales are directly aligned with the body of research and factor analysis has been conducted (Rogers et al., 2019).

\section{Instruments}

Teacher self-efficacy. Teacher self-efficacy was measured by the Teacher Self-Efficacy Scale (TSES) using two of the three long-form subscales: (a) efficacy in instructional strategies, and (b) efficacy in student engagement (Tschannen-Moran \& Woolfolk Hoy, 2001). It is noted 
that this instrument can be used to assess efficacy with subscale scores and/or total scale scores (Tschannen-Moran \& Woolfolk Hoy, 2001). Each subscale included eight items for a total of 16 items. A five-point Likert scale was used for the TSES subscales with responses ranging from "none at all" (1) to "a great deal" (5). Examples of items are: "How well can you implement alternative strategies in your classroom?" (efficacy in instructional strategies) and "How much can you do to get students to believe they can do well in school work?" (efficacy in student engagement). Reliabilities for these subscales have been reported as .87 for engagement and .91 for instruction (Tschannen-Moran \& Woolfolk-Hoy, 2001).

Reflective capacity. Reflective capacity was measured by the Reflective Practice Questionnaire (RPQ) (Priddis \& Rogers, 2018; Rogers et al., 2019), which measures reflective capacity using four subscales: (a) reflecting in action; (b) reflecting on action; (c) reflecting with others; and (d) self-appraisal. While the RPQ is a new instrument, it has been found to be reliable in initial studies across different career contexts (Priddis \& Rogers, 2018; Rogers et al., 2019), as well as within the general population (Priddis \& Rogers, 2018), with the tool revealing acceptable internal consistency, with each administration. The RPQ was piloted within a general population sample with a Cronbach's alpha $>0.82$ for all sub-scales. A follow-up study conducted with mental health practitioners revealed Cronbach's alpha $>0.70$ for all subscales except for job satisfaction, which was 0.68 ; "results provide evidence that the RPQ contains internally consistent items for assessing domains of reflection that are relevant to reflective supervision practices in work settings" (Priddis, 2018). An additional study (Rogers et al., 2019) was conducted using the scale to measure reflective capacity of medical students and was found to be reliable in medical students with Cronbach's alpha 0.84 ; factor analysis was also conducted. Results of this study state the "RPQ can be utilized for education where students and 
practitioners complete the questionnaire as part of their own self-reflection and professional development" (para 44). Each subscale included four items; a six-point Likert response scale was used for with response options ranging from "not at all" (1) to "extremely" (6). In this study the word clients was changed to student to represent the educational context of the study. An example item is: "After interacting with students I wonder about the student's experience of the interaction" (reflecting-on-action).

Job satisfaction. For this study, level of job satisfaction was measured using the job satisfaction subscale of the RPQ (Priddis \& Rogers, 2018; Rogers, Priddis, Michels, Tieman, \& Van Winkle, 2019). For this study, job satisfaction was defined according to the definition asserted by Priddis \& Rogers (2018) in relationship to the Reflective Practice Questionnaire (RPQ) (Priddis \& Rogers, 2018; Rogers et al., 2019). This subscale asks respondents to evaluate: (a) level of fulfilment gained through participation in their job, (b) the extent to which they value their work beyond the extrinsic motivation of monetary gain, (c) how much enjoyment they receive from engaging in their work, and (d) level of motivation for attending their job (Priddis \& Rogers, 2018; Rogers et al., 2019). A sample item is: "My work provides me with a lot of fulfillment" (job satisfaction) and responses were given on a 6-point scale from "not at all" to "extremely".

\section{Data Analysis}

Paired samples $t$-tests were conducted to compare pre- and post- attendance means for self-efficacy, reflective capacity, and job satisfaction. To control for Type I error within this small sample, as well as given that a total of nine analyses were performed on the same data set, a Bonferroni-corrected level of significance for all analyses was established as $p<0.006$. 


\section{Results}

Self-efficacy. A paired-samples $t$-test was conducted to compare pre-academy selfefficacy and post-academy self-efficacy. Given the small sample size of $n=21$, the assumption of normally distributed difference was confirmed with Shapiro Wilk of $p=.242$. The assumption of normality was further satisfied, as skew and kurtosis levels were 0.001 and -1.177 , respectively. Furthermore, strong, positive correlation was noted between pre-academy and post-academy level of self-efficacy with $r=0.74, p<0.001$, suggesting paired samples $t$-test was appropriate. There was a significant difference between pre-academy self-efficacy ( $M=3.62$, $S D=0.40)$ and post-academy self-efficacy $(M=4.3, S D=0.37) ; t(20)=-10.37, p<.001$. Cohen's $d=2.263$, which is considered a large effect size based on Cohen's (1992) guidelines (McLeod, 2019). Results indicate that there was a statistically significant increase in selfefficacy scores before and after the intervention. Data were analyzed by subscale to provide additional insights into the impact of Missouri Teacher Academy on level of teacher self-efficacy (see Table 1).

\section{Table 1}

Paired Sample T-tests Subscale Results Comparing Pre-and Post-Academy Self-Efficacy (SE)

\begin{tabular}{lccccccc}
\hline & $n$ & $M$ & $S D$ & $t$ & $d f$ & $p$ & $d$ \\
\hline (Pre)SE - Instructional Strategies & 22 & 3.63 & .44 & -7.81 & 21 & $<.001$ & 1.67 \\
(Post)SE- Instructional Strategies & 22 & 4.30 & .38 & & & & \\
(Pre)SE - Student Engagement & 22 & 3.65 & .50 & -5.63 & 21 & $<.001$ & 1.20 \\
(Post)SE - Student Engagement & 22 & 4.2502 & .48 & & & & \\
\hline
\end{tabular}

Note. Cohen's $d>0.8$, considered to show a large effect size (McCleod, 2019) is noted for self-efficacy as well as for both subscales. 
Reflective capacity. A paired-samples $t$-test was conducted to compare pre-academy reflective capacity and post-academy reflective capacity. Given the small sample size of $n=22$, the assumption of normally distributed difference was confirmed with Shapiro Wilk of $p=.164$. The assumption of normality was further considered to be satisfied, as skew and kurtosis levels were estimated at 0.379 and -1.030 , respectively. However, weak positive correlation between pre-academy reflective capacity and post-academy reflective capacity was noted with $r=0.336$. There was significant difference between pre-academy reflective capacity $(M=4.73, S D=0.51)$ and post-academy reflective capacity $(M=5.16, \mathrm{SD}=0.45) ; \mathrm{t}(21)=-3.59, p=.002$. Cohen's $d$ $=.765$, which is considered to be a medium effect size based on Cohen's (1992) guidelines (McLeod, 2019). Results indicate that there was a statistically significant increase in reflective capacity scores before and after the intervention. Reflective capacity data were analyzed by subscale (see Table 2).

Job satisfaction. A paired-samples $t$-test was conducted to compare pre-academy job satisfaction and post-academy job satisfaction. Given the small sample size of $n=22$, the assumption of normally distributed difference was confirmed with Shapiro Wilk of $p=.125$. The assumption of normality was further considered to be satisfied, as skew and kurtosis levels were estimated at .442 and .039 , respectively. Furthermore, strong positive correlation between pre-academy job satisfaction and post-academy job satisfaction was noted with $r=.775, p<$ .001 . There was a significant difference between pre-academy job satisfaction $(M=4.9, S D=$ $0.72)$ and post-academy job satisfaction $(M=5.26, S D=0.57) ; t(21)=-3.751, p=.001$. Cohen's $d=.8$, which is considered to be a large effect size based on Cohen's (1992) guidelines (McLeod, 2019). Results indicate that there was a statistically significant increase in job satisfaction scores before and after the intervention. 
Table 2

Paired Sample T-test Subscales Comparing Pre- and Post-Academy Reflective Capacity (RC)

\begin{tabular}{lccccccc}
\hline & $n$ & $M$ & $S D$ & $t$ & $d f$ & $p$ & $d$ \\
\hline $\begin{array}{l}\text { Pre)Reflecting-in-Action } \\
\text { (Post)Reflecting-in-Action }\end{array}$ & 22 & 4.33 & .70 & -4.798 & 21 & $<.001$ & 1.04 \\
(Pre)Reflecting-on-Action & 22 & 4.86 & .95 & -1.685 & 21 & .107 & .359 \\
(Post)Reflecting-on-Action & 22 & 5.16 & .65 & & & & \\
(Pre)Reflecting-with-Others & 22 & 4.93 & .60 & -1.715 & 21 & .101 & .366 \\
(Post)Reflecting-with-Others & 22 & 5.23 & .56 & & & & \\
(Pre)Self-Appraisal & 22 & 4.81 & .54 & -3.184 & 21 & .004 & .679 \\
(Post)Self-Appraisal & 22 & 5.20 & .52 & & & &
\end{tabular}

Note. Cohen's $d>0.5$, considered a medium effect size (McCleod, 2019) is noted for reflective capacity as well as for the self-appraisal subscale. Cohen's $d>0.8$, considered to show a large effect size (McCleod, 2019) is noted for reflecting-in-action.

\section{Discussion}

The results of the study indicated improvement in participant level of self-efficacy, reflective capacity, and job satisfaction from the beginning to the end of the Missouri Teacher Academy. Results showed increases in teacher self-efficacy in teachers who attended Missouri Teacher Academy with a large effect size noted. The 22 participants who attended the Missouri Teacher Academy increased their self-efficacy scores in instructional strategies. Self-efficacy in instructional strategies has been specifically noted to have a direct correlation to job satisfaction (Klassen \& Chiu, 2010). Given this relationship, known relationships between self-efficacy, job satisfaction and teacher retention, and the findings of this study, consideration of the role of 
Missouri Teacher Academy as a state-level program designed to support teacher retention through effective professional development is strengthened.

In addition to increases in teacher self-efficacy and job satisfaction, participants who attended Missouri Teacher Academy increased their scores on teacher reflective capacity with the greatest effect size noted for the difference in scores on the reflection-in-action subscale. Missouri Teacher Academy emphasizes teacher inquiry and encourages teachers to engage in reflective observations of their own practice during their instruction. This finding may support effectiveness of the program in increasing teacher reflective practice through these methods, however, given the limitations of the study,

This study has several limitations. One limitation of the study is the small sample size. Although statistically significant differences between pre- and post- program groups were identified, random sampling was not utilized and individual participant growth was only able to be evaluated for a small group. Further research within a larger sample would need to be conducted to substantiate these findings. A second limitation exists in the inability of this study to identify specific program elements which may be contributing to these findings. Qualitative studies, including focus groups and/or interviews, may be helpful in providing more details into specific structures and/or activities contributing to the program's impact on self-efficacy, reflective capacity, and/or job satisfaction. Another limitation of this study was the use of the RPQ (Priddis \& Rogers, 2018), which is a new instrument. While designed for use across professions, this study appears to be the first time it was utilized within an educational setting.

This study serves as an important first step in understanding potential impacts of Missouri Teacher Academy and contributes to research regarding the use of effective professional development as a state level retention strategy. Additionally, the study presents a 
conceptual framework connecting effective professional development to reflective capacity, selfefficacy, and job satisfaction as mechanisms for increasing teacher retention. Longitudinal studies to determine program impact and/or effectiveness over time are suggested to determine direct correlations between attending Missouri Teacher Academy and a teacher's decision to stay in the career. 


\section{References}

Aloe, A., Amo, L., \& Shanahan, M. (2014). Classroom management self-efficacy and burnout: a multivariate meta-analysis. Educational Psychology Review, 26(1), 101-126.

Ashton, P., \& Webb, R. (1986). Making a difference: Teachers' sense of efficacy and student achievement. New York, NY: Longman.

Awkard, T. (2017). The power of reflective action to build teacher efficacy. Kappan, 98(6), 5357.

Babaei, M., \& Abednia, A. (2016). Reflective teaching and self-efficacy beliefs: Exploring relationships in the context of teaching EFL in Iran. Australian Journal of Teacher Education, 41(9), 1-26.

Baldwin, B., (2006). A statewide network of teacher academies through the nine regional professional development centers. Missouri Department of Elementary and Secondary Education Professional Development Grant Proposal.

Belcher, C., \& Vinson, G. (1997, August) The Teachers' Academy: A Collaborative Approach to Preparing Teachers for Leadership Roles in the Public Schools. Paper presented at the Summer Workshop of the Association of Teacher Educators, Las Vegas, NV. Retrieved from https://files.eric.ed.gov/fulltext/ED412192.pdf

Borman, G., \& Dowling, N. (2008). Teacher attrition and retention: A meta-analytic and narrative review of the research. Review of Educational Research, 78(3), 367-409.

Brouwers, A., Evers, W., \& Tomic, W. (2001). Self-efficacy in eliciting social support and burnout among secondary school teachers. Journal of Applied Social Psychology, 31, 1474-1491. 
Brown, C. (2012). A systematic review of the relationship between self-efficacy and burnout in teachers. Educational and Child Psychology, 29(4), 47-63.

Bruffee, K. (1999). Collaborative Learning: Higher Education, Interdependence, and the Authority of Knowledge (2nded.). Baltimore, MD: The Johns Hopkins University Press.

Caprara, G., Barbaranelli, C., Steca, P., \& Malone, P. (2006). Teachers' self-efficacy beliefs as determinants of job satisfaction and students' academic achievement: A study at the school level. Journal of School Psychology, 44(6), 473-490.

Carroll, T. (2007). Policy Brief: The high cost of teacher turnover. Washington, D.C.: National Commission on Teaching and America's Future.

Carver-Thomas, D., \& Darling-Hammond, L. (2017). Teacher turnover: Why it matters and what we can do about it. Palo Alto, CA: Learning Policy Institute.

Chen, J. (2014). Teaching nontraditional adult students: Adult learning theories in practice. Teaching in Higher Education, 19(4), 406-418.

Cherniss, C. (1993). Role of professional self-efficacy in the etiology and amelioration of burnout. In W. B. Schaufeli, C. Maslach, \& T. Marek (Eds.), Series in applied psychology: Social issues and questions. Professional burnout: Recent developments in theory and research (pp. 135-149). Philadelphia, PA, US: Taylor \& Francis.

Collie, R., Shapka, J., and Perry, N., (2012). School climate and social-emotional learning: Predicting teacher stress, job satisfaction, and teaching efficacy. Journal of Educational Psychology,104(4), 1189-1204.

Conway, P. (2001). Anticipatory reflection while learning to teach: From a temporally truncated to a temporally distributed model of reflection in teacher education. Teaching and Teacher Education, 17, 89-106. 
Creswell, J. (2014). Research design: Qualitative, quantitative, and mixed methods approaches (4th ed.). Los Angeles, CA: Sage.

Cueva, M. (2010). A living spiral of understanding: Community-based adult education. New Directions for Adult and Continuing Education, 125, 79-90.

Darling-Hammond, L. (2003). Keeping good teachers: Why it matters and what leaders can do. Educational Leadership, 60(8), 6-13.

Darling-Hammond, L., Burns, D., Campbell, C., Goodwin, A., Hammerness, K., Low, E., McIntyre, A., Sato, M., \& Zeichner, K. (2017). Empowered educators: How highperforming systems shape teaching quality around the world. San Francisco, CA: Jossey Bass.

Darling-Hammond, L., Hyler, M., \& Gardner, M. (2017). Effective teacher professional development. Palo Alto, CA: Learning Policy Institute.

Dewey, J. (1933). How we think: A restatement of the relations of reflective thinking to the educative process (2nd revised ed.). Boston, MA: D.C. Heath.

Farrell, T. (2012). Reflecting on reflective practice: (Re)visiting Dewey and Schön. TESOL Journal, 3(1), 7-16.

Fields, A. (2018). Discovering statistics using IBM SPSS statistics (5th ed.). Thousand Oaks, CA: Sage.

Garcia, E., \& Weiss, E. (2019a). The teacher shortage is real, large and growing, and worse than we thought: The first report in 'the perfect storm in the teacher labor market' series. Washington, D.C.: Economic Policy Institute.

Garcia, E., \& Weiss, E. (2019e). The role of early career supports, continuous professional development, and learning communities in the teacher shortage: The fifth report in 'the 
perfect storm in the teacher labor market' series. Washington, D.C.: Economic Policy Institute.

Gibson, S., \& Dembo, M. (1984). Teacher efficacy: A construct validation. Journal of Educational Psychology, 76(4), 569-582.

Goddard, R., Hoy, W., \& Woolfolk Hoy, A. (2004). Collective efficacy beliefs: Theoretical developments, empirical evidence, and future directions. Educational Researcher, 33, 313.

Gray, L., Taie, S., \& O'Rear, S. (2015). Public school teacher attrition and mobility in the first five years: Results from the first through fifth waves of the 2007-08 beginning teacher longitudinal study (NCES 2015-337). U.S. Department of Education. Washington, DC: National Center for Education Statistics. Retrieved from: http://nces.ed.gov/pubsearch

Guarino, C., Santibáñez,, L., \& Daley, G. (2006). Teacher recruitment and retention: A review of the recent empirical literature. Review of Educational Research 76(2), 173-208.

Heneman, H., Kimball, S., \& Milanowski, A. (2006). The Teacher sense of efficacy scale: Validation evidence and behavioral prediction. WCER Working Paper No. 2006-7, Madison, WI: University of Wisconsin-Madison, Wisconsin Center for Education Research.

Hirsh, S. (2019). 4 cornerstones of professional learning: Fundamental principles pave the way for educators' actions. Oxford, OH: Learning Forward.

Ingersoll, R. (2001). Teacher turnover and teacher shortages: an organizational analysis. American Educational Research Journal, 38, 499-534.

Ingersoll, R. (2003). Is There Really a Teacher Shortage?. Retrieved from https://repository.upenn.edu/gse_pubs/133 
Ingersoll, R., \& Smith, T. (2003). The wrong solution to the teacher shortage. Educational Leadership, 60(8), 30-33.

Jacob, A., Vidyarthi, E., \& Carroll, K. (2012). The irreplaceables: Understanding the real retention crisis in America's urban schools. New York, NY: The New Teacher Project.

Jensen, B., Sandoval-Hernandez, A., Knoll, S., \& Gonzalez, E. (2012). The Experience of new teachers: Results from TALIS 2008. OECD Publishing. Retrieved from: http://www.oecd.org/education/school/49846877.pdf

Johnson, S., Berg, J., \& Donaldson, M. (2005). Who stays in teaching and why: A review of the literature on teacher retention. Washington, DC: NRTA.

Kelley, L. (2004). Why induction matters. Journal of Teacher Education, 55(5). 438-448.

Klassen, R., \& Chiu, M. (2010). Effects on teachers' self-efficacy and job satisfaction: Teacher gender, years of experience, and job stress. Journal of Educational Psychology, 102(3), 741-756.

McLeod, S. A. (2019, July 10). What does effect size tell you? Simply psychology: https://www.simplypsychology.org/effect-size.html

Missouri Department of Elementary and Secondary Education, (2017). Every Student Succeeds Act: Missouri's consolidated state plan. Retrieved from: https://dese.mo.gov/sites/default/files/ESSA-Plan-Final.pdf

Missouri Department of Elementary and Secondary Education. (2020). State board of education outreach plan update. Retrieved from: https://dese.mo.gov/sites/default/files/OutreachPlanJan2020.pdf

National Council on Teacher Quality. (2019). NCTQ data burst: Teacher leadership opportunities. Retrieved from: nctq.org/publications/NCTQ-Databurst:-TeacherLeadership-Opportunities 
Perrachione, B., Petersen, G., Rosser, V. (2008). Why do they stay? Elementary teachers' perceptions of job satisfaction and retention. The Professional Educator, 32(2), 25-41.

Pfitzner-Eden F. (2016). Why do I feel more confident? Bandura's sources predict preservice teachers' latent changes in teacher self-efficacy. Frontiers in Psychology, 7, 1486.

Podolsky, A., Kini, T., Bishop, J., \& Darling-Hammond, L. (2016). Solving the Teacher Shortage: How to Attract and Retain Excellent Educators. Palo Alto, CA: Learning Policy Institute.

Priddis, L., \& Rogers, S. (2018). Development of the reflective practice questionnaire: preliminary findings. Reflective Practice, 19(1), 89-104.

Rahimi, M., \& Weisi, H. (2018). Reflective practice, self-efficacy, and research practice of EFL teachers: Examining possible relationships. Issues in Educational Research, 28(3), 756780.

Redding, C., \& Smith, T. (2016). Easy in, easy out: Are alternatively certificated teachers turning over at increased rates? American Educational Research Journal, 53(4), 10861125. doi.10.3102/0002831216653206

Reeves, D. (2018) Seven keys to restoring the teacher pipeline. Educational Leadership, 75(8). Retrieved from ascd.org/publications/educational leadership/may18/vol75/num08/SevenKeys-to-Restoring-the-Teacher-Pipeline.aspx

Rogers, S. Priddis, L., Michels, M., Tieman, M., \& Van Winkle, L. (2019). Applications of the reflective practice questionnaire in medical education. BMC Medical Education,19(47), $1-11$.

Sass, D., Seal, K., \& Martin, N. (2010). Predicting teacher retention using stress and support variables. Journal of Educational Administration, 49(2), 200-215. 
Schön, D. (1983). The reflective practitioner: How professionals think in action. London: Temple Smith.

Skaalvik, E., \& Skaalvik, S. (2007). Dimensions of teacher self-efficacy and relations with strain factors, perceived collective teacher efficacy and teacher burnout. Journal of Educational Psychology, 99, 611-625.

Skaalvik, E., \& Skaalvik, S. (2010). Teacher self-efficacy and teacher burnout: a study of relations. Teaching and Teacher Education, 26, 1059-1069.

Strunk, K., \& Robinson, J. (2006). Oh won't you stay: A multilevel analysis of the difficulties in retaining qualified teachers. Peabody Journal of Education, 81(4), 65-94.

Sutcher, L., Darling-Hammond, L., \& Carver-Thomas, D. (2016). A coming crisis in teaching? Teacher supply, demand, and shortages in the USA. Palo Alto, CA: Learning Policy Institute.

Taie, S., \& Goldring, R. (2018). Characteristics of public elementary and secondary school teachers in the United States: Results from the 2015-16 national teacher and principal survey first look (NCES 2017-072rev). U.S. Department of Education. Washington, DC: National Center for Education Statistics. Retrieved: nces.ed.gov

Taylor, E. (2009). Fostering transformative learning. In J. Mezirow, E. Taylor, \& Associates (Eds.), Transformative learning in practice: Insights from community, workplace, and higher education (pp. 3-1731). San Francisco, CA: Jossey-Bass.

Thoonen, E., Sleegers, P., Oort, F., Peetsma, T., \& Geijsel, F. (2011). How to improve teaching practices: The role of teacher motivation, organizational factors, and leadership practices. Educational Administration Quarterly, 47(3), 496-536. 
Tschannen-Moran, M., Woolfolk Hoy, A., \& Hoy, W. (1998). Teacher efficacy: Its meaning and measure. Review of Educational Research, 68(2), 202-248.

Tschannen-Moran, M., \& Woolfolk Hoy, A. (2001). Teacher efficacy: Capturing an elusive construct. Teaching and Teacher Education, 17, 783-805.

van Manen, M. (1995). On the epistemology of reflective practice. Teachers and Teaching: Theory and Practices, 1(1), 33-50

Viel-Ruma, K., Houchins, D., Jolivette, K., \& Benson, G. (2010). Efficacy beliefs of special educators: The relationships among collective efficacy, teacher self-efficacy, and job satisfaction. Teacher Education and Special Education: The Journal of the Teacher Education Division of the Council for Exceptional Children, 33, 225-233.

Woolfolk, A., \& Hoy, W. (1990). Prospective teachers' sense of efficacy and beliefs about control. Journal of Educational Psychology, 82(1), 81-91.

Woolfolk, A., Rosoff, B., \& Hoy, W. (1990) Teachers' sense of efficacy and their beliefs about managing students. Teaching and Teacher Education, 6, 137-148.

Yost, D. (2006). Reflection and self-efficacy: Enhancing the retention of qualified teachers from a teacher education perspective. Teacher Education Quarterly, 33(4), 59-76.

Zee, M., \& Koomen, H. (2016). Teacher self-efficacy and its effects on classroom processes, student academic adjustment, and teacher well-being: A synthesis of 40 years of research. Review of Educational Research, 86(4), 981-1015. 
SECTION SIX: SCHOLARLY PRACTITIONER REFLECTION 


\section{Dissertation Influence on Leadership Practice}

Along the dissertation road, through reflection-in-action, I became "a researcher in the practice context" (Schön, 1983, p. 68), learning through failure and success; I have had more of both of these throughout my dissertation journey than quite possibly during any other time of my life. There is no doubt the greatest impacts of the dissertation on my work as an educational leader are still ahead of me, and as of yet, unseen. However, in identifying some close effects, I am clearly able to identify three main areas where the dissertation, having woven itself into my work, has impacted my: (a) skill in leading change; (b) confidence in my capacity to learn, and (b) understanding of participative leadership.

Leading Change. A reflective practitioner engages in a "transaction with the situation, he shapes it and makes himself a part of it. Hence, the sense he makes of the situation must include his own contribution to it. Yet he recognizes that the situation, having a life its own distinct from his intentions, may foil his projects and reveal new meanings" (Schön, 1983, p.163). Having begun my journey far from where I have ended, I am reminded of the transactional nature of the dissertation at points along the way with the most notable transactional situation occurring at the end of doctoral coursework, when I started over.

Many of my cohort colleagues had spent coursework years progressively building their thesis, gaining a foundation for the independent journey of dissertation. I wandered, investigating interests away from the scope of my employment. I embraced my interest in the emergence of the Fourth Industrial Revolution and the Internet of Things. I connected to technology usage by teachers, learning about the impact of ethical dispositions on behavior, specifically related to technological usage by teachers. This led me into digital divides and concepts of equitable access and usage of technology. Indulging my learner strength, I traveled 
and invested time into dreams of dissertation study related to the potential impact of teacher ethical beliefs on digital divides related to inequitable acquisition of student social capital. How quickly the coursework days went by. I remember the day I realized there was simply no way to realistically complete a dissertation in an area separate from my employment, especially in light of a corresponding drastic shift to my job description. This forced a situation leading to the transaction of last-minute topic change.

The suddenness of finding myself in the last two weeks of coursework, heading into comprehensive exams without a clear dissertation path was jarring; for some time, I held onto thoughts of how I had wasted so much time pursuing other interests. Looking back, however, I cherish the time I had to get lost on different pathways. The detours have given me a broader scope of knowledge from which to draw. Additionally, dealing with sudden, unexpected change became the most valuable skill gained from my dissertation experience, and the one I drew from the most during the 2020 Covid-19 crisis when I needed to adapt quickly and chart new courses (many simultaneously) not only for myself, but also for those I lead.

\section{Confidence in Learning Capacity}

My dissertation journey presented many moments of pause when I would run into barriers from voids in my knowledge and/or skills. Most of the time, these gaps required a stop accompanied by an intense time of learning in order to proceed. Each pause offered an enticing opportunity to drift away from the project, and each required greater determination than the last to find the ability to continue. The continually compounding complexity of each level of learning produced uncertainty in my capacity to continue, and, at times, disinterest and general dissertation fatigue. The challenge was ever-present, and incremental learning, moving step-bystep, was the only way forward to completion. Each movement towards completion, moving 
past a pause, corresponded to an increase in my confidence in my capacity to learn anything... even quantitative analyses! Finding success at each juncture contributed to building my level of confidence, giving me the courage to take risks and expand my work in new ways.

Through the dissertation, I gained knowledge and skills related to conducting program evaluations, which are now a core component within the scope of my work. I had the courage to put together and lead an evaluation team, and we have been working to develop evaluations for MTDS programs. Additionally, most surely due to what I have learned through dissertation, I was recently asked to develop a project proposal and tasked with leading the evaluation process for the project. The expansion of my work into program evaluation, made possible due to skills gained while conducting my study, grew from increased confidence in my ability to learn. The increased capacity gave me courage. Although I am just starting in that work, I now have the confidence in my capacity to learn anything needed to lead the team in the work of finding and disseminating "practical knowledge generated through this type of inquiry [that] can then effectively guide administrative practice that will, in turn, generate more knowledge" (Schultz, 2010, p.53).

\section{Understanding of Participative Leadership}

'No one is successful if they merely present a plan in finished form to others. It doesn't matter how brilliant or correct the plan is - it simply doesn't work to ask people to sign on when they haven't been involved in the planning process" (Wheatley, 2006, p. 68). Whew, this was a difficult learning moment! I began working at the age of 12, and from that point on, I worked to be the best... on my own. Transitioning from being the brilliant planner to the leader of teams has taken some work, and the dissertation process has shown me some areas in need of improvement. 
My study relied on the assistance of program facilitators; when planning the dissertation study, I misunderstood the importance of engaging stakeholders early in the process. I also failed to account for how strongly tradition and culture could factor into the successful implementation and acceptance of the study. During coursework, I always struggled with gaining access to the data needed for our group projects, and I had always appreciated those within my group who were able to be the gate-keepers. On my own, entering into an established, long-standing program with a completed instrument and a unilateral plan was more of a challenge than I had anticipated. It was only overcome due to the immense, warm-hearted, graciousness and patience of the facilitators I am lucky to now lead. In hindsight, I would have made greater efforts to directly involve them in the process, beginning with identifying program goals and collaboratively determining methods of measurement. The difficulty encountered when introducing this study to those who would be administering it, changed my thinking greatly, which has been key in the work of the evaluation team, who now work collaboratively to design evaluations to measure program impacts. While I am still learning in this area, I am more aware of the importance of involving others and gaining participation within teams than I was prior to the dissertation. I have learned the importance of including stakeholders in the process from the beginning and strive for "uniting stakeholders in a shared purpose, embrac[ing] democracy as a fundamental value in [my] philosophy of leadership" (Schultz, 2010, p. 55).

\section{Dissertation Influence as a Scholar}

Given the dissertation was so directly related to my current career role, it would seem likely that the impact on practice would be greater than the scholarly influence of the experience. However, the two are tightly woven together and inseparable within my work, as my work has largely become focused on conducting scholarly inquiries to inform the practice of myself and 
others. Since engaging in my dissertation, I am now involved in on-going "inquiry as practice wherein the leader as scholar and her/his leadership practice are inseparable" (Jenlink \& Horn, 2001, p. 5, as cited in Schultz, 2010). Over the last two years, I have been leading the development of a career-spanning framework of learning for teachers. The dissertation inquiry has opened many opportunities to engage in scholarly work, including the development of the framework competencies and progressions, which were generated through an intensive qualitative thematic analysis and synthesis of multiple bodies of research. With the knowledge and skills gained through the dissertation process, I am now developing tools for measuring these competencies, which will inform programs and the system as a whole, and "creating a body of knowledge for educational practice, generated through a lens of critical inquiry of and within practice" (Schultz, 2010, p. 54) has become a key aspect of my role as a leader. As I think about the future beyond dissertation, I am excited to, once again, start over as I move into the next phase of my journey. I am looking forward to realizing the outcomes of this trek for the rest of my life as I draw back upon this period of intense study to bring my learning into whatever lies ahead. 


\section{REFERENCES}

Akbari, R. (2007). Reflections on reflection: A critical appraisal of reflective practices in L2 teacher education. System, 35, 192-207.

Allensworth, E., Ponisciak, S., \& Mazzeo, C. (2009). The schools teachers leave: Teacher mobility in Chicago Public Schools. Chicago, IL: Consortium on Chicago School Research at the University of Chicago.

Allinder, R. M. (1994). The relationship between efficacy and the instructional practices of special education teachers and consultants. Teacher Education and Special Education, 17, 86-95.

Aloe, A., Amo, L., \& Shanahan, M. (2014). Classroom management self-efficacy and burnout: a multivariate meta-analysis. Educational Psychology Review, 26(1), 101-126.

Anderson, R. N., Greene, M. L., \& Loewen, P. S. (1988). Relationships among teachers' and students' thinking skills, sense of efficacy, and student achievement. Alberta Journal of Educational Research, 34(2), 148-165.

Armor, D., Conry-Oseguera, P., Cox, M., King, N., McDonnell, L., Pascal, A., Pauly, E., \& Zellman, G. (1976). Analysis of the school preferred reading program in selected Los Angeles minority schools. Santa Monica, CA: Rand Corporation.

Ashton, P., \& Webb, R. (1986). Making a difference: Teachers' sense of efficacy and student achievement. New York, NY: Longman.

Awkard, T. (2017). The power of reflective action to build teacher efficacy. Kappan, 98(6), 5357. 
Babaei, M., \& Abednia, A. (2016). Reflective teaching and self-efficacy beliefs: Exploring relationships in the context of teaching EFL in Iran. Australian Journal of Teacher Education, 41(9), 1-26.

Bandura, A. (1977). Toward a unifying theory of behavioral change. Psychological Review, 84, $1919-215$.

Bandura, A. (1999). Social cognitive theory: An agentic perspective. Asian Journal of Social Psychology, 2, 21-41.

Beauchamp, C. (2014). Reflection in teacher education: Issues emerging from a review of current literature. Reflective Practice, 16(1), 123-141.

Belcher, C., \& Vinson, G. (1997, August) The Teachers' Academy: A Collaborative Approach to Preparing Teachers for Leadership Roles in the Public Schools. Paper presented at the Summer Workshop of the Association of Teacher Educators, Las Vegas, NV. Retrieved from https://files.eric.ed.gov/fulltext/ED412192.pdf

Bobbitt, S., Faupel, E., \& Burns, S. (1991). Stayers, movers, and leavers: Results of the 1988-89 teacher follow-up survey. Washington, DC: National Center for Education Statistics.

Bolman, L. G., \& Deal, T. E. (2013). Reframing organizations: Artistry, choice and leadership (5th ed.). San Francisco, CA: Jossey-Bass.

Borman, G., \& Dowling, N. (2008). Teacher attrition and retention: A meta-analytic and narrative review of the research. Review of Educational Research, 78(3), 367-409.

Brouwers, A., Evers, W., \& Tomic, W. (2001). Self-efficacy in eliciting social support and burnout among secondary school teachers. Journal of Applied Social Psychology, 31, 1474-1491. 
Brown, C. (2012). A systematic review of the relationship between self-efficacy and burnout in teachers. Educational and Child Psychology, 29(4), 47-63.

Bruffee, K. (1999). Collaborative Learning: Higher Education, Interdependence, and the Authority of Knowledge (2nded.). Baltimore, MD: The Johns Hopkins University Press.

Caprara, G., Barbaranelli, C., Steca, P., \& Malone, P. (2006). Teachers' self-efficacy beliefs as determinants of job satisfaction and students' academic achievement: A study at the school level. Journal of School Psychology, 44(6), 473-490.

Carroll, T. (2007). Policy Brief: The high cost of teacher turnover. Washington, D.C.: National Commission on Teaching and America's Future.

Carver-Thomas, D., \& Darling-Hammond, L. (2017). Teacher turnover: Why it matters and what we can do about it. Palo Alto, CA: Learning Policy Institute.

Chang, M. (2009). An appraisal perspective of teacher burnout: Examining the emotional work of teachers. Educational Psychology Review, 21(3), 193-218.

Chen, J. (2014). Teaching nontraditional adult students: Adult learning theories in practice. Teaching in Higher Education, 19(4), 406-418.

Cherniss, C. (1993). Role of professional self-efficacy in the etiology and amelioration of burnout. In W. B. Schaufeli, C. Maslach, \& T. Marek (Eds.), Series in applied psychology: Social issues and questions. Professional burnout: Recent developments in theory and research (pp. 135-149). Philadelphia, PA, US: Taylor \& Francis.

Chiefs for Change. (2017). Evidence and funding: Connecting the dots. Retrieved: chiefsforchange.org

Chiefs for Change. (2016). ESSA and evidence: Why it matters. Retrieved: chiefsforchange.org 
Collin, S., Karsenti, T., \& Komis, V. (2013). Reflective practice in initial teacher training: Critiques and perspectives. Reflective Practice: International and Multidisciplinary Perspectives, 14, 104-117.

Conway, P. (2001). Anticipatory reflection while learning to teach: From a temporally truncated to a temporally distributed model of reflection in teacher education. Teaching and Teacher Education, 17, 89-106.

Cowan, J., Goldhaber, D., Hayes, K., Theobald, R. (2016). Missing elements in the discussion of teacher shortages. Educational Researcher, 45(8), 460-462. doi.10.3102/0013189X16679145

Creswell, J. (2014). Research design: Qualitative, quantitative, and mixed methods approaches (4th ed.). Los Angeles, CA: Sage.

Cueva, M. (2010). A living spiral of understanding: Community-based adult education. New Directions for Adult and Continuing Education, 125, 79-90.

Darling-Hammond, L. (1999). Teacher quality and student achievement: A review of state policy evidence. Seattle, WA: Center for the Study of Teaching and Policy, University of Washington.

Darling-Hammond, L. (2003). Keeping good teachers: Why it matters and what leaders can do. Educational Leadership, 60(8), 6-13.

Darling-Hammond, L., Burns, D., Campbell, C., Goodwin, A., Hammerness, K., Low, E., McIntyre, A., Sato, M., \& Zeichner, K. (2017). Empowered educators: How highperforming systems shape teaching quality around the world. San Francisco, CA: Jossey Bass. 
Darling-Hammond, L., Hyler, M., \& Gardner, M. (2017). Effective teacher professional development. Palo Alto, CA: Learning Policy Institute.

Dewey, J. (1933). How we think: A restatement of the relations of reflective thinking to the educative process (2nd revised ed.). Boston, MA: D.C. Heath.

Dirkx, J. (1997). Nurturing soul in adult learning. New Directions for Adult and Continuing Education, 1997(74), 79-88.

Evers, W., Brouwers, A., \& Tomic, W. (2002). Burnout and self-efficacy: a study on teachers' beliefs when implementing an innovative educational system in the Netherlands. British Journal of Educational Psychology, 72, 227-243.

Farrell, T. (2012). Reflecting on reflective practice: (Re)visiting Dewey and Schön. TESOL Journal, 3(1), 7-16.

Fields, A. (2018). Discovering statistics using IBM SPSS statistics (5th ed.). Thousand Oaks, CA: Sage.

Freese, A. (2006). Reframing one's teaching: Discovering our teacher selves through reflection and inquiry. Teaching and Teacher Education, 22, 110-119.

Friedman, I. (2003). Self-efficacy and burnout in teaching: The importance of interpersonalrelations efficacy. Social Psychology of Education, 6, 191-215.

Friedman, I., \& Farber, B. (1992). Professional self-concept as a predictor of teacher burnout. Journal of Educational Research, 86, 70-84.

Galea, S. (2012). Reflecting reflective practice. Educational Philosophy and Theory, 44, 245258. 
Garcia, E., \& Weiss, E. (2019a). The teacher shortage is real, large and growing, and worse than we thought: The first report in 'the perfect storm in the teacher labor market' series. Washington, D.C.: Economic Policy Institute.

Garcia, E., \& Weiss, E. (2019b). U.S. schools struggle to hire and retain teachers: The second report in 'the perfect storm in the teacher labor market' series. Washington, D.C.: Economic Policy Institute.

Garcia, E., \& Weiss, E. (2019c). Low relative pay and high incidence of moonlighting play a role in the teacher shortage, particularly in high-poverty schools: The third report in 'the perfect storm in the teacher labor market' series. Washington, D.C.: Economic Policy Institute.

Garcia, E., \& Weiss, E. (2019d). Challenging working environments ('school climates'), especially in high-poverty schools, play a role in the teacher shortage: The fourth report in 'the perfect storm in the teacher labor market' series. Washington, D.C.: Economic Policy Institute.

Garcia, E., \& Weiss, E. (2019e). The role of early career supports, continuous professional development, and learning communities in the teacher shortage: The fifth report in 'the perfect storm in the teacher labor market' series. Washington, D.C.: Economic Policy Institute.

Gibson, S., \& Dembo, M. (1984). Teacher efficacy: A construct validation. Journal of Educational Psychology, 76(4), 569-582.

Glickman, C., \& Tamashiro, R. (1982). A comparison of first-year, fifth-year, and former teachers on efficacy, ego development, and problem solving. Psychology in the Schools, $19(4), 558-562$. 
Goddard, R., Hoy, W., \& Woolfolk Hoy, A. (2004). Collective efficacy beliefs: Theoretical developments, empirical evidence, and future directions. Educational Researcher, 33, 313.

Goldring, R., Taie, S., \& Riddles, M. (2014). Teacher attrition and mobility: Results from the 2012-13 teacher follow-up survey (NCES 2014-077). U.S. Department of Education. Washington, DC: National Center for Education Statistics. Retrieved from http://nces.ed.gov/pubsearch

Gray, L., Taie, S., \& O’Rear, S. (2015). Public school teacher attrition and mobility in the first five years: Results from the first through fifth waves of the 2007-08 beginning teacher longitudinal study (NCES 2015-337). U.S. Department of Education. Washington, DC: National Center for Education Statistics. Retrieved from: http://nces.ed.gov/pubsearch

Guarino, C., Santibáñez, L., \& Daley, G. (2006). Teacher recruitment and retention: A review of the recent empirical literature. Review of Educational Research 76(2), 173-208.

Gün, B. (2011). Quality self-reflection through reflection training. ELT Journal, 65(2), 126 134.

Guskey, T. (1988). Teacher efficacy, self-concept, and attitudes toward the implementation of instructional innovation. Teaching and Teacher Education, 4(1), 63-69.

Hattie, J. (2003). Teachers make a difference: What is the research evidence? Paper presented at the Building Teacher Quality: What does the research tell us? ACER Research Conference, Melbourne, Australia. Retrieved from: http://research.acer.edu.au/research_conference_2003/4/

Heifetz, R., \& Laurie, D. (1997). The work of leadership. In HBR's 10 must reads: On leadership (pp. 57-78). Boston, MA: Harvard Business Review Press. 
Helgesen, S. (1995). The web of inclusion. New York, NY: Currency/Doubleday.

Helland, M., \& Winston, B. (2005). Towards a deeper understanding of hope and leadership. Journal of Leadership \& Organizational Studies, 12(2), 42-54.

Heneman, H., Kimball, S., \& Milanowski, A. (2006). The Teacher sense of efficacy scale: Validation evidence and behavioral prediction. WCER Working Paper No. 2006-7, Madison, WI: University of Wisconsin-Madison, Wisconsin Center for Education Research.

Henson, R. (2002). From adolescent angst to adulthood: Substantive implications and measurement dilemmas in the development of teacher efficacy research. Educational Psychologist, 37(3), 137-150).

Hirsh, S. (2019). 4 cornerstones of professional learning: Fundamental principles pave the way for educators' actions. Oxford, OH: Learning Forward.

Holzberger, D., Philipp, A., \& Kunter, M. (2013). How teachers' self-efficacy is related to instructional quality: A longitudinal analysis. Journal of Educational Psychology, 105, 774-789.

Ilker E, Sulaiman A., Rukayya S. (2016). Comparison of convenience sampling and purposive sampling. American Journal of Theoretical and Applied Statistics, 5(1), 1-4. doi.10.11648/j.ajtas.20160501.11

Ingersoll, R. (2001). Teacher turnover and teacher shortages: an organizational analysis. American Educational Research Journal, 38, 499-534.

Ingersoll, R. (2003). Is There Really a Teacher Shortage? Retrieved: repository.upenn.edu Ingersoll, R., \& Smith, T. (2003). The wrong solution to the teacher shortage. Educational Leadership, 60(8), 30-33. 
Ingersoll, R., Merrill, L., \& Stuckey, D. (2014). Seven trends: The transformation of the teaching force. Philadelphia, PA: Consortium for Policy Research in Education, University of Pennsylvania.

Jacob, A., Vidyarthi, E., \& Carroll, K. (2012). The irreplaceables: Understanding the real retention crisis in America's urban schools. New York, NY: The New Teacher Project.

Jaquith, A., \& McLaughlin, M. (2010). A temporary, intermediary organization at the helm of regional educational reform: Lessons from the Bay Area School Reform Collaborative. In A. Hargreaves, A. Lieberman, M. Fullan, \& D. Hopkins (Eds.), Second International Handbook of Educational Change, 1, 85-103. London: Springer.

Jaquith, A., Mindich, D., Wei, R., \& Darling-Hammond, L. (2010). Teacher professional learning in the United States: Case studies of state policies and strategies. Oxford, $\mathrm{OH}$ : Learning Forward.

Jensen, B., Sandoval-Hernandez, A., Knoll, S., \& Gonzalez, E. (2012). The Experience of new teachers: Results from TALIS 2008. OECD Publishing. Retrieved: oecd.org

Johnson, S., Berg, J., \& Donaldson, M. (2005). Who stays in teaching and why: A review of the literature on teacher retention. Washington, DC: NRTA.

Johnson, S., \& Birkeland, S. (2003). Pursuing a "sense of success": New teachers explain their career decisions. American Educational Research Journal, 40, 581-617.

Kelley, L. (2004). Why induction matters. Journal of Teacher Education, 55(5). 438-448.

Klassen, R., \& Chiu, M. (2010). Effects on teachers' self-efficacy and job satisfaction: Teacher gender, years of experience, and job stress. Journal of Educational Psychology, 102(3), $741-756$. 
Klassen, R., Tze, V., Betts, S., Gordon, K. (2011). Teacher efficacy research 1998-2009: Signs of progress or unfulfilled promise? Educational Psychology Review, 23(1), 21-43.

Kotter, J. (1990). What leaders really do. In HBR's 10 must reads: On leadership (pp. 37-55). Boston, MA: Harvard Business Review Press.

Larrivee, B. (2008). Development of a tool to assess teachers' level of reflective practice. Reflective Practice, 9(3), 341-360.

Learning Forward-Missouri. (n.d.). MSDC history. Retrieved from: learningforwardmo.org Maslach, C., \& Leiter, M. (2008). Early predictors of job burnout and engagement. Journal of Applied Psychology, 933, 498-512.

McLeod, S. A. (2019, July 10). What does effect size tell you? Simply psychology: simplypsychology.org

Mena Marcos, J., Sánchez, E., \& Tillema, H. (2011). Promoting teacher reflection: What is said to be done. Journal of Education for Teaching: International Research and Pedagogy, 37, 21-36.

Missouri Department of Elementary and Secondary Education. (2020). State board of education outreach plan update. Retrieved: dese.mo.gov

Muijs, D., \& Reynolds, D. (2002). Teachers' beliefs and behaviors: What really matters? Journal of Classroom Interaction, 37, 3-15

National Council on Teacher Quality. (2019). NCTQ data burst: Teacher leadership opportunities. Retrieved from: nctq.org/publications/NCTQ-Databurst:-TeacherLeadership-Opportunities

Noffke, S., \& Brennan, M. (2005). The dimensions of reflection: A conceptual and contextual analysis. International Journal of Progressive Education, 1, 58-78. 
Northouse, P. (2016). Leadership: Theory and practice (7th ed.). Los Angeles, CA: Sage.

Perrachione, B., Petersen, G., Rosser, V. (2008). Why do they stay? Elementary teachers' perceptions of job satisfaction and retention. The Professional Educator, 32(2), 25-41.

Pfitzner-Eden F. (2016). Why do I feel more confident? Bandura's sources predict preservice teachers' latent changes in teacher self-efficacy. Frontiers in Psychology, 7, 1486.

Podolsky, A., Kini, T., Bishop, J., \& Darling-Hammond, L. (2016). Solving the Teacher Shortage: How to Attract and Retain Excellent Educators. Palo Alto, CA: Learning Policy Institute.

Priddis, L., \& Rogers, S. (2018). Development of the reflective practice questionnaire: preliminary findings. Reflective Practice, 19(1), 89-104.

Rahimi, M., \& Weisi, H. (2018). Reflective practice, self-efficacy, and research practice of EFL teachers: Examining possible relationships. Issues in Educational Research, 28(3), 756780.

Redding, C., \& Smith, T. (2016). Easy in, easy out: Are alternatively certificated teachers turning over at increased rates? American Educational Research Journal, 53(4), 10861125. doi.10.3102/0002831216653206

Reeves, D. (2018) Seven keys to restoring the teacher pipeline. Educational Leadership, 75(8). Retrieved from ascd.org/publications/educational leadership/may18/vol75/num08/SevenKeys-to-Restoring-the-Teacher-Pipeline.aspx

Robson, L., Shannon, H., Goldenhar, L., Hale, A. (2001). Guide to Evaluating the Effectiveness of Strategies for Preventing Work Injuries: How to show whether a safety intervention really works (DHHS (NIOSH) Publication No. 2001-119). Cincinnati, OH: National Institute for Occupational Safety and Health. 
Rogers, S. Priddis, L., Michels, M., Tieman, M., \& Van Winkle, L. (2019). Applications of the reflective practice questionnaire in medical education. BMC Medical Education,19(47), 1-11.

Ronfeldt, M., Loeb, S., \& Wyckoff, J. (2013). How teacher turnover harms student achievement. American Educational Research Journal, 50(1), 4-36. doi.10.3102/0002831212463813

Rooke, D., \& Torbert, W. (2005). Seven transformations of leadership. In HBR's 10 must reads: On leadership (pp. 137-161). Boston, MA: Harvard Business Press.

Rotter, J. B. (1966). Generalized expectancies for internal versus external control of reinforcement. Psychological Monographs: General and Applied, 80(1), 1-28.

Sass, D., Seal, K., \& Martin, N. (2010). Predicting teacher retention using stress and support variables. Journal of Educational Administration, 49(2), 200-215.

Schön, D. (1983). The reflective practitioner: How professionals think in action. London: Temple Smith.

Schultz, J. R. (2010). The scholar-practitioner: A philosophy of leadership. Scholar-Practitioner Quarterly, 4(1), 52-64.

Schwerdtfeger, A., Konermann, L., \& Schönhofen, K. (2008). Self-efficacy as a healthprotective resource in teachers? A biopsychological approach. Health Psychology, 27(3), $358-368$.

Skaalvik, E., \& Skaalvik, S. (2007). Dimensions of teacher self-efficacy and relations with strain factors, perceived collective teacher efficacy and teacher burnout. Journal of Educational Psychology, 99, 611-625. 
Skaalvik, E., \& Skaalvik, S. (2010). Teacher self-efficacy and teacher burnout: a study of relations. Teaching and Teacher Education, 26, 1059-1069.

Smylie, M. (1988). The enhancement function of staff development: Organizational and psychological antecedents to individual teacher change. American Education Research Journal, 25, 1-30.

Sorensen, L., \& Ladd,H. (2018). The hidden costs of teacher turnover (Working Paper No. 2030918-1). Retrieved from: files.eric.ed.gov/fulltext/ED591843.pdf

Stallions, M., Murrill, L., \& earp, L. (2012). Don’t quit now!: Crisis, reflection, growth, and renewal for early career teachers. Kappa Delta Pi Record, 48, 123-128.

Strauss, V. (2017, November 27). Why it's a big problem that so many teachers quit-and what to do about it. Washington Post. Retrieved from: washingtonpost.com

Strunk, K., \& Robinson, J. (2006). Oh won't you stay: A multilevel analysis of the difficulties in retaining qualified teachers. Peabody Journal of Education, 81(4), 65-94.

Sutcher, L., Darling-Hammond, L., \& Carver-Thomas, D. (2016). A coming crisis in teaching? Teacher supply, demand, and shortages in the USA. Palo Alto, CA: Learning Policy Institute.

Sutherland, L., Howard, S., \& Markauskaite, L. (2010). Professional identity creation: Examining the development of beginning preservice teachers' understanding of their work as teachers. Teaching and Teacher Education, 26, 455-465.

Taie, S., \& Goldring, R. (2018). Characteristics of public elementary and secondary school teachers in the United States: Results from the 2015-16 national teacher and principal survey first look (NCES 2017-072rev). U.S. Department of Education. Washington, DC: National Center for Education Statistics. Retrieved: nces.ed.gov 
Taylor, E. (2009). Fostering transformative learning. In J. Mezirow, E. Taylor, \& Associates (Eds.), Transformative learning in practice: Insights from community, workplace, and higher education (pp. 3-1731). San Francisco, CA: Jossey-Bass.

Thompson, N., \& Pascal, J. (2012). Developing critically reflective practice. Reflective Practice: International and multidisciplinary perspectives, 13, 311-325.

Thoonen, E., Sleegers, P., Oort, F., Peetsma, T., \& Geijsel, F. (2011). How to improve teaching practices: The role of teacher motivation, organizational factors, and leadership practices. Educational Administration Quarterly, 47(3), 496-536.

Thurlings, M., Evers, A., \& Vermeulen, M. (2015). Toward a model of explaining teachers' innovative behavior: A literature review. Review of Educational Research, 85(3), 430471.

Tschannen-Moran, M., Woolfolk Hoy, A., \& Hoy, W. (1998). Teacher efficacy: Its meaning and measure. Review of Educational Research, 68(2), 202-248.

Tschannen-Moran, M., \& Woolfolk Hoy, A. (2001). Teacher efficacy: Capturing an elusive construct. Teaching and Teacher Education, 17, 783-805.

United States Department of Education. (2016) Non-regulatory guidance: Using evidence to strengthen education investments. Retrieved from: 2ed.gov

Urzúa, A., \& Vásquez, C. (2008). Reflection and professional identity in teachers’ futureoriented discourse. Teaching and Teacher Education, 24, 1935-1946.

van Manen, M. (1995). On the epistemology of reflective practice. Teachers and Teaching: Theory and Practices, 1(1), 33-50

Viel-Ruma, K., Houchins, D., Jolivette, K., \& Benson, G. (2010). Efficacy beliefs of special educators: The relationships among collective efficacy, teacher self-efficacy, and job 
satisfaction. Teacher Education and Special Education: The Journal of the Teacher Education Division of the Council for Exceptional Children, 33, 225-233.

Warin, J., Maddock, M., Pell, A., \& Hargreaves, L. (2006). Resolving identity dissonance through reflective and reflexive practices in teaching. Reflective Practice, 7, 233-245.

Wheatley, K. (2002). The potential benefits of teacher efficacy doubts for educational reform. Teaching and Teacher Education, 18, 5-22.

Wheatley, M. (2006). Leadership and the new science: Discovering order in a chaotic world. San Francisco: Berrett-Koehler

Woolfolk, A., \& Hoy, W. (1990). Prospective teachers' sense of efficacy and beliefs about control. Journal of Educational Psychology, 82(1), 81-91.

Woolfolk, A., Rosoff, B., \& Hoy, W. (1990) Teachers' sense of efficacy and their beliefs about managing students. Teaching and Teacher Education, 6, 137-148.

Woolfolk Hoy, A. \& Burke Spero, R. (2005) Changes in teacher efficacy during the early years of teaching: A comparison of four measures. Teaching and Teacher Education, 21, 343356.

Yost, D. (2006). Reflection and self-efficacy: Enhancing the retention of qualified teachers from a teacher education perspective. Teacher Education Quarterly, 33(4), 59-76.

Zee, M., \& Koomen, H. (2016). Teacher self-efficacy and its effects on classroom processes, student academic adjustment, and teacher well-being: A synthesis of 40 years of research. Review of Educational Research, 86(4), 981-1015. 


\section{APPENDICES}




\section{A. Informed Consent Form}

\section{Informed Consent}

Research Purpose: Teacher Academy is designed to transform teacher practice and focuses on instructional strategies, student engagement, and reflective practice. This survey is designed to gather information about the effectiveness of the program and its impact on teacher self-efficacy, reflective practice, and job satisfaction.

Time Required: The survey should take less than 10 minutes to complete.

Risks and Benefits: No risks are anticipated with participation in this survey. Your responses are important to the program, and the results of this survey will inform and potentially impact program decisions for future participants.

Confidentiality: Responses to this survey are confidential.

Voluntary Participation and Withdrawal: It is your choice whether to participate or not. The choice you make will have no effect on your participation in Missouri Teacher Academy. You may change your mind and stop participating at any time.

\section{Questions or Concerns?}

Should you have any questions or concerns about this project and your part in it, please contact:

Tracy Gross, Missouri State University Cynthia MacGregor, Missouri State University tracygross@missouristate.edu CMacgregor@MissouriState.edu (417)836-4074 417-836-6046

Thank you for taking time to provide this valuable information.

The nature and purpose of this study have been sufficiently explained, and I voluntarily consent to be a participant in this study. I understand I am free to withdraw at any time.

Yes

No 


\section{B. Independent Samples (Whole Group) Demographic Charts}

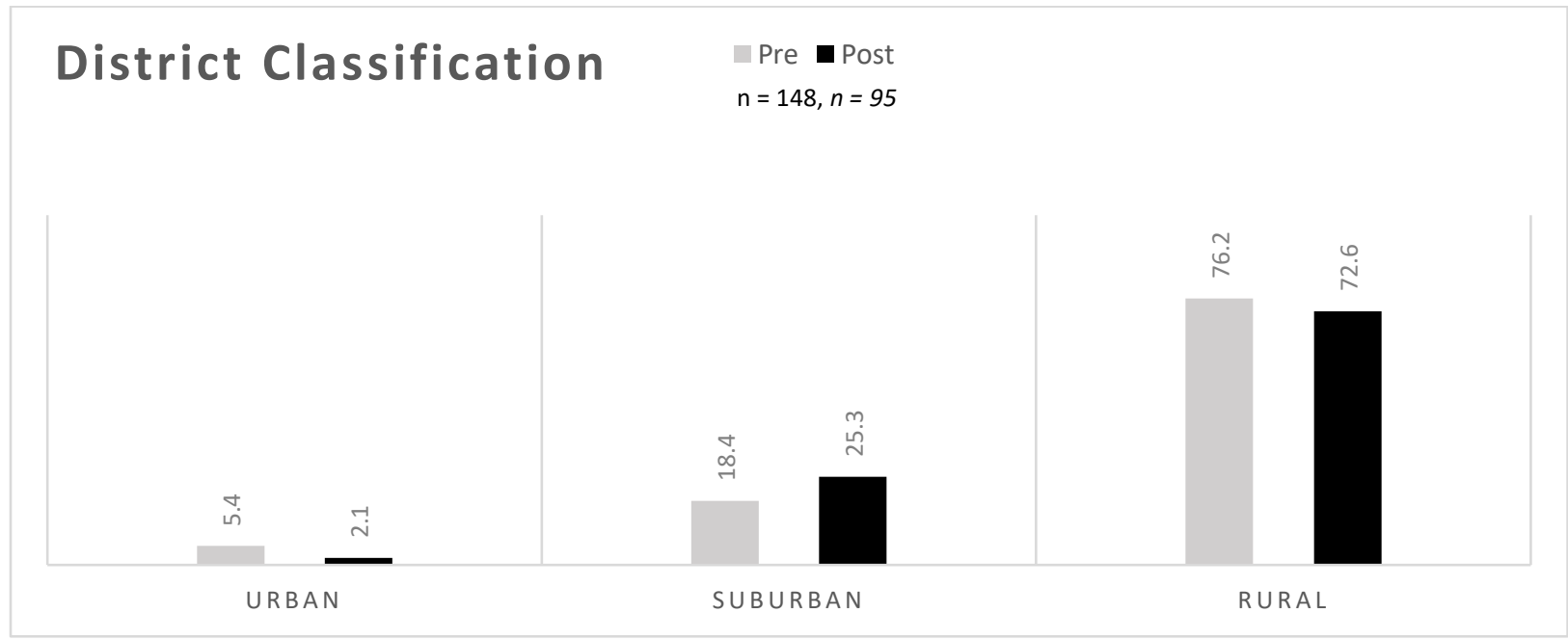

\section{Years of Experience

$$
\text { Pre } \mathbf{\square} \text { Post }
$$$$
\mathrm{n}=148, n=95
$$

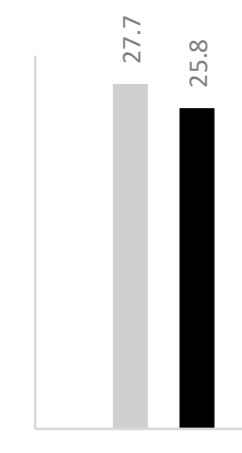

$$
\text { 3-5 YRS }
$$
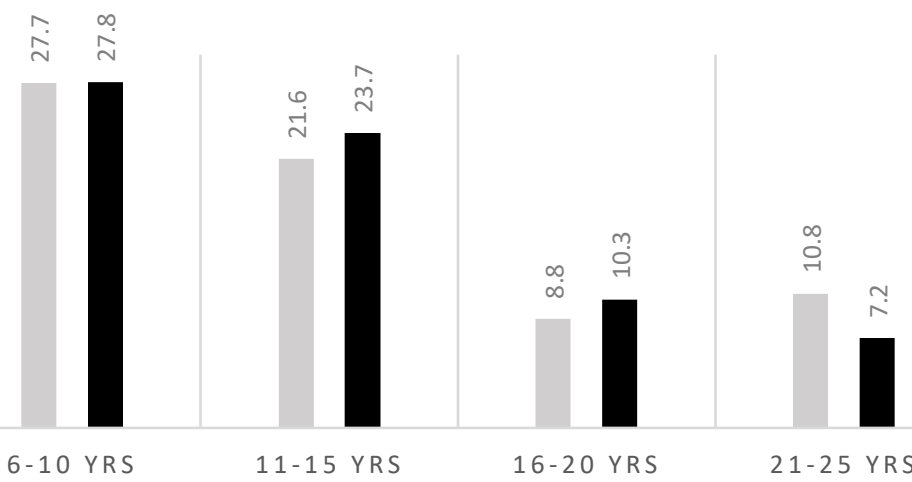

Grade Level

$$
\begin{aligned}
& \text { Pre Post } \\
& \mathrm{n}=148, n=96
\end{aligned}
$$

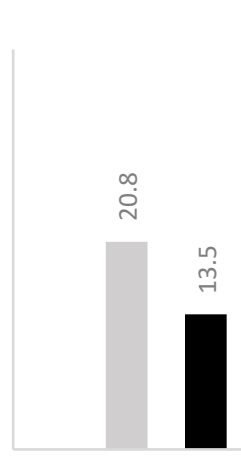

PK-2

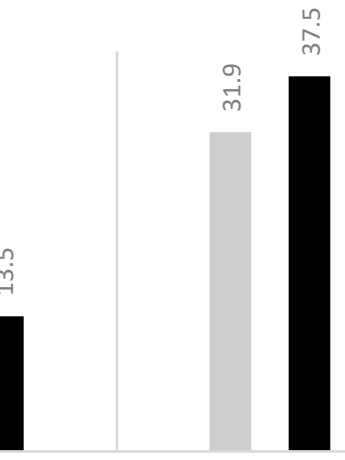

GRADE 3-5

GRADE 6-8

GRADE 9-12

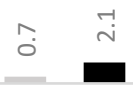

PK-8 


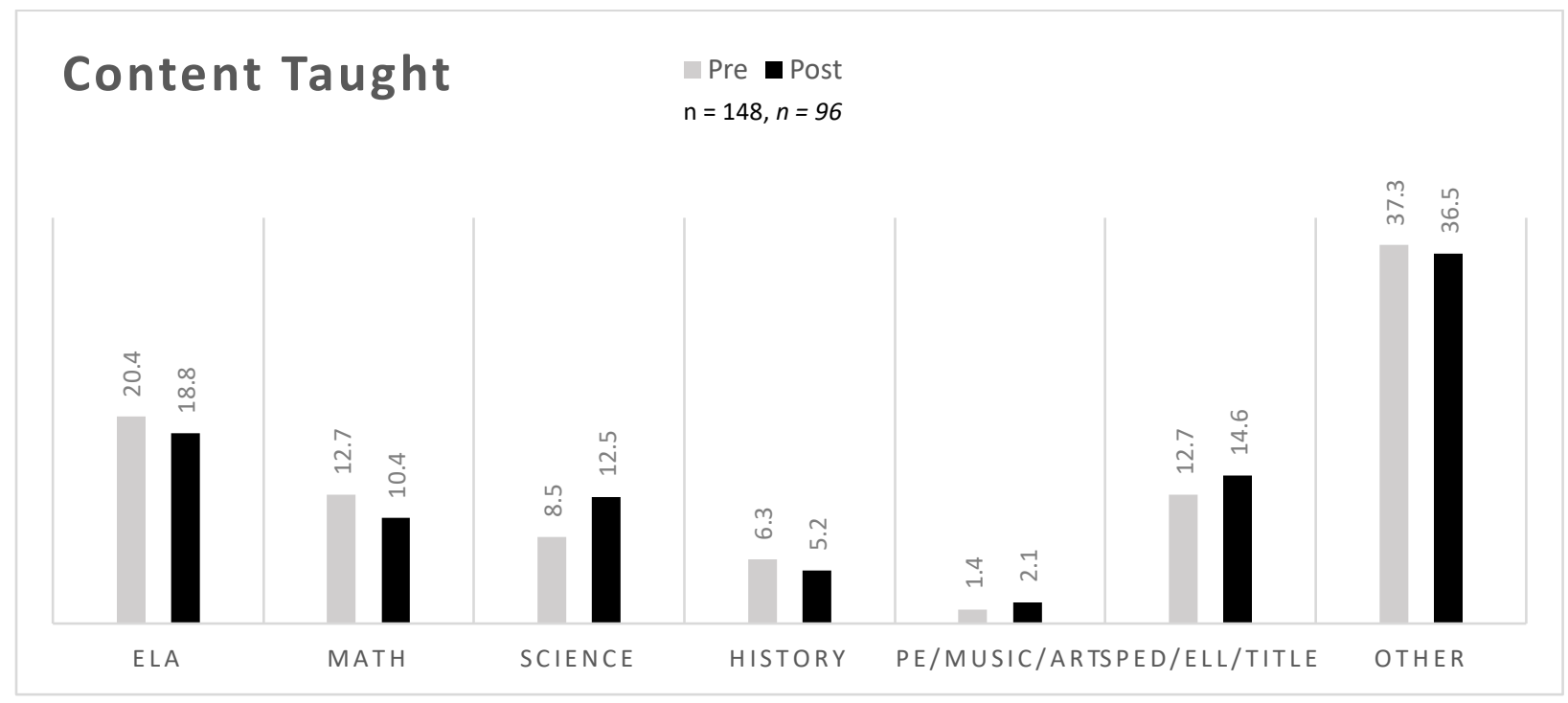

\section{Age Pre $\square$ Post \\ $\mathrm{n}=148, n=95$}

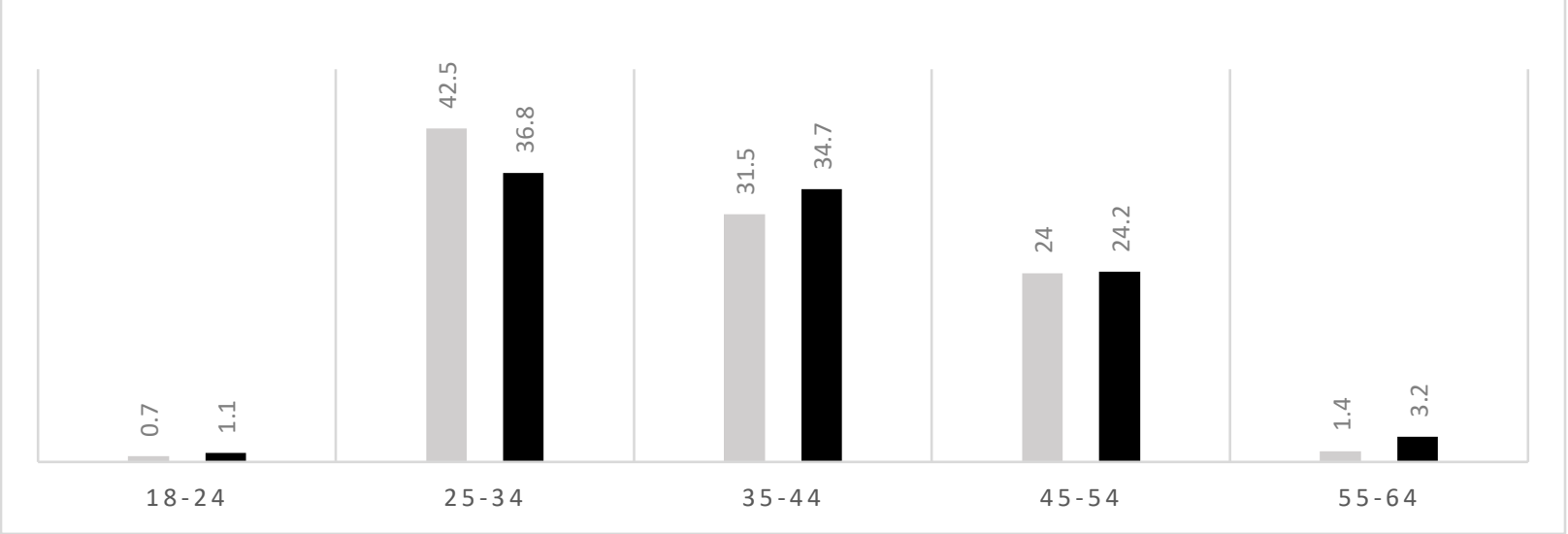



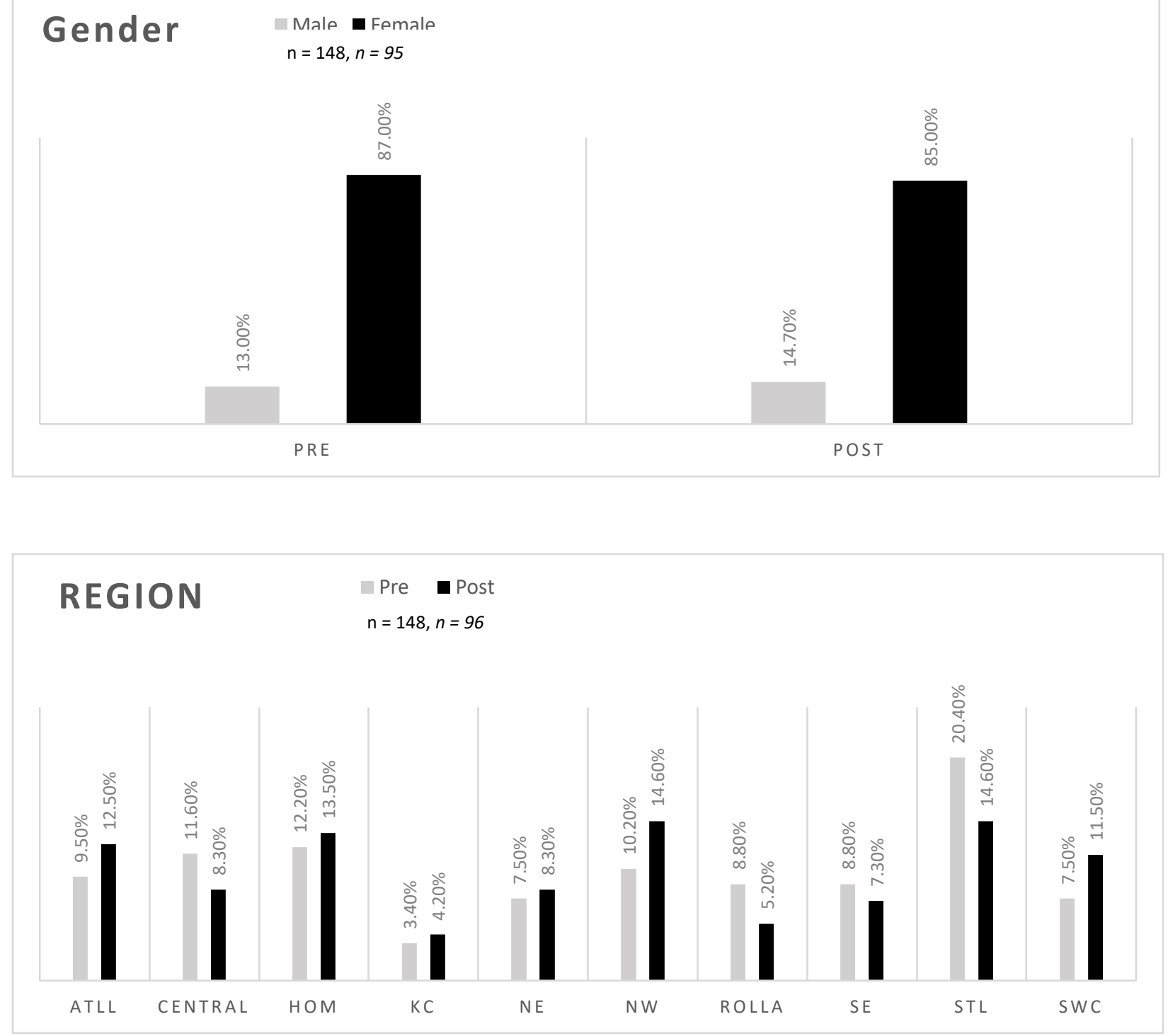


\section{Paired Samples (Subgroup) Demographic Charts}

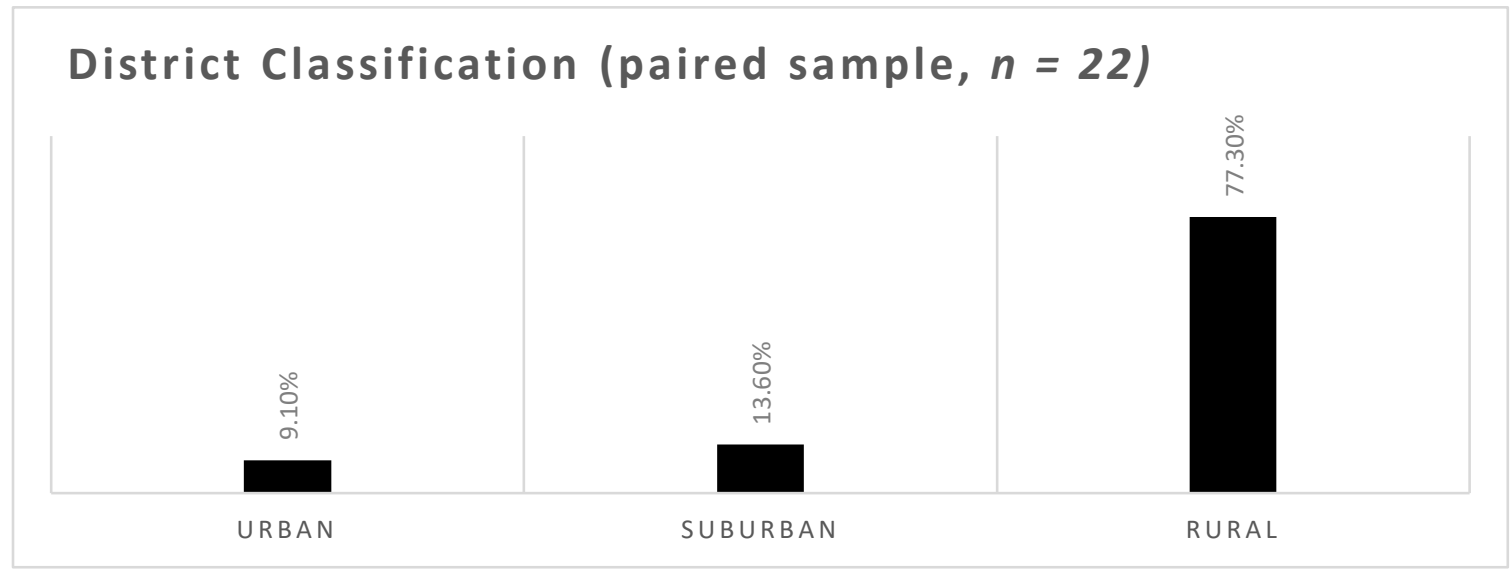

Years of Experience (paired sample, $n=22$ )

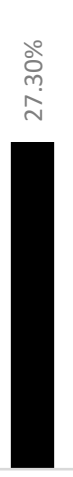

3 TO 5

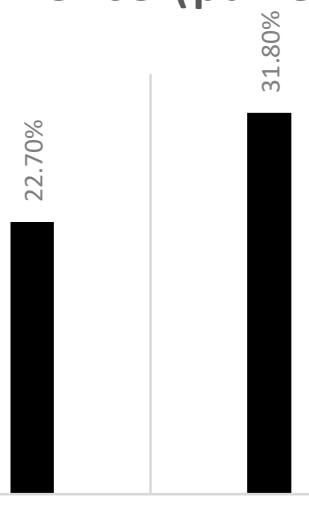

6 TO 10

11 TO 15

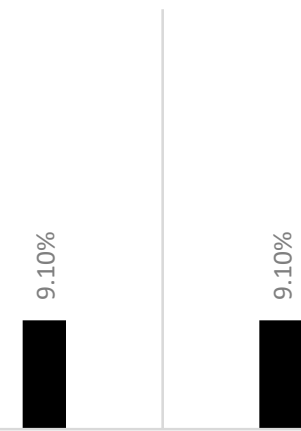

21 TO 25

Grade Level Taught (paired sample, $n=22$ )
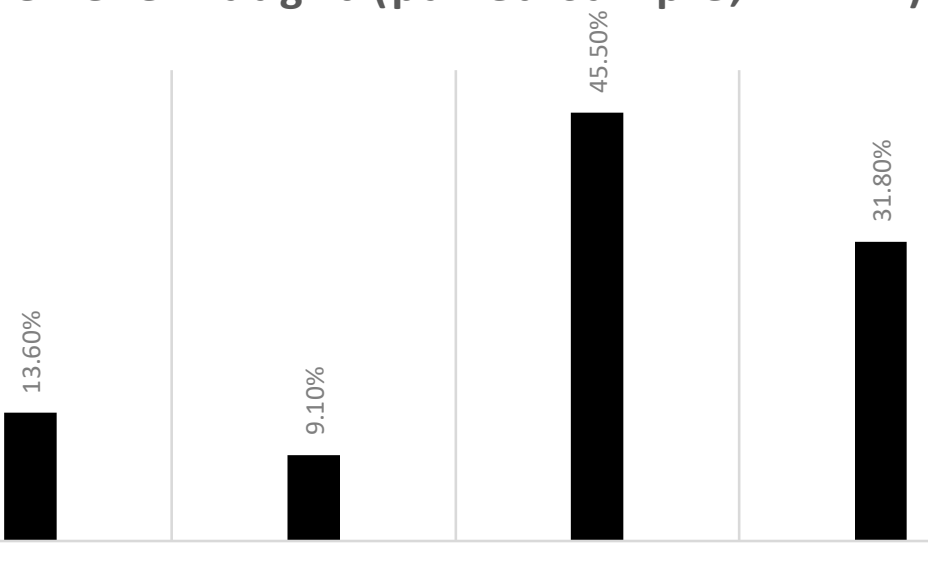

PK-2

$3-5$

$6-8$

$9-12$ 
Content Taught (paired sample, $n=22$ )

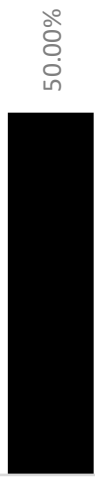

ELA

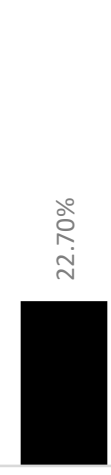

MATH

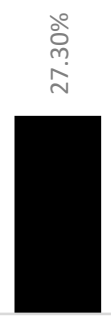

SCIENCE

Age (paired sample, $n=22$ )
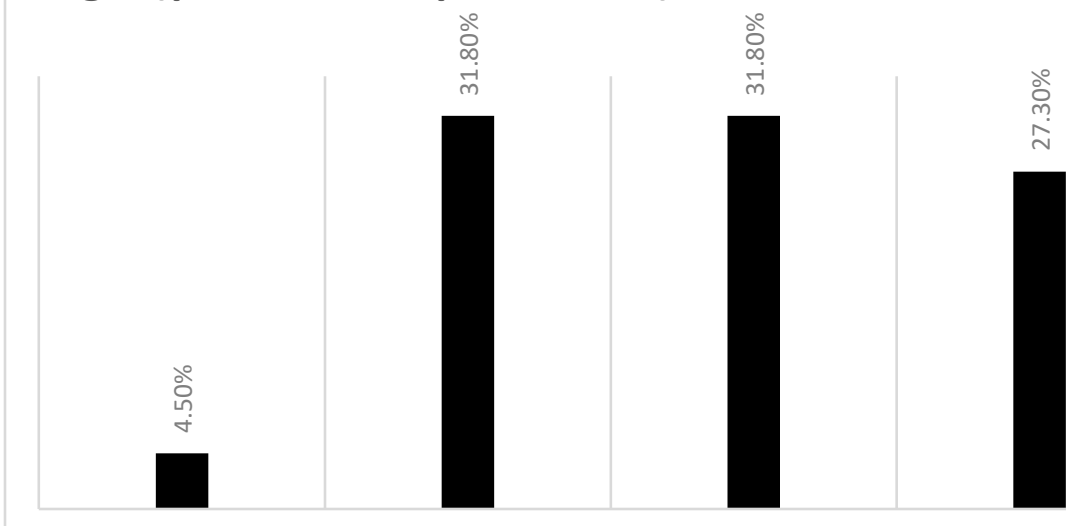

$18-24$

$25-34$

35- 44

$45-54$

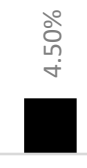

$55-64$

Gender (paired sample, $n=22$ )

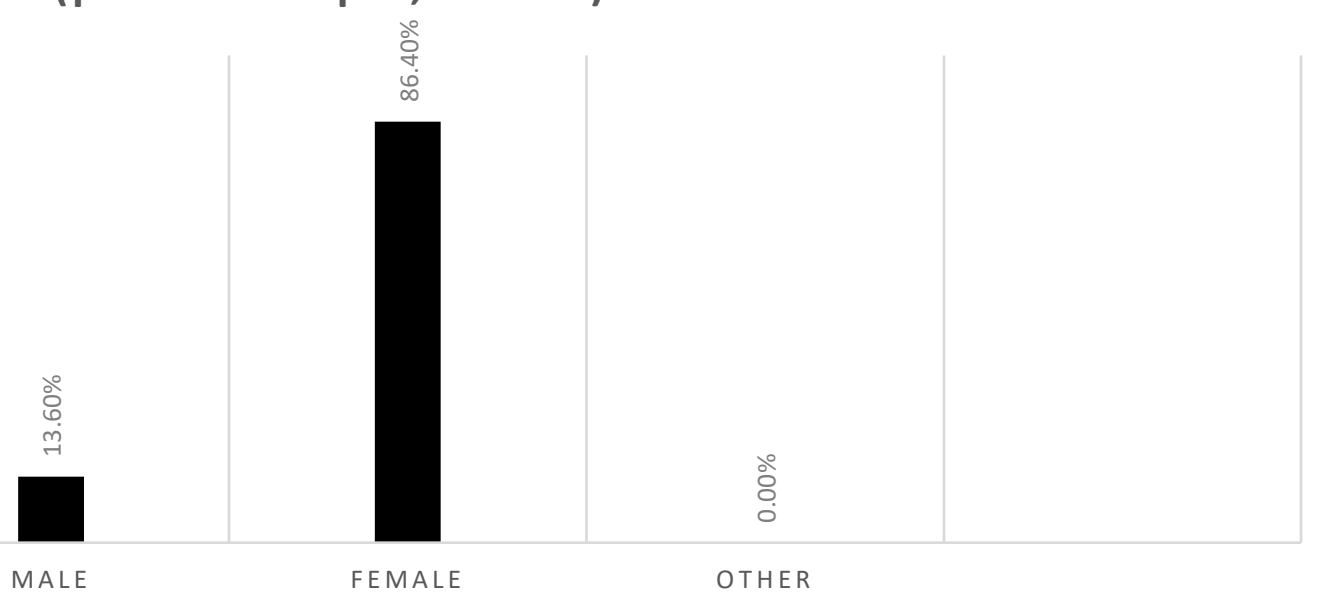




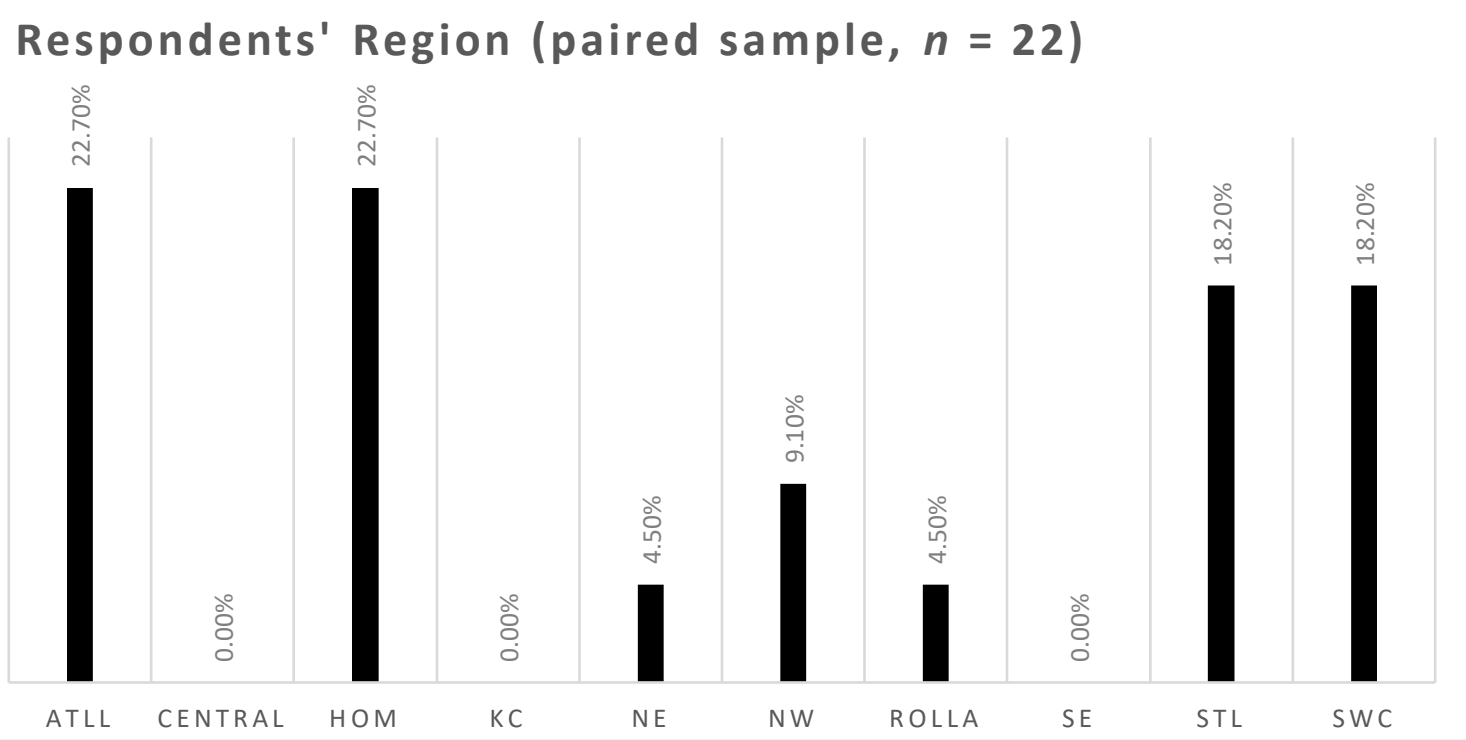




\section{Survey Instrument}

Teacher Self-Efficacy Scale (Tschannen-Moran \& Woolfolk Hoy, 2001)

\begin{tabular}{|c|c|c|c|c|c|}
\hline $\begin{array}{l}\text { For each question, circle the response that best } \\
\text { describes how you feel. }\end{array}$ & $\begin{array}{l}\bar{Z} \\
\tilde{\sigma} \\
\mathbb{Z} \\
\tilde{0} \\
z\end{array}$ & 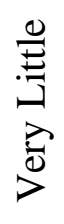 & 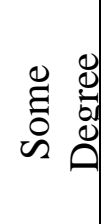 & 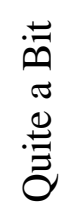 & 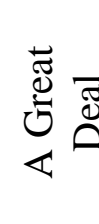 \\
\hline $\begin{array}{l}\text { How much can you do to get through to the most } \\
\text { difficult students? }\end{array}$ & 1 & 2 & 3 & 4 & 5 \\
\hline $\begin{array}{l}\text { How much can you do to help your students think } \\
\text { critically? }\end{array}$ & 1 & 2 & 3 & 4 & 5 \\
\hline $\begin{array}{l}\text { How much can you do to motivate students who } \\
\text { show low interest in school work? }\end{array}$ & 1 & 2 & 3 & 4 & 5 \\
\hline $\begin{array}{l}\text { How much can you do to get students to believe } \\
\text { they can do well in school work? }\end{array}$ & 1 & 2 & 3 & 4 & 5 \\
\hline $\begin{array}{l}\text { How much can you do to help your students } \\
\text { value learning? }\end{array}$ & 1 & 2 & 3 & 4 & 5 \\
\hline $\begin{array}{l}\text { How much can you do to foster student } \\
\text { creativity? }\end{array}$ & 1 & 2 & 3 & 4 & 5 \\
\hline $\begin{array}{l}\text { How much can you do to improve the } \\
\text { understanding of a student who is failing? }\end{array}$ & 1 & 2 & 3 & 4 & 5 \\
\hline $\begin{array}{l}\text { How much can you assist families in helping } \\
\text { their children do well in school? }\end{array}$ & 1 & 2 & 3 & 4 & 5 \\
\hline $\begin{array}{l}\text { How much can you use a variety of assessment } \\
\text { strategies? }\end{array}$ & 1 & 2 & 3 & 4 & 5 \\
\hline $\begin{array}{l}\text { How well can you respond to difficult questions } \\
\text { from your students? }\end{array}$ & 1 & 2 & 3 & 4 & 5 \\
\hline $\begin{array}{l}\text { How much can you gauge student } \\
\text { comprehension of what you have taught? }\end{array}$ & 1 & 2 & 3 & 4 & 5 \\
\hline $\begin{array}{l}\text { To what extent can you craft good questions for } \\
\text { your students? }\end{array}$ & 1 & 2 & 3 & 4 & 5 \\
\hline
\end{tabular}




\begin{tabular}{|c|c|c|c|c|c|}
\hline $\begin{array}{l}\text { For each question, circle the response that best } \\
\text { describes how you feel. }\end{array}$ & 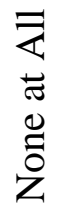 & 莺 & 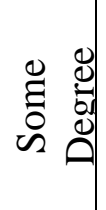 & 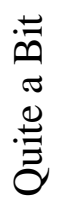 & 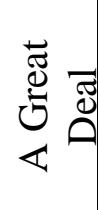 \\
\hline $\begin{array}{l}\text { How much can you do to adjust your lessons to } \\
\text { the proper level for individual students? }\end{array}$ & 1 & 2 & 3 & 4 & 5 \\
\hline $\begin{array}{l}\text { To what extent can you provide an alternative } \\
\text { explanation or example when students are } \\
\text { confused? }\end{array}$ & 1 & 2 & 3 & 4 & 5 \\
\hline $\begin{array}{l}\text { How well can you implement alternative } \\
\text { strategies in your classroom? }\end{array}$ & 1 & 2 & 3 & 4 & 5 \\
\hline $\begin{array}{l}\text { How well can you provide appropriate challenges for } \\
\text { very capable students? }\end{array}$ & 1 & 2 & 3 & 4 & 5 \\
\hline
\end{tabular}

Teacher Self-Efficacy Scale (Tschannen-Moran, 2001)

\begin{tabular}{|c|c|c|c|c|c|c|}
\hline $\begin{array}{l}\text { For each question, circle the response that best describes } \\
\text { how you feel. }\end{array}$ & 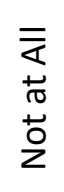 & 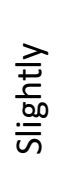 & 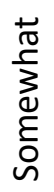 & $\begin{array}{l}\frac{\lambda}{ \pm} \\
\frac{\pi}{\pi} \\
\frac{0}{0} \\
\frac{0}{2} \\
\sum\end{array}$ & 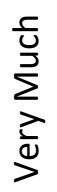 & 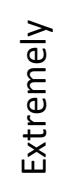 \\
\hline $\begin{array}{l}\text { During interactions with students I recognize when my pre- } \\
\text { existing beliefs are influencing the interaction. }\end{array}$ & 1 & 2 & 3 & 4 & 5 & 6 \\
\hline $\begin{array}{l}\text { During interactions with students I consider how my } \\
\text { personal thoughts and feelings are influencing the } \\
\text { interaction. }\end{array}$ & 1 & 2 & 3 & 4 & 5 & 6 \\
\hline $\begin{array}{l}\text { During interactions with students I recognize when my } \\
\text { students' pre-existing beliefs are influencing the } \\
\text { interaction. }\end{array}$ & 1 & 2 & 3 & 4 & 5 & 6 \\
\hline $\begin{array}{l}\text { During interactions with students I consider how their } \\
\text { personal thoughts and feelings are influencing the } \\
\text { interaction. }\end{array}$ & 1 & 2 & 3 & 4 & 5 & 6 \\
\hline $\begin{array}{l}\text { After interacting with students I spend time thinking about } \\
\text { what was said and done. }\end{array}$ & 1 & 2 & 3 & 4 & 5 & 6 \\
\hline
\end{tabular}

Reflective Practice Questionnaire (Priddis \& Rogers, 2019) 


\begin{tabular}{|c|c|c|c|c|c|c|}
\hline $\begin{array}{l}\text { For each question, circle the response that best describes } \\
\text { how you feel. }\end{array}$ & $\begin{array}{l}\bar{\Sigma} \\
+ \\
\pi \\
+0 \\
2\end{array}$ & 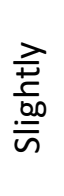 & 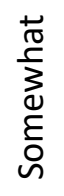 & $\begin{array}{l}\frac{\lambda}{ \pm} \\
\frac{\pi}{0} \\
\frac{0}{0} \\
\frac{0}{2} \\
\sum\end{array}$ & $\sum_{\substack{\frac{c}{2} \\
\frac{\mathrm{U}}{2}}}^{\frac{1}{2}}$ & 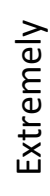 \\
\hline $\begin{array}{l}\text { After interacting with students I wonder about my own } \\
\text { experience of the interaction. }\end{array}$ & 1 & 2 & 3 & 4 & 5 & 6 \\
\hline $\begin{array}{l}\text { After interacting with students I wonder about the } \\
\text { student's experience of the interaction. }\end{array}$ & 1 & 2 & 3 & 4 & 5 & 6 \\
\hline $\begin{array}{l}\text { After interacting with students I think about how things } \\
\text { went during the interaction. }\end{array}$ & 1 & 2 & 3 & 4 & 5 & 6 \\
\hline $\begin{array}{l}\text { When reflecting with others about my work I become } \\
\text { aware of things I had not previously considered. }\end{array}$ & 1 & 2 & 3 & 4 & 5 & 6 \\
\hline $\begin{array}{l}\text { When reflecting with others about my work I develop new } \\
\text { perspectives. }\end{array}$ & 1 & 2 & 3 & 4 & 5 & 6 \\
\hline $\begin{array}{l}\text { I find that reflecting with others about my work helps me } \\
\text { to work out problems I might be having. }\end{array}$ & 1 & 2 & 3 & 4 & 5 & 6 \\
\hline $\begin{array}{l}\text { I gain new insights when reflecting with others about my } \\
\text { work. }\end{array}$ & 1 & 2 & 3 & 4 & 5 & 6 \\
\hline I think about my strengths for working with students. & 1 & 2 & 3 & 4 & 5 & 6 \\
\hline I think about my weaknesses for working with students. & 1 & 2 & 3 & 4 & 5 & 6 \\
\hline $\begin{array}{l}\text { I think about how I might improve my ability to work with } \\
\text { students. }\end{array}$ & 1 & 2 & 3 & 4 & 5 & 6 \\
\hline $\begin{array}{l}\text { I critically evaluate the strategies and techniques I use in } \\
\text { my work with students. }\end{array}$ & 1 & 2 & 3 & 4 & 5 & 6 \\
\hline $\begin{array}{l}\text { I think I am good at creating a safe environment so that my } \\
\text { students' feel comfortable enough to share information } \\
\text { with me. }\end{array}$ & 1 & 2 & 3 & 4 & 5 & 6 \\
\hline I feel confident sharing with colleagues. & 1 & 2 & 3 & 4 & 5 & 6 \\
\hline I am good at providing clear expectations to my students. & 1 & 2 & 3 & 4 & 5 & 6 \\
\hline $\begin{array}{l}\text { I am good at listening to my students with genuine } \\
\text { curiosity. }\end{array}$ & 1 & 2 & 3 & 4 & 5 & 6 \\
\hline
\end{tabular}


My work provides me with a lot of fulfillment.

\begin{tabular}{|l|l|l|l|l|l|}
1 & 2 & 3 & 4 & 5 & 6 \\
\hline
\end{tabular}

Reflective Practice Questionnaire (Priddis \& Rogers, 2019)

\begin{tabular}{|c|c|c|c|c|c|c|}
\hline $\begin{array}{l}\text { For each question, circle the response that best describes } \\
\text { how you feel. }\end{array}$ & $\begin{array}{l}\bar{\alpha} \\
+\pi \\
+0 \\
+0 \\
Z\end{array}$ & 辛 & 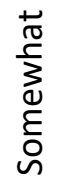 & 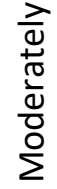 & 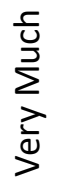 & 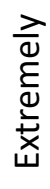 \\
\hline My work means more to me than simply earning money. & 1 & 2 & 3 & 4 & 5 & 6 \\
\hline I enjoy my work. & 1 & 2 & 3 & 4 & 5 & 6 \\
\hline $\begin{array}{l}\text { There are times when I find myself wishing I did not have } \\
\text { to go to work. }\end{array}$ & 1 & 2 & 3 & 4 & 5 & 6 \\
\hline
\end{tabular}

Reflective Practice Questionnaire (Priddis \& Rogers, 2009) 


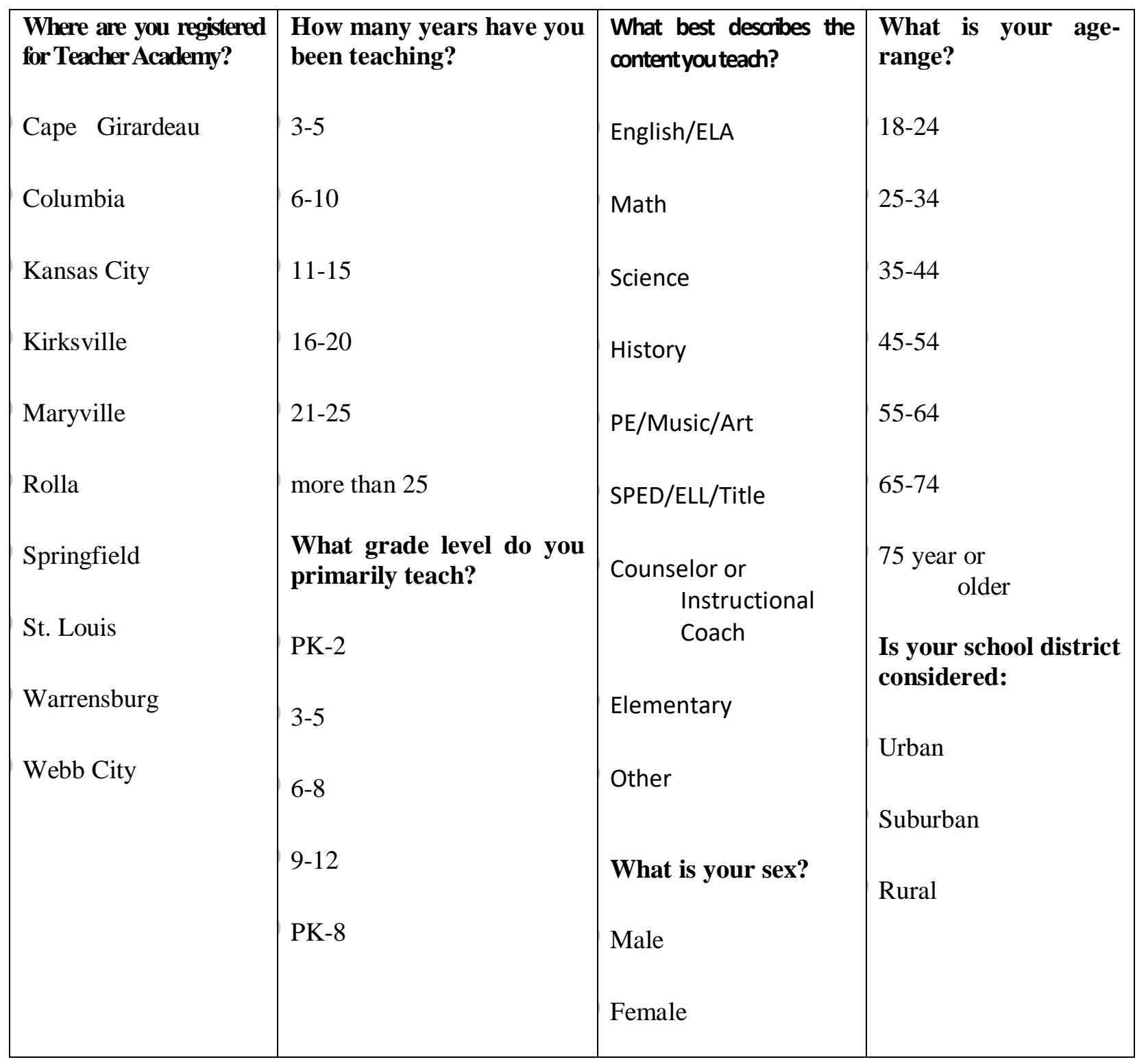




\section{E. RPDC 2011 Academy Proposals}

The Missouri Regional Professional Development Centers provide a unique opportunity to connect regional teacher networks to the Office of Educator Quality's current focus on developing and implementing the newly revised Missouri Teacher Standards.

Participating RPDC regions will choose a minimum of one regional teacher network in which to emphasis the Missouri Teacher Standards as a working document included in the network's curriculum and reflection processes during the 2011-2012 school year.

This pilot project will provide a diverse teacher audience to learn about, reflect on, and react to, the newly adopted Missouri Teacher Standards.

Regions will:

- Determine the appropriate teacher network(s) in which to integrate the Teacher Standards document.

- Determine linkage of the individual network objectives to the Teacher Standards

- Submit an outline of the objectives of the network, its linkage to the specific standards, and a network budget.

- Provide the network facilitators, content and all logistical details.

- Provide both a qualitative and quantitative summary report to the office of Quality Educators at the end of the 2011-2012 school term which will include:

1. An appropriate pre-post data set - Developed by that region for the context of their network(s).

2. Feedback from the participants on the Missouri Teacher Standards.

The OEQ will:

- Award funding per regional network appropriate to the scope of work.

- Provide support as necessary in connecting potential statewide aspects of this pilot project as appropriate. 
(Southeast RPDC Proposal)

The Southeast RPDC will continue its Teacher Academy learning opportunity to provide support and enhance the skill set of educators in its nineteen (19) county region of Southeast Missouri. The major objectives that the Southeast Teachers'Academy will focus on are:

- Differentiated Instruction

Learning styles, Math and ELA strategies

- Brain Research

Girls/boys learning

John Almarode, Presenter, Differentiation and the Brain

- Student Engagement

Power of Talk

IPI (Instructional Practices inventory)

- Cooperative Learning

\section{- Reflection}

Teacher Academy participants will increase their knowledge and use of strategies to guide reflection on instruction.

Teachers' Academy participants will increase their use of evidence from student learning to guide reflective practices.

Teachers' Academy participants will use evidence gained through reflective practices to change instruction resulting in changes in student performance.

All of the Missouri Teaching Standards will be integrated into the objectives of the Southeast Teachers' Academy. Standards 1-9 will be targeted and integrated into the eight sessions of the academy.

\section{Evaluation for Impact and Learning:}

The Southeast Teachers' Academy will use the June 2011 Teacher Standards as a pre- and postassessment for each TA participant. This beginning reflective work will both educate the teacher as to the content of the standards document, and provide a basis for consideration as they establish their personal growth goals for the year. The Standards will then be woven into the session content as appropriate throughout the year. Using one or more of the Teaching

Standards in a job embedded study, participants will track student performance/achievement through the course of the Academy. Results of this action research will be presented to facilitators, administrators and fellow TA participants via data fair presentations.

Two classroom observations will be conducted by facilitators/trainers to provide feedback to the participants on the specific teacher standard they chose to focus. 
At the end of the Academy, participants will again complete an assessment using the Teacher Standards. This post-review of the Standards will provide participants with an opportunity to assess their growth in the 9 major areas.

(Heart of Missouri Proposal)

The Heart of Missouri RPDC will continue its Teacher Academy learning opportunity to provide support and enhance the skill set of educators in its 15 county region of Mid-Missouri. The objectives of the HOM Teacher Academy are focused on:

\section{- Instructional Practice}

Teachers will increase their knowledge and use of high yield instructional strategies defined as cooperative learning; identifying similarities and differences; summarizing and note taking; nonlinguistic representation; generating and testing hypotheses; and advance questioning, cues and organizers.

\section{- Engagement}

Teachers Academy participants will increase their knowledge and use of strategies to engage learners in the classroom.

\section{- Reflection}

Teacher Academy participants will increase their knowledge and use of strategies to guide reflection on instruction.

Teachers' Academy participants will increase their use of evidence from student learning to guide reflective practices.

Teachers' Academy participants will use evidence gained through reflective practices to change instruction resulting in changes in student performance.

All of the Missouri Teacher Standards will integrate into the objectives of the HOM Teacher Academy. Specifically, Standards 3-9 will be targeted and integrated into the ten sessions of the academy.

\section{Evaluation for Impact and Learning:}

The HOM Teacher Academy will use the June 2011 Teacher Standards as a base self-assessment document for each TA participant. This beginning reflective work will both educate the teacher as to the content of the standards document, and provide a basis for consideration as they establish their personal growth goals for the year. The Standards will then be woven into the session content as appropriate throughout the year. Documentation of the Standards 
integration and connection will be included in the facilitator's session reflections. Indications of change in student performance will be evidenced through participant data fair presentations.

This same reflective process will be used at the end of the academy experience as a post training assessment. In the post training assessment participants will be asked to use a growth perspective and indicate where they would now rank themselves before their learning and also after their learning.

Additional evaluation surveys will be used as well.

(SW RPDC)

The Southwest RPDC will offer a Kindergarten Teacher Academy learning opportunity to provide support and build capacity to effectively implement the Common Core State Standards in the their classrooms. Central to this training will be discussion of what's included in the Common Core Standards, with a careful eye for what's new. A discussion of Missouri's state-level GLE's, followed by an analysis of the standards, will provide the foundation for the thoughtful development of instructional strategies that will meet the expectations of the Common Core.

The Academy will provide a facilitated, structured forum for teachers seeking to enhance their capacity as teachers and extend their instructional skills. Throughout the Academy experience, teachers from diverse school districts will form a cadre that promotes networking, collaboration, reflection, and growth.

2011-12 Kindergarten teachers have the unique opportunity of initiating their

students into the full progression of the Common Core State Standards. The objectives of the SW Kindergarten Teacher Academy are focused on:

\section{- Learner Growth}

Kindergarten Teacher Academy participants will increase their knowledge of student diversity in approaches to learning and will build instructional capacity to meet individual student learning needs within the context of the increased rigor and relevant application embedded in the Common Core State Standards.

\section{Standard \#2 Understanding and Encouraging Student, Learning Growth and Development}

The teacher understands how students learn, develop, and differ in their approaches to learning. The teacher provides learning opportunities that are adapted to diverse learners and support the intellectual, social, and personal development of all students.

\section{- Critical thinking}


Kindergarten Teacher Academy participants will increase their knowledge critical thinking development and guidance while building capacity around the implementation of instructional activities that foster the development of higher order thinking skills including inquiry-based questioning techniques and problembased learning.

\section{Standard \#4 Teaching for critical thinking}

The teacher uses a variety of instructional strategies to encourage students' development and critical thinking, problem solving, and performance skills including instructional resources

\section{- Reflection}

Kindergarten Teacher Academy participants will increase their knowledge and use of strategies to guide reflection on instruction.

Kindergarten Teacher Academy participants will increase their use of evidence from student learning to guide reflective practices.

Kindergarten Teacher Academy participants will use evidence gained through reflective practices to change instruction resulting in changes in student performance.

\section{Standard \#7 Use of Student Assessment Data to Analyze and Modify Instruction}

The teacher understands and uses formative and summative assessment strategies to assess the learner's progress, uses assessment data to plan ongoing instruction, monitors the performance of each student and devises instruction to enable students to grow and develop.

All of the Missouri Teacher Standards will integrate into the objectives of the SW Kindergarten Teacher Academy. Specifically, Standards 2,4,\& 7 will be targeted and integrated into the six sessions of the academy.

\section{Evaluation for Impact and Learning:}

The SW Teacher Academy will use the June 2011 Teacher Standards as a base self-assessment document for each TA participant. This beginning reflective work will both educate the teacher as to the content of the standards document, and provide a basis for consideration as they establish their personal growth goals for the year. The Standards will then be woven into the session content as appropriate throughout the year. Documentation of the Standards integration and connection will be included in the facilitator's session reflections. Indications of change in student performance will be evidenced through participant data fair presentations.

This same reflective process will be used at the end of the academy experience as a post training assessment. In the post training assessment participants will 
be asked to use a growth perspective and indicate where they would now rank themselves before their learning and also after their learning.

Additional evaluation surveys will be used as well. These are available upon request.

(Central RPDC)

The Central Regional Professional Development Center will choose a minimum of two teacher networks to emphasis the Missouri Teacher Standards. First, the Central RPDC will continue the Outreach Teacher's Academy program. The Academy will begin its 12 year of providing support and enhancing the skill set of educators. The objectives of the Outreach Teacher Academy are focused on:

\section{- Instructional Practice}

Teachers will increase their knowledge and use of high yield instructional strategies defined as cooperative learning; identifying similarities and differences; summarizing and note taking; nonlinguistic representation; generating and testing hypotheses; and advance questioning, cues and organizers.

\section{- Engagement}

Teachers Academy participants will increase their knowledge and use of strategies to engage learners in the classroom.

\section{- Reflection}

Teacher Academy participants will increase their knowledge and use of strategies to guide reflection on instruction.

Teachers' Academy participants will increase their use of evidence from student learning to guide reflective practices.

Teachers' Academy participants will use evidence gained through reflective practices to change instruction.

All of the Missouri Teacher Standards will integrate into the objectives of the Outreach Teacher Academy. Specifically, the Standard on Differentiated Instruction will be targeted and integrated into the sessions of Outreach Teacher's Academy this year.

\section{Evaluation for Impact and Learning:}

The Outreach Teacher's Academy will use the June 2011 Teacher Standards as a base self-assessment document for each participant. This beginning reflective work will both educate the teacher as to the content of the standards document, 
and provide a basis for consideration as they establish their personal growth goals for the year. The Standards will then be woven into the session content as appropriate throughout the year. Documentation of the Standards integration and connection will be included in the facilitator's session reflections.

The instructional information and data gained will be used to promote changes in the teachers' instructional practices to improve student learning. Teachers will collect samples of student work to strengthen teaching practice and improve student learning.

This same reflective process will be used at the end of the experience as a post training assessment. In the post training assessment participants will be asked to use a growth perspective and indicate where they would now rank themselves before their learning and also after their learning.

Additional evaluation surveys will be used as well. These are available upon request. 
(Kansas City RPDC)
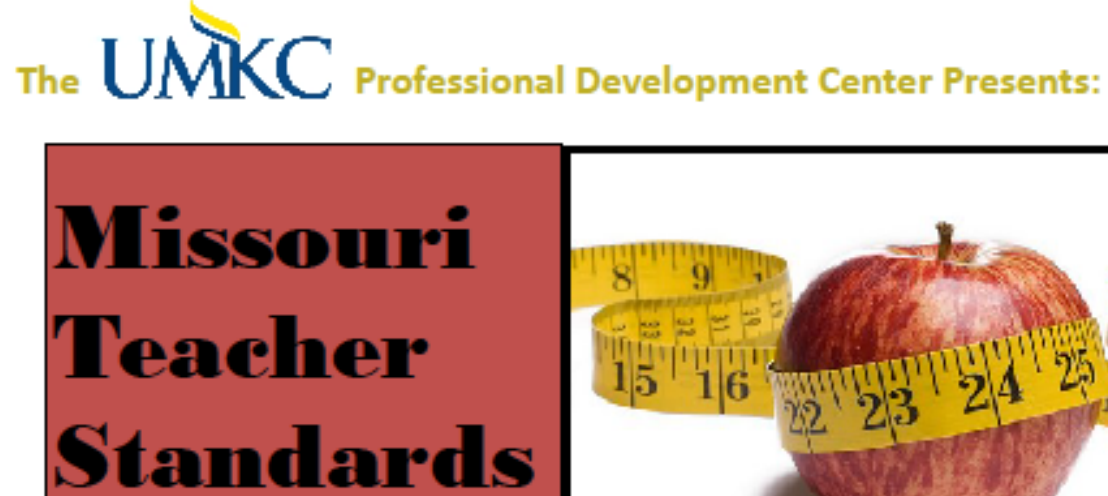

Advisory Network

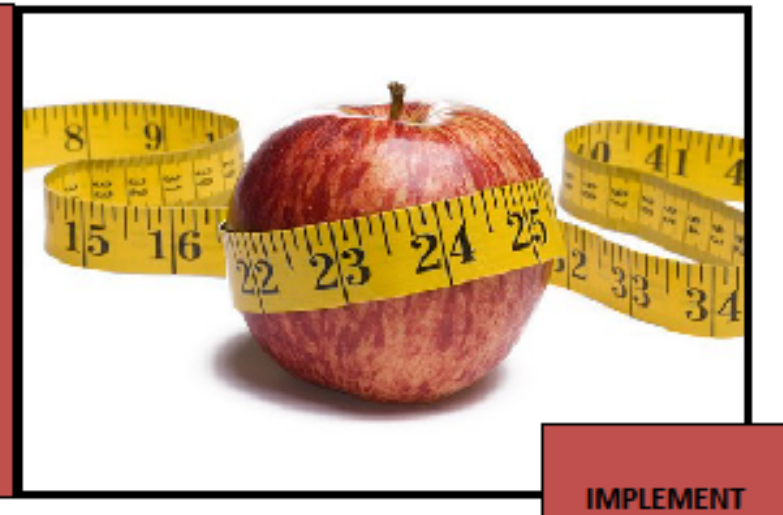

This series supports teachers dedicated to reflective examination and earnest application of the newly adopted (June 2011) Missouri Teacher Standards. Participants will implement standards, in beta-test fashion, reflecting on their alignment to their current practice, and identifying challenges and implications for their future practice.

Participants will walk away with a clear understanding of the Missouri Teacher standards, insight into their own practice, as well as provide valued input toward The Department's refinement of the document. It will benefit new as well as distinguished teachers, in fact participants will benefit most from enrollment that represents highly diverse expertise.

Session 1: Content Knowledge \& Curriculum

Session 2: Child Development \& Teaching

Session 3: Practice \& Collaboration

Session 4: Environment \& Communication

Session 5: Data

Session 6: Final Analysis and Recommendations

\begin{tabular}{|c|c|}
\hline Where: & $\begin{array}{l}\text { UMKC Professional Development Center } \\
\text { Union Station-30 West Pershing Road Suite } 401\end{array}$ \\
\hline When: & Sept 1- Nov 28-Jan 16-Feb 20-Mar 26-May 14 \\
\hline Registration: & $8: 00$ a.m. $-8: 30$ a.m. (coffee and pastries) \\
\hline Workshop: & 8:30 a.m. - 3:30 p.m. \\
\hline Cost: & $\$ 200.00$ per individual \\
\hline
\end{tabular}

1. level of quality or excellence: the level of quality or excellence attained by somebody or something

2. level of quality accepted as norm: a level of quality or excellence that is accepted as the norm or by which actual attainments are judged

3. item in usual repertoire: something performed as part of the usual repertoire. 


\title{
F. Teacher Academy Common Language Artifact from 9.16.15
}

\section{Common Language}

\author{
Sharing a Mental Model
}

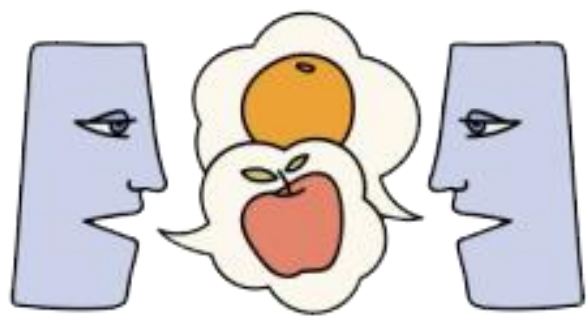

\section{Strategies and Delivery Methods}

\section{Advanced/Graphic Organizers:}

$\checkmark$ Advanced - An instructional strategy that is used before direct instruction or before a new topic; allows the learner to recall and transfer prior knowledge to the new information being presented in the lesson

$\checkmark$ Graphic - a visual communication tool using symbols to convey meaning, express ideas, or depict relationships between facts, terms, and or ideas within a learning task

- May be referred to as knowledge maps, concept maps, story maps, cognitive organizers, or concept diagrams.

Class Discussion: Dialogue among students and teacher

- Open-ended questions are used and students are encouraged to ask questions of each other

Cooperative Learning: Students with assigned roles working together as partners or in structured small teams on clearly defined learning tasks

- Students may be responsible for each other's learning and are held individually accountable for the group's success. Examples include think-pair-share, round robin, jigsaw, inside/outside circle, etc.

\section{Depth of Knowledge}

$\checkmark$ Depth of Knowledge Recall: Generally requires students to identify, list, or define facts, terms, concepts, trends, generalizations and theories. If the knowledge necessary to answer an item automatically provides the answer to the item, then the item is Level 1.

$\checkmark$ Depth of Knowledge Skill Concept: Generally requires students to USE information or conceptual knowledge. For example, students may contrast or compare people, places, events and concepts; convert information from one form to another; give an example; classify or sort items into meaningful categories; describe, interpret or explain issues and problems, patterns, reasons, cause and effect, significance or impact, relationships, points of view or processes. Level 2 is more complex; more than one step.

$\checkmark$ Depth of Knowledge Strategic Thinking: Generally requires students to use reasoning and to develop a plan or a sequence of steps. Students go beyond 
explaining or describing "how and why" to justifying the "how and why" through application and evidence. Items at Level 3 include drawing conclusions; citing evidence; applying concepts to new situations; using concepts to solve problems; analyzing similarities and differences in issues and problems; proposing and evaluating solutions to problems; recognizing and explaining misconceptions or making connections across time and place to explain a concept or big idea. Complex and abstract; more demanding reasoning; more than one possible answer.

Group Work: Students working together in partners or small groups

- Groups of students sitting together doing their own work who are free to talk with each other as they work

- Groups of students completing a project together without clear identification of roles

Guided Practice: Teacher-led short activities with students attempting the task at hand

- The teacher must closely monitor what the students are doing to see that the instruction has "taken." Mistakes need to be corrected if seen by the teacher

Hands-On/Active Learning: Instructional activities that include both content and process promoting student discussion

\section{Independent Student Work:}

- Individual work - worksheets, activities, or textbook reading assigned for individual practice or study

- Distance Learning - Usually involves a situation in which the teacher and students are separated by time, location, or both $\bigcirc$ It can be used to supplement or enhance curriculum and assessment through real-time electronic field trips or videoconferencing, to deliver and/or receive courses in real time from remote sites, or to take online courses.

Inquiry Based Learning: Students explore problems or scenarios; could include small scale investigations or projects; helps develop content knowledge, problem solving, and/or reasoning. Students are not given established facts, focuses on student discovery; teacher is facilitator.

Learning Centers: Designated classroom areas where students partake in specific learning activities.

Lecture: Delivery of information to a group by the teacher

- teacher-controlled

Nonlinguistic Representations: Students acquire and retain knowledge through visual imagery, kinesthetic activity, auditory experiences, and so forth. Students may create concept maps, idea webs, dramatizations, or computer simulations to represent their thinking.

Peer Evaluation: Instructional activities, such as peer review, peer assessment, peer tutoring, and peer editing, designed to give students real responsibility to assess and provide feedback. 
Project Based Learning: A teaching method that requires students to use knowledge and skills they have acquired or need to develop to solve a real-world problem through an extended inquiry process.

Question/Answer: An expression of inquiry that calls for a reply.

Similarities/Differences: Students identify similarities and differences using or creating comparisons, classifications, metaphors, or analogies.

Student Presentations: Students present projects, experiences, or discoveries to their classmates in a formal setting.

Summarizing/Note Taking: Students learn to identify the most important aspects of what they are learning by summarizing material and/or taking notes.

\section{Student Engagement}

$\checkmark$ Student Engagement High: This means that there is evidence that $75-100 \%$ of the students were physically and/or cognitively participating in the content.

$\checkmark$ Student Engagement Moderate: This means that there is evidence that $50-75 \%$ of the students were physically and/or cognitively participating in the content.

$\checkmark$ Student Engagement Low: This means that there is evidence that $25-50 \%$ of the students were physically and/or cognitively participating in the content.

$\checkmark$ Student Engagement Disengaged: This means that there is evidence that $0-25 \%$ of the students were physically and/or cognitively participating in the content. 


\section{G. "What is our Why?" Artifact from Facilitator Meeting 9.16.15}

\section{Teacher Academy Facilitator Meeting}

9.25.16

\section{Designing \& Delivering HQPL}

- PPT attached in email

- What is our WHY?

- Celebration of teaching

- Model best practice

Whole is more than sum of parts

Increased student achievement

- Increased teacher growth

- Sharing bext practices=teacher growth

Collaboration=teacher growth

- Validates practice

- Teacher learning=student growth

Supporting teachers

- Developing highly effective teachers

- Make a difference for adults and kids

- Makes time to reflect 


\section{H. Missouri Teacher Development System Competencies by Domain}

Missouri Teacher Development System (MTDS)

Competencies Organized by Domain
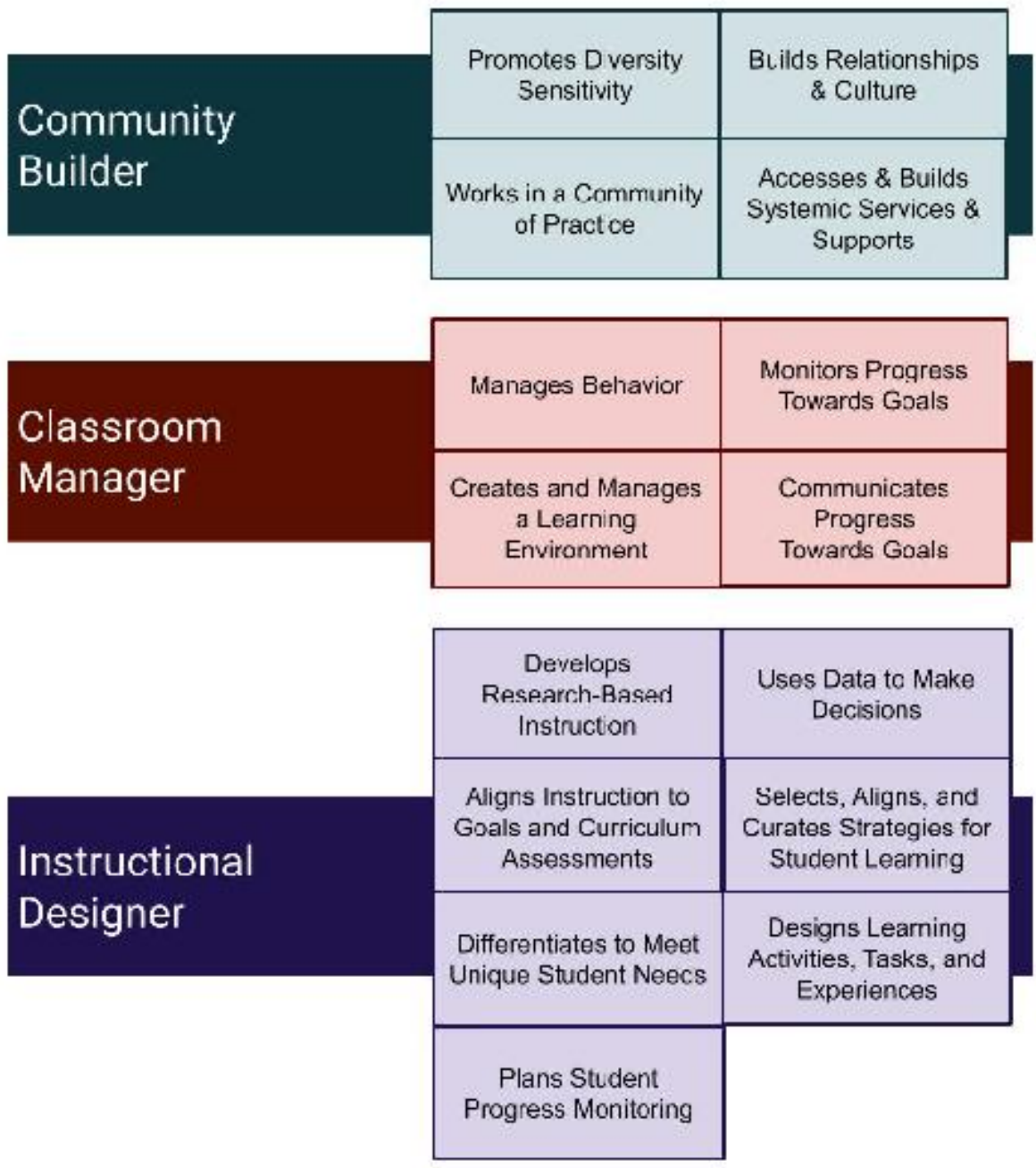

MTDS Draft January 2020 


\section{Missouri Teacher Development System (MTDS)}

Competencies Organized by Domain

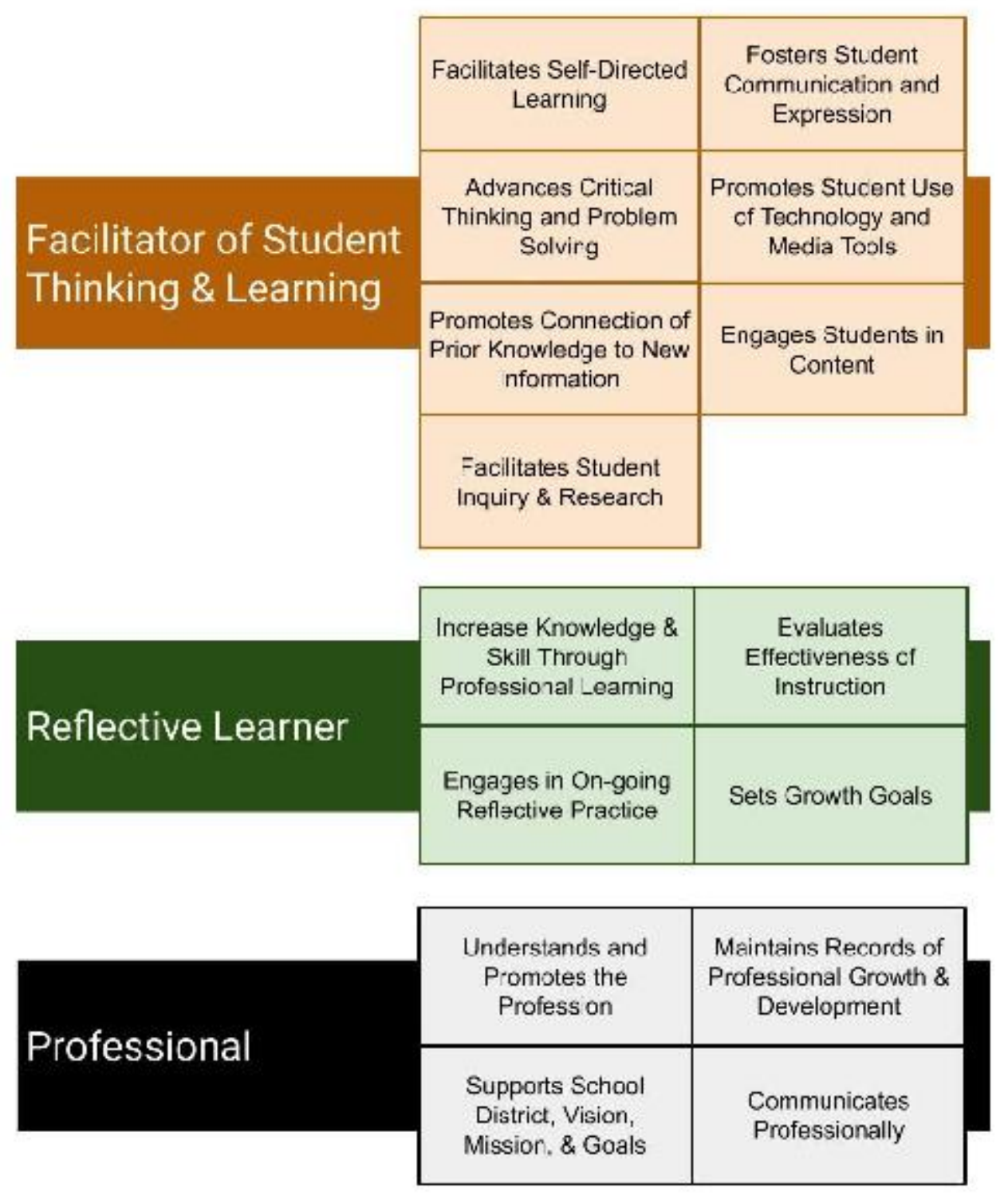

MTDS Draft January 2020 
Tracy Gross is a teacher development specialist for Missouri State's Agency for Teaching, Leading, and Learning. Her most recent work includes designing and leading the Missouri Teacher Development System, which is a state-level framework of learning for teachers that spans the entire career. Her interests include systems theory, trends in education, the $4^{\text {th }}$ industrial revolution, and the internet of things. She earned her EdD in Educational Leadership and Policy Development from the University of Missouri. 